Historic, archived document

Do not assume content reflects current scientific knowledge, policies, or practices. 

U. S. DEPARTMENT OF AGRICULTURE, BUREAU OF ENTOMOLOGY - BULLETIN No. 52.

L. O. HOWARD, Entomologist.

\section{PROCEEDINGS}

OF THE

\section{SEVENTEENTH ANNUAL MEETING}

OF THE

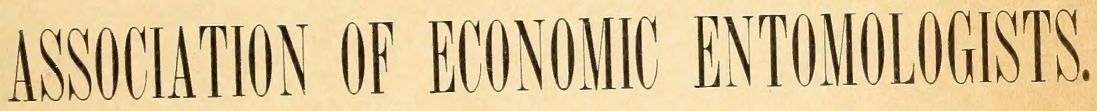

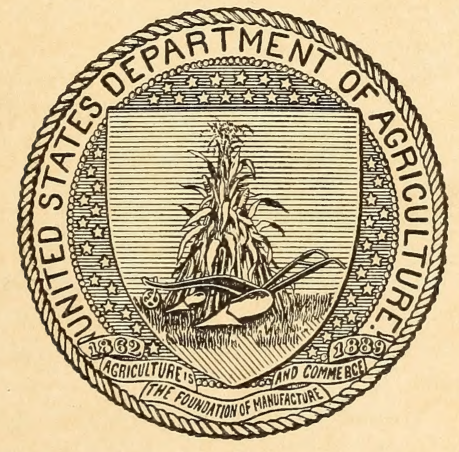

WASHINGTON :

GOVERNMENT PRINTING OFEICE.

1905 . 


\section{LETTER OF TRANSMITTAI.}

United States Departanent of Agriculiture,

Bureau of Entomology,

Washington, D. C., March 20, 1905.

SIR: I have the honor to transmit herewith the manuscripts of the Proceedings of the Seventeenth Annual Meeting of the Association of Economic Entomologists, which was held at Philadelphia, Pa., December 29 and 30,1904 . As the papers presented at the meetings of this association are of very considerable economic importance, and as the Department of Agriculture has hitherto published the reports of the secretaries of these meetings as bulletins, I recommend the publication of the present report as bulletin No. 52 of this Bureau. The text figures are necessary for the illustration of the text.

Respectfully,

I. O. Howard,

Entomologist and Chief of Bureau.

Hon. James Wilson,

Secretary of Agriculture. 
Seventeenth Annual Meeting of the Association of Economic EntoMOLOGISTS.

Some Present-Day Features of Applied Entomology in America,

A. L. Quaintance.

Experiments with Lime-Sulphur Washes E. P. Felt -

Notes on Cuban Insects (abstract) Mel. T. Cook

Some Observations on the Cotton Boll Weevil (illustrated),

E. Dwight Sanderson.-

The Fall Webworm Partially Double-brooded in Connecticut,

W. E. Britton -

Preliminary Report upon Work against a Destructive Leaf-Hopper (Empoasca mali Le B.) (illustrated) ..............F. L. Washburn .. Additions to our Knowledge of the Cabinet Beetle (Anthrenus verbasci

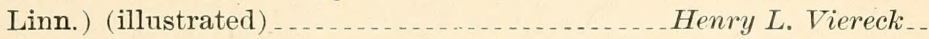
* Spraying Apples against the Plum Curculio _... . . . . . . S. A. Forbes * Value of Copper Sulphate against Mosquito Larvæ . _ C. L. Marlatt Brief Notes on Ohio Insects for 1904_ _. . . . . . . . Herbert Osborn _.

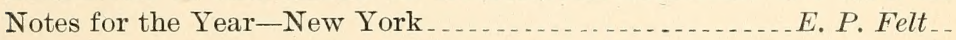
Some Economic Insects for the Year 1904 in Ohio ....... A. F. Burgess . Injurious Insects in Minnesota in 1904 ........... F. L. Washburn _. Insects of the Year in Colorado (illustrated) ........... C. P. Gillette_Distribution and Migrations of the Mormon Cricket (Anabrus simplex Hald.) in Colorado (illustrated) .............. S. Arthur Johnson .Miscellaneous Notes from Texas ......................... F. Conradi . Insects of the Year 1904 in Georgia _. Wilmon Newell and R. I. Smith _The Present Status of the Predatory Insects introduced into New Jersey, John B. Smith.-

Report on the "New Orleans" Ant (Iridomyrmex humilis Mayr) (illus-

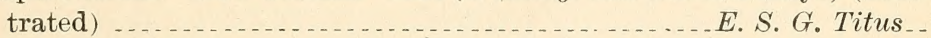

The Cottony Maple Scale: An Unusual Outbreak, and Experiments with Insecticides ........................... Arthur Johnson .. Some Experiences with Pulvinaria ............ Howard Evarts Weed.. * Laboratory Experiments with Carbon Bisulphid_.. F. L. Washburn _Some Notes on the Fumigation of Household Insects and their Eggs with Hydrocyanic-Acid Gas..... . . . . . . . . . . . . . . . J. L. Phillips _. * Insects Collected from the Flowers of Tree and Bush Fruits,

W. E. Britton and Henry L. Viereck..

*A Destructive Ptinid New to North America . ....... James Fletcher.

* Injurious Insects of the Year in Canada . . . . . . . . . James Fletcher..

* The Amount of Injury from the Cotton Boll Weevil,

E. Dwight Sanderson _.

The Coffee Leaf-Miner (Leucoptera coffeella Stain.) _.... Mel. T. Cook

* Gypsy Moth and Brown-tail Moth Conditions during 1904,

C. L. Marlatt _-

Black-Fly Studies.

A. F. Conradi.-

The Fumigation of a Fruit House for Controlling the Codling Moth,

The Importation and Breeding of Honey Bees of Various Types

A. F. Burgess -- 


\section{L L USTRATIONS.}

FiG. 1. Diagram showing normal mean montbly temperature and the mean monthly temperature during 1904 at Victoria, Tex

Page.

2. Outfit used for spraying young apple trees for Empoasca mali

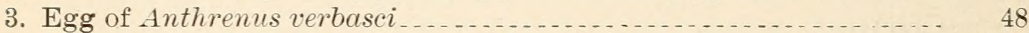

4. Section of radish, showing injury from maggot of Anthomyia sp _. 60

5. Cross section of radish, showing injury from Anthomyia sp _..... 60

6. Map showing territory infested by Anabrus simplex in Colorado _.. 64

7. Persimmons, showing protective covering made by Iridomyrmex humilis 


\title{
THE SEVENTEENTH ANNUAL MEETING OF THE ASSOCIATION OF ECONOMIC ENTOMOLOGISTS.
}

\author{
MORNING SESSION, THURSDAY, DECEMBER 29, 1904.
}

The Association met in the laboratory of physiology and pathology of the University of Pennsylvania, Philadelphia, Pa., on December 29 and 30,1904 . The following were in attendance at the several sessions:

W. B. Alwood, Blacksburg, Va.; G. M. Bentley, Raleigh, N. C.; Frank Benton, Washington, D. C.; F. C. Bishopp, Washington, D. C.; W. E. Britton, New Haven, Conn.; A. F. Burgess, Columbus, Ohio; C. E. Chambliss, Clemson College, S. C.; M. T. Cook, Santiago de las Vegas, Cuba; E. B. Engle, IIarrisburg, Pa.; E. P. Felt, Albany, N. Y.; H. T. Fernald, Amherst, Mass.; Tames Fletcher, Ottawa, Canada; S. A. Forbes, Urbana, Ill.; H. Garman, Lexington, Ky.; C. P. Gillette, Fort Collins, Colo.; L. O. Howard, Washington, D. C. ; W. D. Hunter, Washington, D. C.: William Lochhead, Guelph, Ontario, Canada; A. D. Macfillivray, Ithaca, N. Y. ; C. L. Marlatt, Washington, D. C. ; G. W. Martin, Nashville, Tenn.; Leslie Martin, Washington, D. C.; Yasushi Nawa, Gifu, Japan; Herbert Osborn, Columbus, Ohio; J. L. Phillips, Blacksburg, Va.; A. L. Quaintance, Washington, D. C. ; W. A. Riley, Ithaca, N. Y. ; E. D. Sanderson, Durham, N. H. ; William Saunders, London, Ontario, Canada : W. M. Scott, Washington, D. C. ; Henry Skinner, Philadelphia, Pa.; M. V. Slingerland, Ithaca, N. Y.; J. B. Smith, New Brunswick N. J. ; H. E. Summers, Ames, Iowa; H. A. Surface, Harrisburg, Pa.; E. S. G. Titus, Washington, D. C. ; H. L. Viereck, New Haven, Conn.; F. L. Washburn, St. Anthony Park, Minu. ; F. M. Webster, Urbana, Ill.

The meeting was called to order at 10 a. m. by the president, Mr. A. L. Quaintance, who delivered his annual address as follows:

\section{SOME PRESENT-DAY FEATURES OF APPLIED ENTOMOLOGY IN AMERICA}

By A. L. Quaintance, Washington, D. C.

It is one of the present-day beliefs that we are living in a period of unexampled scientific activity. A census of achievement during the past two or three decades would undoubtedly furnish evidence that this belief is well founder. This activity has been as notable in applied as in pure science. Indeed, the tendency toward almost immediate utilization of scientific discoveries in practical affairs has 
been characteristic of modern times, and to this must be attributed much of the advancement which, as a nation, we have made in agriculture, in commerce, and in manufacture.

Agriculture, especially, has benefited by this activity. Agricultural chemistry, plant pathology, horticulture, bacteriology, entomology, and other branches of pure and applied science have each made notable contributions. It would be to no purpose to discuss the relative importance of the contributions which these respective sciences have made and are making to agriculture, for they are as the links in a chain and are closely related in theory and in practice; but a prominent place must be conceded to economic entomology, which has, perhaps, been as productive of immediate practical results as any other. Although, in the United States, among the youngest of the sciences concerned with problems relating to agriculture, the results achieved have placed economic entomology in the front rank.

In explanation of its phenomenal growth it may be said that one of our necessities, as a rapidly developing country, has been the reduction of insect losses to permit the profitable cultivation of many of our important crops. With the constantly increasing population, new regions have been settled and the lands planted in crops, the more or less isolated farms of former days giving way to practically unbroken areas of corn, wheat, cotton, and other crops, often of many miles in extent, thus furnishing ideal conditions for the development and spread of noxious species. Being preeminently a practical people, we have devised ways and means as the demand has grown, and at the present time the status of economic entomology is quite in keeping with our agricultural conditions.

The rate and magnitude of our agricultural growth and the consequent stimulus to applied entomology may, perhaps, be fairly judged from certain statistics concerning the production of some of our staple crops during the decade covered by the Twelfth Census. The increase in plantings of corn from 1889 to 1899 in the United States was 22,829,159 acres, an increase of 31.7 per cent. In the decade from 1890 to 1900 the area of wheat in the country shows a gain of 56.6 per cent, or about $19,000,000$ acres. The increase in the area of cotton from 1889 to 1899 was 4,099,831 acres, a gain of 20.3 per cent, and it bears on the subject to note that of this total increase Texas, Oklahoma, and Indian Territory furnished 3,637,398 acres, or 88.i per cent. The State and Territories mentioned, it will be rememhered, are at the present time suffering more severely from insect depredations on cotton than is any other part of the cotton belt.

The increase in plantings of deciduous fruits has been scarcely less remarkable. At the present time there are numerous orchards, of 
peach especially, with from 2,000 to 3,000 acres in practically unbroken rows of trees. Orchards of still larger size are planned and are being planted at the present time. In the following table, compiled from che reports of the Twelfth Censis, is indicated the increase in bearing trees, during the decade 1890 to 1900, of the more important pomaceous and drupaceous fruits:

TABLE I.-Number of bearing trees in orchards in 1900 as compared with those in 1890.

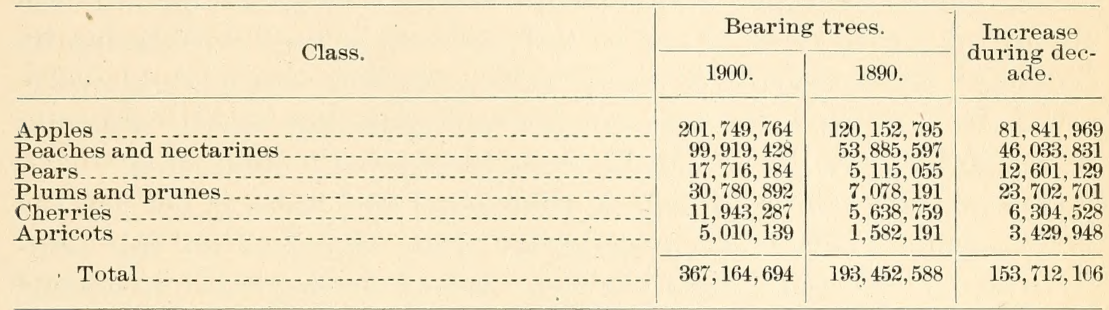

The total increase in plantings of fruit trees of this class is thus seen to have been $153,712,106$ trees, a number sufficient to plant a solid orchard, with trees 20 by 20 feet apart, of somewhat more than $1,400,000$ acres. More recent information indicates a still greater proportionate increase during the present decade. Thus, in the State of Georgia I am informed that the present estimated plantings of peach trees are aproximately 18,000,000, both young and old. Leaving out of account the unreported young trees of the census of 1900 , this shows the enormous gain of about $7,500,000$ trees in four years. The increased plantings of apple, notably in Missouri, are also remarkable. In that State alone over $20,000,000$ trees are reported for 1900 as against 8,000,000 for 1890 .

These figures, I think, explain one of the principal causes for the rapid development of economic entomology in America. The sudden and wide disturbance of nature's balance between insects and their food plants by the cultivation of large areas of crops has resulted in insect depredations, both from native and introduced species, of such proportions as to render relief immediately necessary.

Our problems have been, therefore, largely of a character to demand earnest and instant effort for their solution, and the rapidity with which one problem has succeeded another has utilized to the fullest extent our capacity for work. The results of investigations have been of a character to justify the public in providing for their continuance and extension, and the demand for workers has been greater than the supp!y. This continued activity has brought about a considerable accumulation of knowledge concerning injurious spe- 
cies, and our economic literature to-day is doubtless more extensive than that of any other country.

Most fortunately traditions and theories have had but little place in applied entomology. The accuracy of published statements concerning the life and habits of insects and the value of remedial measures proposed have often been at once put to practical test and their soundness or futility determined. Investigations by several different workers over a considerable range of territory have been a most fertile means of rapid accumulation of knowledge concerning the biology of a given species and of the means to be used in reducing its ravages. Much of error, in theory and in practice, which might otherwise have lived for many years with a corresponding baneful influence on the standing of the science has thus been quickly eliminated.

Our official existence has been strenuous, and, were it not for the considerable number of investigators often engaged on the same problem and the immediate practical test of conclusions, our rate of progress could but mean superficial work. Many of the problems with which economic entomology concerns itself must be worked out from the beginning, and many of our economic workers have been forced to do strictly systematic work as a basis for contemplated work along economic lines. The common observation that applied science does not wait, in its development, on the theoretically necessary precedence of the pure science on which it is dependent is perhaps nowhere so well illustrated as in the case of applied entomology. Of necessity many of our workers are systematists, and their accomplishments in this field are scarcely less than in the domain of practical entomology. In addition to having an acquaintance with the details of insect classification and with fundamental biologic facts, an economic entomologist must be versed in the details of agricultural and horticultural practices, in chemistry, in botany, in forestry, in plant pathology, in animal husbandry, and in business methods.

Under conditions and requirements such as these has applied entomology grown to its present condition; and, although young in years, there is probably no branch of the utilitarian sciences which so nearly touches every hüman interest.

There are at the present time some features of applied entomology in the United States which are significant of its increasing scope and importance and which appear to me appropriate for consideration on an occasion of this kind. The very existence of this association, with its present membership of 175 , is but one of the signs of the times. The writer doubts if there are similar scientific bodies which can show a higher average attendance or which are pervaded with a greater degree of professional interest than are the meetings of this 
Association. Its influence, directly and indirectly, for the betterment of applied entomology has been most important and is increasing from year to year. The bulletins which contain the proceedings of the 16 annual meetings of the association, and which cover in all 1,541 pages, are a most valuable feature of our literature.

It must be a matter of much satisfaction to all entomologists to note the increasing appreciation in which the work of the economic entomologist is held, both by his constituents and the general public. In the earlier days of the science his work was often far from appreciated at its true worth. Experience, however, has been a constant teacher. Certain injurious insects, by their widesprear injury to important farm and orchard crops, have served to bring prominently before the people the importance of the rôle which insects play, not only in the matter of crop production, but in influencing the price of staple articles of food and clothing in the markets of the world. The recently established fact of the transmission and carriage of riseases of man by mosquitoes and flies has arrested the attention of people of many classes, and, along with other discoveries of scarcely less importance, has been the means of exciting the interest and attention of many who previously were largely ignorant of the work and aims of the science. The considerable alarm following the announcement of the establishment of the San Jose scale in the East had scarcely begun to wane before the increasing ravages of the Mexican cotton boll weevil brought this species into wide notoriety, and probably never in the history of the world has an insect species been more generally the subject of comment than has the latter.

The present recognized importance of insect control in its relation to the welfare of our agricultural classes can not be better indicated than by calling attention to the prominent mention given to entomological matters by the President in his recent message to the Congress of the United States. The following are his words:

The cotton crop of the country is threatened with root rot and with bollworm and the boll weevil. Our pathologists will find immune varieties that will resist the root rot, and the bollworm can be dealt with, but the boll weevil is a serious menace to the cotton crop. It is a Central American insect that has become acclimated in Texas and has done great damage. A scientist of the Department of Agriculture has found the weevil at home in Guatemala, being kept in check by an ant which has been brought to our cotton fields for observation. It is hoped that it may serve a good purpose. ***

The insect friends and enemies of the farmer are getting attention. The enemy of the San Jose scale was found near the Great Wall of China and is now cleaning. up our orchards. The fig-fertilizing insect imported from Turkey has helped to establish an industry in California that amounts to from 50 to 100 tons of dried figs annually. and is extending over the Pacific coast. A parasitic fly from South Africa is keeping in subjection the black scale, the worst pest of the orange and lemon industry in California. 
Careful preliminary work is being done toward producing our own silk. The mulberry is being distributed in large numbers; eggs are being importer and distributed; improved reels were imported from Europe last year, and two expert reelers were brought to Washington to reel the crop of cocoons and teach the art to our own people.

However, in this general awakening of the public the importance of other factors than widespread insect ravages must not be overlooked. The numerous well-illustrated books, more or less popular in character, and the frequent magazine articles dealing with general or economic aspects of the science have brought the subject, in this day of much reading, to the attention of a much larger number of people than could have been possible even a few years ago. Nature study in schools, which usually includes work with insects, has awakened many an American youth, and through them their parents, to the preserce of these interesting creatures. Many of our agricultural colleges and other institutions giving courses in agriculture have now for some years been giving instruction in applied entomology, and students have returned to their homes and put in practice the methods learned for reducing insect losses. In many communities there have thus been object lessons which have been the means of inducing others to take up the fight against insects. But probably the most important single factor in awakening this widespread interest in insects remains to be mentioned, namely, the influence of the economic entomologist himself. In the lecture room, at farmers' institutes, at horticultural and agricultural meetings and elsewhere, in season and out of season, it has been his custom to speak from the text of injurious insects.

I would not convey the impression that I believe the farmers, fruit growers, and others are availing themselves to the fullest extent of the means placed at their disposal for mitigating insect losses. While most commendable progress has been made in this direction, yet our most important problem still consists in inducing utilization, by those in need of them, of the means known to be of value in reducing insect injuries. Emergencies such as those brought about by the ravages of the San Jose scale or the boll weevil leave but little alternative to the sufferer, and while the experience is costly, the lesson is well learned. In the writer's opinion, the notable improvement in this direction during recent years may be held to prophesy a rapid increase in the adoption of insect remedies and preventives in the future.

The extent of increase in the number of workers in economic entomology during recent years may not, perhaps, be generally realized. As nearly as I have been able to ascertain, there are at present, in the United States and Canada, 145 persons trained in methods of entomological research, devoting the whole or a part of their time to the study of injurious insects. If account be taken of the many inspectors employed by various States and State horticultural organi- 
zations in the enforcement of crop pest and nursery inspection laws, the number of persons officially engaged in work pertaining to insect control would be easily doubled.

Investigations in economic entomology are made leading lines of work in 43 out of 48 of the agricultural experiment stations, and this subject is taught in practically as many of the agricultural colleges. Much valuable work is being done by several of the State departments of agriculture and State boards of horticulture. In the Bureau of Entomology of the United States Department of Agriculture the force now engaged in strictly entomological work numbers 59 as compared with 14 under the division organization of 1900 .

The increase in workers has naturally been dependent on an increased financial support. It no previous time has so large a sum of money been devoted to the study of injurious insects. The sum total of money annually devoted to work of this character may be only approximately indicated, for separate accounts are not kept in most of the agricultural colleges and experiment stations of the money spent in entomological research. However, from actual figures, in many cases, and from conservative estimates, I would place the amount at not less than $\$ 285,000$. This, of course, does not include special appropriations, as, for instance, that by the Federal Government of $\$ 250.000$ for work against the boll weevil and other cotton insects and diseases, the $\$ 25,000$ appropriated by the State of Louisiana for the same purpose, and notable emergency appropriations of the past, such as that for the gypsy moth.

Viewed from a business standpoint, it is pertinent to inquire what economic entomology has done in the way of returns in dollars and cents for the money invested by the pubiic. A balance sheet which would show the present status of the account and be even approximately correct can not be prepared, owing to the difficulty of accurately estimating the credits. We can, however, make estimates so well within the bounds of reason as to run no possible risk of overstating the case. I have therefore gone over the literature with a view to deciding how far economic entomology has been instrumental in increasing the output of some of our staple crops and fruits. The original estimates were cut in half, and there still remains a credit sufficiently large to satisfy the ideas of profit of some of our presentday multimillionaire corporations.

The following table shows the value of certain classes of crops in the United States for the year 1899, as reported in the Twelfth Census, with the estimated benefits resulting from the teachings of economic entomology stated in percentage and also in dollars and cents. The writer believes this to be a most conservative estimate of 
the annual saving, to the producers of the crops mentioned, resulting directly or indirectly from the efforts of economic entomologists:

TABLE II.-Values of certain crops in the United States, and the percentage and value of the increased production due to economic entomology.

\begin{tabular}{|c|c|c|c|}
\hline Class of crops. & Value in 1899. & $\begin{array}{l}\text { Percent- } \\
\text { age of in- } \\
\text { creased } \\
\text { produc- } \\
\text { tion. }\end{array}$ & $\begin{array}{l}\text { Value of in- } \\
\text { crease. }\end{array}$ \\
\hline $\begin{array}{l}\text { Qrehard fruits } \\
\text { Grapes } \\
\text { Subtropical fruits } \\
\text { Truck crops and small fruits } \\
\text { Cereals } \\
\text { Cotton }\end{array}$ & $\begin{array}{r}\$ 83,751,840 \\
14,090,937 \\
8,549,863 \\
98,894,319 \\
1,484,231,038 \\
370,708,746\end{array}$ & $\begin{array}{r}25 \\
20 \\
10 \\
20 \\
5 \\
10\end{array}$ & $\begin{array}{r}\$ 20,937,960 \\
2,818,187 \\
854,986 \\
19,778,863 \\
74,211,551 \\
37,070,874\end{array}$ \\
\hline Total annual increase ... & & .... & $155,672,421$ \\
\hline
\end{tabular}

Notwithstanding the progress which has been made in reducing loss from insects, this loss, by reason of our increased plantings of crops of all kinds, continues to be rery great. Estimates have been made from time to time indicating, in dollars and cents, the losses caused by one or more species over a greater or less territory. Recently, interesting comparisons have been made by Professors W'ebster and Slingerland of losses to crops in certain States and the country at large as compared with the amounts of money required for the support of our rarious institutions. Thus we are told that the annual loss occasioned by insects in the Cnited States amounts to more than is required for all educational purposes; nearly twice as much as is required for the support of our Army and Nary: orer twice the losses from fire. and nearly three times the estimated ralue of the products of all fruit orchards, rineyards, and small fruit farms in our country.

Careful estimates have shown that the total annual loss from insect depredations in the United States at the present time is not less than $\$ 300,000,000$. In the face of such figures it would appear that we have scarcely entered the threshold of achierement in conquering injurious species. It may not. howerer, be argued from the figures giren that little has thu; far been accomplished. It will be remembered that rears-ago, in 1860, insect losses in the country at large were placed by Walsh at not less than $\$ 300.000,000$ annually. If these estimates are correct the losses appear to have been held stationary, notwithstanding our great agricultural derelopment during the forty years interrening. Present-day estimates are based on a 10 per cent reduction of all crops by the combined attack of the rarious species which prey upon them. In Walsh's time the percentage of injury must have been much higher, as determined by the value of farm products at that time. 
It has been pointed out by Doctor Howard, and possibly others, that widespread injury, such as that from the Hessian fly or the chinch bug, while undoubtedly resulting in a great diminution in the output of the crop attacked, does not represent a corresponding loss in money to the growers, for the resulting scarcity of the commodity brings about an increased valuation which may really leave the farmer little, if any, the worse off financially. Taking this into account, present-day estimates of insect injuries may, on the whole, be too high, but it should be noted that the burden is simply transferred to the consumer, who pays the farmer, or more often the speculator, for the ravages suffered.

Present resources in the ways and means of reducing insect ravages place a much greater responsibility on the farmer, fruit grower, and other's subject to injury than heretofore. In the case of many of our prominently injurious species their life histories have been worked out, their most vulnerable points of attack shown, and appropriate means for reaching them indicated. A mere list of the various insecticides and mechanical methods employed in insect warfare would require more time than is here available and would serve no useful purpose, for the tendency at the present time is mainly toward the use of certain few substances to the exclusion of others formerly in considerable repute.

Paris green and other arsenites, kerosene emulsion, hydrocyanicacid gas, carbon bisulphid, and the lime, sulphur, and salt wash comprise the more important insecticides used to-day. To the three principal periods in the evolution of insecticides in the United States must now be added, in the writer's opinion, that in which was discovered the efficiency of the lime, sulphur, and salt wash in the East. The demonstration of the value of this wash, made almost simultaneously by several workers, ranks among the most important of the notable advances in economic entomology in recent times. The extensive experiments made with this wash under varying weather conditions in Illinois, Georgia, Ohio, Maryland, New York, Connecticut, and other States now permit no reasonable doubt as to its efficiency in controlling the San Jose and other scales in orchards, and it has already been largely adopted by commercial orchardists. It is possible that further experiments may reduce the inconvenience at present involved in its preparation, and may modify its disagreeable character. Should this be accomplished, the two features which now constitute a ground for objection to its use would be eliminated.

The importance of purely agricultural methods in reducing insect losses, especially to some of our staple crops, is becoming much more generally realized than heretofore. A series of demonstrations of this character during the past few years may be held to mark another 
era in the erolution of methods of insect control. Such a simple expedient as delaying the time of planting wheat so as to avoid injury from the fall swarm of the Hessian fly has been the means of saving millions of dollars to the wheat growers in the territory infested with this insect. The important work on this species by Doctor Hopkins permits the determination of the normal time of appearance of the fall brood for any latitude or altitude. Professor Webster, by observations extending over many years, has been able to chart the State of Ohio into belts indicating the safe periods for the planting of this crop.

The recognition of the value of late fall or winter plowing, of rotation of crops, of certain classes of fertilizers, and of better cultivation in the control of noxious species will make this class of work very important in the future. During the last few years the importance of improved cultural methods has been demonstrated on a large scale in the control of two serious pests of the cotton plant, namely, the boil weevil and the bollworm.

In the case of the cotton boll weeril its advent in the cotton fields of Texas coincided with conditions of cotton culture which greatly aggravated its destructiveness. The natural fertility of the land and the tenant system largely in rogue had brought about an indifference to those economical methods of farming found necessary in older sections, where the fertility of the land is less and the difficulty of producing profitable crops is greater. Indifferent preparation and cultivation of the land, the use of unselected and more or less rundown seed-often from the public ginneries and of absolutely unknown rariety-hat placed the cotton-growing industry in a condition to be seriously threatened by the introduction of any inimical factor. The remedial measures now found necessary are along the line of better farming, and we have the not unusual case of entomologists showing the farmer liow to farm. The success with which this work has been carried out must in part be attributed to the readiness of landowners to adopt methods which they recognized as practicable and desirable in themselves, to say nothing of their value in circumventing weevil injury. In a recent communication from Mr. IT. D. Hunter, in charge of the cotton boll weeril investigations of the Bureau of Entonology. he mentions certain phases of his work which are pertinent here as bearing on the methods and extent of this cultural work as applied to what is one of our most important present day insect problems. He writes as follows:

During the several years that the Bureau of Entomology of the United States Department of Agriculture has carried on inrestigations of the Mexican cotton boll weeril it has been possible to perfect a system of aroiding damage by the pest. This system, founded upon al careful study of all the habits of the insect, is now generally known as the "cultural system." Its basis is in the fact 
that a very small percentage of weevils survive the winter. Consequently, in the fall it is possible to practice a strictly remedial step, namely, the destruction of the plants in toto as soon as the possibility of obtaining any more cotton becomes remote. Experiments have shown that a very high perrentage of weevils which would hibernate to damage the crop during the next season can be destroyed. Following this all-important step, the work of the Bureau of Entomology has shown the necessity of obtaining an early crop. The remarkable powers of reproduction of the pest allow such an increase by the midlle of summer that the progeny of a very few hibernated individuals is sufficient to practically destroy all new fruit as it is set upon the plants. The fall destruction of the plants can be practiced without important modifications in any quarter. However, there are many modifications of the system of hastening the maturity of the crop that must be practiced in different regions, owing to diverse climatic and soil conlitions. During the seuson of 1904 the Bureau has established a number of experimental farms to ascertain definitely what these modifications must be. In Texas and Louisiana at present there is a weevil-infested region of at least $9,000,000$ acres of cotton land. This extends from Brownsville northward a distance of 500 miles over very diversified soil formations, with their consequent diversity in plantation practices.

The extent of the infested territory, from west to east, is also in the neighborhood of 5 (n) miles. In this territory the rainfall varies from such a small amount as to make irrigation absolutely necessary, in the west, to the Red Rirer in Louisiana, where the normal annual precipitation is in the neighborhood of 60 inches. These two variations in soil, involving the essential farm operations, and in rainfall, changing the development of the weevil very considerably, are the factors that have made it necessary to establish experiwental farms at a number of points. Fifteen of these farms have been in operation. In most cases in the neighborhood of 100 acres is deroted to each one. In the aggregate about 1,800 acres are involved. Although the work on these farms is strictly experimental, they have an incidental value as demonstration farms. From the experimental standpoint it has been necessary to evolve a careful system of checks. Consequently, whenever a plat is planted with the seed of a certain variety, or with certain fertilizers, or cultivated in some certain way, one alongside of it is treated in all respects according to the ordinary methods in rogue among the planters of the locality. It is fortunate for the performance of such work that the boll weevil moves about but little in the fields until at least as late as midsummer. Were this not the case, it would be necessary to have the plats far removed from one another. However, sufficient separation is brought about by simply planting a few rows of sorghum or some similar crop between the different plats. The actual weevil conditions in each plat are determined by careful observations each week or ten days. Early in the season the number of adult weevils per plant is estimated by the examination of a fixed number in the plats. Later, when the truit is being damiged, the exact status is determined by the figuring of the nercentage of infested fruit on grouls of ten or more plants in three different locations in a plat. Of course the yield of cotton is important, but from an (ntomological standpoint the tables showing percentages of infestation are the exact indication of the effects of the work.

All this field work is carried on under an original system, which relieves the Bureau of the trouble and expense of running the land and working the crop, but at the same time gives it absolute charge of as much area of cotton land as it is desired to utilize for experiments. Contracts are entered into with 
reputable planters. This contract binds the planter to follow the directions of the Bureau in all respects. from the preparation of the soil through to the marketing of the crop. In consideration of this agreement on the part of the Planter, the Department guarantees him a certain rield per acre. 'The amount of this guaranty is determined as far as possible upon the competitive bid basis, although the personal attitude of the planter is considered to be fully as important as the lowness of the proposal. This system has been found to work in a very satisfactory manner. On seren of the fifteen farms in operation Curing the past season the crop produced has been more than the amount suaranteed. The work on about 700 acres. therefore. cost the Department nothing. On some of the remaining farms. owing to intentional late planting. or to other conditions, the rield has been much below the amount guaranteed. In such cases the contract binds the Department to pay the planter for the difference between the amount actually produced and the amount guaranteed at the arerage price receired for what crop the land did produce.

A novel method for securing the subjugation of an insect was adopted by the State of Texas. The legislature of that State roted a reward of $\$ 50,000$ to the person or persons who should devise a practicable, cheap, and effective plan for the control of the boll weevil. A commission of farmers was appointed to pass upon claimants for the reward and to put the various plans to a practical test.

The chairman of this commission. Hon. Jefferson Johnson, of Austin. Tex., has kindly furnished a brief statement, which may be of interest, concerning the varieties of remedies proposerl.

This work has involved an outlay of considerable time. There were more than 300 claimants for the reward. Not all of these, howerer, complied with the requirements of the latw. Three thousind letters have been receired from reople who beliered that they knew something that mould be of ralue to the crimmission.

It would be hard to determine how many principles were depended upon to support these rarious claims. The majority of them trusterl to cultural methods. A large number presented some form of poisoning. There was quite a number of theories for fumigation either to kill the meeril or drive it from the field. Sereral claims depended upon placing in the soil some ingredients or poison that would be taken up by the plant and thus make the plant distasteful or poisonous. Others along the samie line proposed methods to make the plant immune. There were sereral claimants who depended upon inoculation of the weeril with some contagious disease, and in this manner so destroying the yowers of propagation as to rid the coutry of the pest in this way. Several claimants insisted that Providence had sent the insect. and that Proridence aione could remore $\mathrm{jt}$, and these trusted in supplication. Yot a fer adranced the theory that noxious plants could be grown with the cotton, thus either destroying the weeril or keeping it from the field. One claimant submitted a proposition to plant poppies, thus destroying the weeril by the opium that the insect would get from this plant.

Many ingenious machines were made for catching weerils and for picking up by mechanical process the squares from the giound. Other machines were invented and tried for burning the squares on the ground. and others for passing the squares between rollers.

These claimants came from erery quarter of the globe, and letters were addressed to the commission in the language of almost all of the civilized world. 
Some of these letters were not answered because of the fart that we were not sble to get a proper translation. No adequate conception of the difference of these plans and the range corered by them can be given in so brief a statement. None of the plans were found satisfactory.

Anyone who has attempted to keep up with the present-day literature of economic entomology must have been impressed with its increasing $]_{y}$ heterogeneous character. Possibly nothing so well illustrates the widening scope of the field of applied entomology as the great range of subjects treated, covering, for instance, such subjects as:

Smyrna Fig Culture in the United States.

Extermination of Malaria-Breeding Mosquitoes.

Aquatic insects of New York State [as bearing on the food supply of fishes]. Insect Enemies of Forests and Forest Products.

Contributions to a Study of the Insect Fiuna of Human Excrement, with especial reference to the spread of Typhoid Fever by Flies.

Combating Insects with Fungous Diseases.

Intraradical Nutrition of Diseased Trees for the Purpose of Curing them and Destroying Parasites.

A long list of titles might be presented, but it is unnecessary. In so fertile a field the literature of economic entomology must become more and more diverse in the future. A very important question arises, namely. How may one keep reasonably well informed as to the results obtained by his co-workers in lines somewhat different from his own? This point has been referred to during previous meetings of this association. Doctor Smith, in his presidential address before this society on the occasion of its seventh annual meeting, expressed himself in reference to this matter as follows:

Can we not devise some plan by means of which we can keep informed of what is going on without the necessity of wasting time- by examining everything and then missing it all?

Perhaps the writer feels more strongly on this point than the situation warrants, but in his efforts to catch up with economic literature after about two years of work in the field under conditions discouraging to efforts of this character, he has been impressed with the desirability of some scheme, as suggested by Doctor Smith. The whole matter has appeared to be of sufficient importance to warrant the consideration of some plan whereby the desired results might be secured. Simply to put the matter in more definite shape for consideration, I would propose that a person be annually designated for each of the principal natural divisions of the general subject whose duty it will be to present, at the following meeting, a résumé of the principal results achieved in that particular branch during the year. The reports of these several persons would become a part of our proceedings and could be referred to at will by workers in other lines.

$25524-$ No. $52-05 \mathrm{M}-2$ 
To further promote the end in view I would suggest the following division of the general subject:

(1) Staple and miscellaneous crop insects.

(2) Small fruit and truck crop insects.

(3) Decidious fruit tree insects, including those infesting nursery stock.

(4) Citrus and subtropical fruit insects.

(5) Oruamental plant and greenhouse insects.

(6) Shade tree and forest insects.

(7) Insects injurious to stored foods, dwellings, clothes, books, and miscellaneous substances.

(8) Insects affecting man and the domestic animals.

(9) Insects concerned in the transmission and carriage of disease.

(10) Beneficial parasitic and predaceous insects.

(11) Insects useful to man as furnishing food, clothing, etc.

(12) Insecticides and machinery.

A most commendable feature of our present-day literature is the increasing amount of thorough and painstaking work on the biology of insects. Shortly after the establishment of the sereral agricultural experiment stations entomological publications were, probably of necessity, largely compilations. owing to the fact that there was need for placing before the public for immediate use such information covering injurious species as had already been obtained. As information of this character has become more and more familiar, its presentation and repetition have become less necessary, and more original work has been brought forth. Rerised bulletins on insecticides and spraying machinery must of necessity be gotten out from time to time as progress is made along these lines, but the notable decrease of purely compiled bulletins and papers concerning insects is a most favorable indication.

Many recent entomological publications, in the quality of subjectmatter. character of illustrations, and wealth of detailed observations leare little to be desired. Improved facilities for careful life-history work have rendered possible the many excellent papers which are at once a credit to the literature of the science and an inspiration to other workers. Careful life-history studies have been an important means of separating two or more species long held to represent but one. Witness the case of the aphids designated as Aphis mali, which Sanderson has shown represent several species. Similarly, Morrill has been able to separate Aleyrodes packardi from Aleyrodes vaporariomm. Certain species may only be distinguished by a comparative study of their respective larral stages, as in the case of Chilocorms bivulnerus and $C$. similis.

In addition to careful biologic studies of insects, the consideration of life zones, of effective temperatures, and of the number of generations in various parts of the country. of forms widely distributed should be given more attention than has been the case in the past. 
The value of a knowledge of effective temperatures is well illustrated in the case of the Hessian fly, and if we had more exact data of this character concerning many of our pests it is not improbable that valuable suggestions in their control would result. The pancity of exact knowledge on some of these points with so common a species as the cotton bollworm was brought to my attention recently in the course of an attempt to determine the number of generations of this species throughout the United States and Canada. Insects of such wide distribution offer exceptional opportunities for studying the laws of temperature limitations and other factors of the greatest interest and probable value. On such problems cooperation must necessarily be secured. The desirability of this has oftei been the occasion of remark in the proceedings of this Association and elsewhere, but its accomplishment appears no nearer realization than during the early days of the society.

Recent years have witnessed an important change of sentiment with regard to insect legislation, and its extent at the present day may doubtless be held as proot of its recognized value. However this may be, the fact remains that, with few exceptions, the various States have adopted laws which have for their end the restriction of one or more species and, in numerous instances, the enforced control of pests already established.

A recent census of legislation in the United States bearing on the control of insect pests shows that of the forty-eight States and Territories the following only are yet without operative laws, and some of these have bills in preparation for passage at coming legislative assemblies: Arizona, Florida, Kansas, Nebraska, Nevada, New Mexico, Oklahoma, South Dakota, Texas, Vermont, and Wyoming. The following insects are mentioned as coming under the operation of various laws, and in many cases provision is made for the designation of other species which at any time it may be judged desirable to quarantine or whose control should be enforced.

\section{PHYTOPTIDE.}

Pear blister mite (Eriophyes pyri Pagenst.).

ORTHOPTERA.

Grasshoppers (Melanoptus spretus Thos.; M. atlanis Riley; M. Jivittatus Say, etc.).

\section{HEMIPTERA.}

San Jose scale (Aspidiotus perniciosus Comst.).

Cherry scale (Aspidiotus forbesi Johns.).

European fruit-scale (Aspidiotus ostrexformis Curt.).

Greedy scale (Aspidiotus rapax Comst.).

Walnut scale (Aspidiotus juglans-regio Comst.). 
Gloomy seale (Chrysomphatus tenebricosus Comst.).

West Indian peach seale (Diaspis pentagona Targ.).

Scurfy scale (Chionaspis furfura Fitch).

Euonymus scale (Chionaspis euonymi Comst.).

Oyster-shell scale (Lepidosaphes uTmi Linn.).

Peach scale (Eulecanium persicce Fab.).

Plum Leeanium (Eulecanium prinastri Fonse.).

Pine Chermes (Chermes pinicorticis Fitch).

Stramberry root-aphis (Aphis forbesi Weed).

Black peach aphis (Aphis persica-niger Erwin Smith).

Woolly apple aphis (Schizoneura lanigera Hausm.).

Pear Psylla (Psylla pyri Linn.).

LEPIDOPTERA.

Gypsy moth (Porthetria dispar Linn.).

Brown-tail moth (Euproctis chrysorrhoea Linu.).

Canker-worms (Paleacrita éneta Peck; d7sophila pometaria Harr.).

Fall webworm (Hyphantria cunea Drury).

Apple-tree tent-caterpillar (Malacosoma americana Harris).

COLEOPTERA.

Cotton boll weeril (Anthonomus grandis Boh.).

Sinuate pear borer (Agritus sinuatus Ol.).

Imported willow borer (Cryptortiynchus lapathi Linn.).

Strawberry crown-borer (Tyloderma fragarice Riley).

Trhen it is stated that of this list only the san Jose scale is common to all States which hare enacted laws for insect control, the dirersity of the requirements of the different states is plain. In a country so diverse, climatically and industrially, as ours the legislation adopted must needs be more or less dissimilar, but the lack of uniformity in legi-lation of this character greatly interferes with the attainment of results the accomplishment of which has been the principal excuse for its establishment. Ihe principal exciting cause of the enactment of laws has been and still is the control of the San Jose scale, and the hasty manner in which many of these rere called into existence following the discorery of this pest in the East must be largely held responsible for their present diversity.

A crisis of a somewhat similar character is now facing the cotton growers of the South, and several States have made provision for the restriction of the cotton boll weevil. There has, hotrerer, been a notable iniprovement in the details of this work, in that the entomologists of the sereral State- interested have agreert on a certain uniformity in the measures to be adopted which will add much to their possible effectiveness.

A most stupendous attempt at insect control is now being contemplated by the State of Texas, designed to reduce injury from the cotton boll weeril by the enforced adoption of certain radical changes in the agricultural practices of their cotton planters. The extent 
and difficulty of the proposed plan can only be appreciated in connection with a knowledge of the enormous territory affected and the peculiar farming conditions which are there in vogue. According to the Twelfth Census the cotton interests of Texas are approximately equal to one-fourth of those of all cotton States combined, covering in 1899 $6,960,367$ acres. It has been determined by the investigations of the Bureau of Entomology that probably the most important single way in which the wholesale destruction of the weevil may be obtained is by the early destruction of the cotton plants in the fall before the weevils are ready to go into hibernation quarters. The difficulty of enforcing destruction of fields of cotton over so wide a territory and at a time when the prospects for continued yield are good need not be commented upon before an audience many individuals of which have had experience in the execution of laws requiring the destruction of a greater or less number of comparatively worthless infested fruit and other plants.

The present status of our knowledge concerning our destructive insects and the efficiency of present methods of control is a subject that might well be enlarged upon did time permit. Undoubtedly the three dominant entomological events of the past few years have been the establishment of the San Jose scale in the East, the invasion of Texas by the cotton boll weevil, and the widespread interest aroused in mosquitoes following the discovery of the rôle which these insects play in the transmission of malarial and yellow fever.

Since about 1894 the San Jose scale has occupied the attention of many of our Eastern entomologists to the practical exclusion of everything else. The matter of control of the insect in nurseries was early solved by a system of inspection and fumigation. Its control in orchards has until recently continued to be a most perplexing problem. The unsatisfactory results following the early experiments with the lime, sulphur, and salt wash practically eliminated this insecticide from consideration among possible remedies. Attention was therefore directed to other means of control. Kerosene and crude petroleum, pure and in mechanical mixture with water and in soap emulsions of varying strengths, various soap washes, hydrocyanic-acid gas, parasitic fungi, and, in fact, almost the whole gamut of insecticides was run through only to discover, after some years, that the lime, sulphur, and salt wash was, after all, a most satisfactory treatment. The establishment of this fact came, so to speak, in the nick of time. While there is abundant testimony as to the safeness and efficiency of the mineral oils in the control of this insect on such fruit trees as the peach and plum, yet the trouble lies in the danger following the injudicious applications which persons inexperienced in such work are likely to make. The many instances of severe and often fatal injury are calculated to bring the recom- 
mendations of the entornologist into disrepute. Howerer, the question of a safe and efficient treatment of this insect in orchards appears now to be settled, and. aside from questions of convenience in preparation and the time of application, the experimental stage is practically passed.

There is a tendency, howerer, in the recent literature on the lime, sulphur. and salt wash, the adrisability of which is perhaps open to question. I refer to the publication for the use of the fruit grower of the various formulæ known in its preparation. He is scarcely able to know what is best; consequently he must simply pay the money and take his choice. As a matter of fact, there appears to be room for great latitude in the proportions of the ingredients used and in the manner of preparation without injuriously affecting the efficiency of the wash. The tendency is perhaps to adopt the so-called even-quantity formula, namely, one part each of the lime, sulphur, and salt to three parts of water. It would appear highly desirable that a standard formula be adopted for the convenience of fruit growers. as the directions for its preparation at the present time differ more or lesis for almost every State. Or is it, perhaps, true that climatic and other conditions vary so much in the Eastern States that a formula found effective in Tirginia, for instance, would not necessarily be as effective in Maryland, Ohio, or Connecticut?

The interest in mosquitoes, which had been steadily growing from about 18.t, as a result, primarily, of the work of Doctor Howard. was giren a great stimulus in the latter part of that decade by the demonstration by a group of medical men of the rôle which these insects play in the transmission of malarial and yellow fever. Immediately these insects became objects of the greatest interest, and entomologists were called upon to furnish information concerning their life histories, habits, and classification. The mosquito has been studied in many quarters, and the contributions of American entomologists have been very important. Since 1900 a remarkably large amount of work has been done, as the following partial list of publications treating of the Culicidæ testifies:

Notes on the Mosquitoes of the United States. Howard, 1900, pp. 70.

Gnats and Mosquitoes. Giles, 1900, pp. 314.

Malaria. Eyre. 1900, pp. 275.

Monograph of the Culicidie. Theobald, Vols. I and II, 1900, pp. 817, plates 59.

Mosquitoes. Howard, 1901, pp. 241.

Our Near Neighbor, the Mosquito. Rich, 1901, pp. 58.

Gnats and Mosquitoes. Giles, 2d ed., 1902, pp. 530.

Laboratory Work with Mosquitoes. Perkely, 1902, pp. 112.

Mosquito Extermination, North Shore, Long Island. 1902, pp. 125.

Mosquito Brigades. Ross, 1902, pp. 98.

First Anti-Mosquito Convention. 1903, pp. 83.

Monograph of the Culicidæ. Theobald, Vol. III, 1903, pl. 539.

Common Mosquitoes of New Jersey. Smith, 1904, pp. 40. 
The astonishing total of 3,383 pages is shown by the works mentioned. Probably no group of insects has so quickly sprung from comparative obscurity as has this family. The great importance of their control in the lessening and prevention of diseases and in adding to the comfort of our citizens warrants the belief that these insects must receive considerable attention at the hands of economic entomologists in the future.

Along with the work on the San Jose scale, the boll weevil, and mosquitoes, much other important and good work has been accomplished. On a closer examination many of our old-time pests are still disclosing new facts. Native or introduced species, previously of but little importance, have, under favorable conditions, become so numerous and injurious that their prompt and thorough study has become necessary. The efficiency of insecticites and remedial practices has been constantly improved. Recent experiments with arsenate of lead for the codling moth give promise of a still greater reduction of the percentage of wormy fruit. The evolution of our knowledge concerning the life and manners of almost any insect species and the development of measures for its control would furnish an interesting chapter in the history of economic entomology in this country, and the gradual accumulation of facts and improvements in remedial measures may properly be compared to the evolution of a harrester or sewing machine. Looking back over the subject, points in life history which at the time of their discovery appeared trivial enough, are seen, in the light of the completed record, to have been the key to the situation. The determination of all points connected with the life and habits of an injurious species is not only warranted for scientific reasons, but we are only able to judge of the importance of any point after all the facts concerning it have been completely rounded up.

The growing efficiency of our battery for insect warfare and the increasing familiarity of growers of crops with its use must result in the important lessening of insect injuries. With numerous species, as the Colorado potato beetle, cankerworms, cabbage worms, and other species feeding on exposed portions of plants, the arsenites are practically specifics, and the question of preventing losses resolves itself largely into inducing the utilization of these remedies. The successful control of other species is frequently more complicated and requires the exercise of considerable judgnient. Thus spraying for the codling moth must be done with reference to the stage of development of the young fruit. The sowing of fall wheat, to a void injury from the Hessian fly, must be timed with nicety. Poisoning cotton for the cotton boll worm must be done with reference to the condition of adjacent corn.

It has perhaps been a standing excuse with us, in accounting for the 
failure of growers to get satisfactory results in the emplorment of the recommended measures, that directions had not been properly followed. Operations against certain pests, to be successful, mist be done with exactness. The requirements are sometimes too complicated, involving considerable familiarity with entomology, so that the arerage man is unable to properly carry out directions. For such cases demonstration work has a legitimate field. It is perhaps an open question whether the responsibilities of the economic entomologist go any further than to study the life and habits of a given rest and to point out the appropriate remedy, leaving the matter of its utilization entirely with those directly concerned; but it has been much to the good of the cause that many workers have demonstrated, sometimes orer and over again, the benefits to be derived from insecticidal applications. Indeed, this has been no small part of the work thus far.

Future problems will probably not materially differ in character from those of the past. but more and more should methods of prevention replace the actual application of insecticides. If there is anything in the idea that rarieties differ with respect to their susceptibility to insect attack, this matter should be thoroughly investigated. Certain facts might be adduced that seem to indicate that this is, in a linited way, true. Certain of our native rines are more resistant to Phylloxera than European rarieties descended from Vinifera. The Torthern Spy apple is said to be much less subject to attack from the woolly aphis than other rarieties, and its roots are often used as grafting stock on this account. The immunity of the Kieffer pear from the attack of the San Jose scale is a matter familiar to most of you. The different rarieties of plums rary much with respect to their susceptibility to the curculio. Other similar instances might be given. The possibility of protecting trees and plants from insect attack $\mathrm{ky}$ the use of certain fertilizers or the introduction into the circulation, through the roots or otherwise, of substances objectionable to insects, has often been suggested. Recent investigations abroad indicate success in this method of preventing insect injury. Doctor Smith, in this country, has been able to reduce the injuries of the pear midge by the use of kainit, and this same fertilizer is considered valuable in protecting cabbage, onions, and numerous other plants from certain of their insect enemies. Thorough detailed life-history studies must replace the often scant remarks concerning the four principal stages of insects, and this improrement is already well under way. The interrelations between insects and their environment, e. g., their parasites, and the influence of climate, altitude, and soil, is as yet almost an untrodden field. A more accurate knowledge of the laws governing the distribution and successful existence of insects must furnish much of practical value. 
Along these various lines will the economic entomologist find opportunity for valuable work in the future. At the present rate of progress the next two or three decades must witness many important discoveries and improvements, and it may be safely predicted that the science will not fail to respond to the demands made upon it with the increasing material development of our people.

After the conclusion of the president's address the report of the secretary-treasurer was read and referred to an auditing committee consisting of Messrs. Fletcher and Sanderson. On motion, an assessment of 25 cents was levied on all members present at the meeting.

On motion of Mr. Burgess the following committees were appointed:

Nominations: Messrs. Slingerland, Osborn, and Phillips.

Membership: Messfs. Smith, Chambliss, and Titus.

Resolutions: Messrs. Felt, Burgess, and Washburn.

Programme: Messrs. Summers, Marlatt, and Skinner.

The following paper was presented:

\section{EXPERIMENTS WITH LIME-SULPHUR WASHES.}

By E. P. Felt, Albany, N. Y.

Experiments with lime-sulphur washes were continued last season largely for the purpose of testing their efficiency and also to gain an idea as to the relative merits of different methods of preparation and the best quantities to use. Several formulx, which gave good results last year (1903), were further tested the past season (190t), the principal ones being 25 pounds of line and 20 pounds of sulphur to 50 gallons of water; 25 pounds of lime to 12 pounds of sulphur, and 30 pounds of lime to 15 pounds of sulphur, respectively, to 50 gallons. All of the washes were prepared as in previous years, the lime being slaked in a few gallons of hot water in a kettle over a fire, the sulphur added, the whole stirred, and the boiling continued actively from half an hour to an hour and a half. Our observations failed to show that the long boiling gave a more effective wash than the one produced by the quicker method. Our experiments confirmed previous conclusions that a little more lime than sulphur was an advantage, and, after consultation and comparison of data with Prof. P. J. Parrott, of the Agricultural Experiment Station at Geneva, N. Y., we both decided to recommend 20 pounds of lime and 15 pounds of sulphur, with at least thirty minutes active boiling, the use of salt being optional. A wash wherein a large amount of lime is used for the purpose of generating heat, so that boiling is not necessary, can be made as recom- 
mended by Mr. 1. I. Bromn. of Delaware. and this preparation uncloubtedly kills a considerable proportion of the scale insects upon a tree. but the results are not equal to those obtained where a boilexl wash is emploved, and we confer- to feeling that in the end it will prove unsatisfactory. though we have known of instance- where very fair results were secured.

Tre have developed a new lime-sulphur wash in which sal sock is uned to asist in bringing about the chemical combination instead of caustic sola. Our result with thi- were most gratifying. Sereral formula were employed. and as the outcome of our experiment- we have lecided to recommend for further experimental work the same amounts of lime and sulphur as before mentioned and 10 pounds of sal socta to 50 gallons of wash. This may be prepared hy placing fire or six pails of hot water in a barrel. preferably a thick pork or oil barrel, adding the lime, and quickly following that with the -ulphur ane sal forla. and then stirring till the slaking is pracetically completed. It may be neces-ary to add cold water at interrals to keep the mixture from boiling orer. Ifter the rapid hubbling or boiling is practically completed corer the open barrel with burlap and allow it to stand thirty minutes or more. A caution regarding stirring shonld be made here. since it seems to affect the composition of the mixture. There should he enough agitation to keep the materials from caking at the bottom. and ret not so much an to - erion-ly hinder the slaking of the lime and accompanying chemical change-. Thi- method of preparation give- an excellent compound, - of far as deep color and little sediment is concerned. provided it is properly prepared. and one of the ex-entials in making it appear- to ha thorongh stirring at the ontert in oreler to intinately mix the lime. sal soclat. and sulphur. I deep red or even pea-green color thould be secorect. This wash spray- nicely. and in experiment- commenced last spring has given an good results in killing the sian ofore scale as any of the lime-sulphur washes. It has sereral aclrantages. Jt respuires no boiling. and the sal sola is a common material, masily hamelled and oldainable in alnost erery locality. It is aloo a little

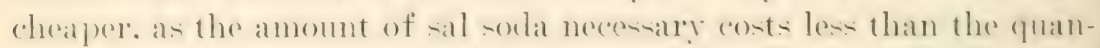
tity of caustic sodal advi-ed for preparing io gallons of wash. Thi matrial has been ueet lut one seatson. though it wa-tried in sereral localities. Profesor Lochlhead, of the Ontario Agricultural Col-

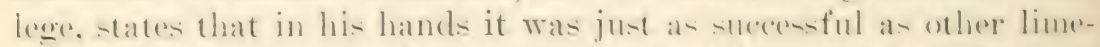
-nlphur wathes. and a few others ohtained from gool to exoellent rente-in -pite of their inability to give it a thorough trial.

In thi- connection it might be well to add that expreriments were

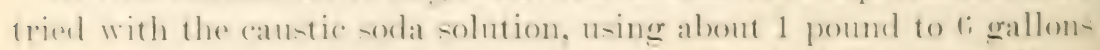
of water. and also with a borkeanx mixture to which of ounces of erorro-ive -ublimate were added to each 50 gallons. The re-ults showed 
that at the end of the season the treated trees were very little better than the checks, and consequently neither material can be considered as valuable in checking the San Jose scale.

Recent disquieting reports, emanating from New Jersey, as to the poor success obtained with lime-sulphur washes led us to inquire rather closely into New York conditions, with the result that, so far as we could learn, wherever the trees were thoroughly sprayed with a lime-sulphur wash the scale was kept in control in a very satisfactory manner. This does not reflect in the slightest upon the work done in New Jersey, but refers simply to our New York conditions, and the statement is made at this time because we can not help feeling that lime-sulphur washes at present afford the most practical method of controlling the San Jose scale, despite the fact that their preparation is laborious and their application exceedingly disagreeable.

Mr. Smith stated that Jime-sulphur mixtures have not been as successful in New Jersey during the past season as in former years. On apple and plum they were especially inefiective. In 1903-4, after a thorough examination of certain areas, the lime-sulphur washes were recommended quite extensively. Several persons made a business of spraying, and careful examination showed that they were doing thorough work. Canstic soda was used in some cases, but no grood results were obtained. Lime-sulphur mixtures were made in all ways, but uniformly poor results followed their use. When apple and peach were planted alternately the results on peach might be excellent, while on the apple failure resulted. One grower who had been using petroleum for years in 1903-4 used lime-sulphur wash on half his trees, consisting of apple and pear. A large share of the pears sprayed with the lime-sulphur-salt mixture were so badly infested as to be unsalable, while the fruit on the oil-sprayed trees was clean. In the case of apples, it seemed as if the pubescence kept the wash from touching the scales, and these get out on the fruit, although the twigs might be practically free from them. While no very marked difference was observed, the boiled wash seemed on the whole to be better than the unboiled.

Mr. Gillette said that perhaps climatic conditions might have been responsible for the failure in these cases.

Mr. Smith said that it had been an excessively cold winter.

Mr. Phillips stated that if carefully prepared the so-called uncooked lime-sulphur mixture really boiled from fifteen to thirty minutes, but in order to secure a long boiling period it is necessary to husband the heat from the slaking lime very carefully. The method suggested was to put the lime and sulphur in the barrel together and use sufficient boiling water to slake the lime, being very careful not to let 
it get dry. The whole mass is stirred until it is reduced to a thin paste, and the barrel is then rorered to retain the heat, but should be opened and the preparation stirred about every five minutes to prevent it from caking at the bottom. Considerable experience is necessary to make a wash by this method, and the strength of the product is rery uncertain. The specific gravity indicates that quite a good deal of the sulphur is left undissolved. The results with this wash in Tirginia have not been good, and it is not recommended. They are recommending the regular boiled preparation, which, he states, should be boiled rigorously for from thirty to forty minutes.

Mr. surface said that in Penn-ylyania, with conditions quite similar to those in New York, about the same results had been reached. Climatic conditions, howerer, were certainly not wholly responsible for such differences in results as were reported by Professor Smith, of New Jersey. Occasionally some persons would get entirely satisfactory results. while others would fail in the same county. The greatest factor in producing unsatisfactory results is lack of care in hoiling and preparation. In some cases the lime-sulphur-soda mixture prepared without boiling has given excellent results.

AFTERYOON SESSION, THURSDAY, TECEMBER 29, 1904.

The meeting was called to order by the president at $2.30 \mathrm{p}$. m., and the following papers were presented:

\section{NOTES ON CUBAN INSECTS.}

By MeL. T. Cook, Santiago de las Vegas, Cuba.

[Abstract.]

The short time the writer has been in Cuba makes it impossible to give more than a preliminary report. Natural conditions are farorable to a multitude of insects. and this report will be confined to those of economic importance. Lepidoptera are among the most conspicuous and many are rery destructive. Cutworms are rery numerous, especially on corn and tobacco. They are frequently parasitized by dipterous and hymenopterous insects. Leaf-miners are rery abundant on both wild and cultivated plants. The coffee leaf-miner (Lencoptera coffeella Stain.) is of greatest importance. Many of the Lepidoptera have rery short periods of puration. From 15 species we have the following ingures:

In pupa five days

Species.

In pupa nine to thirteen days___. 9

Iu pupa sixteen days_..._._.

In pupa twenty-two to twenty-three days_._._. 2

In pupa twenty-seren days_._._. 1.

In jupa twentỹ-nine days...... 
Hymenopterous insects are very numerous and many are undoubtedly valuable in destroying lepidopterous larva. Thus far, however. only one Hymenopter (Atta insularis Guer.) has been studied. These ants are polymorphic leaf-cutters which construct large underground chambers and galleries. They are very destructive and cut great quantities of leares which they carry into their galleries and use for cultivating fungus gardens. These galleries extend from 4 to 8 feet underground and frequently cover large areas.

The Coccidie are very numerons, but are well parasitized both by hymenopterous insects and by fungi. For this reason they are not of such great economic importance as in the United States.

Coleopterous insects are very numerous and frequently very injurious in orange groves. The cotton boll weevil (Anthonomus grandis Boh.) is very abundant.

Gail-producing insects are very abundant. At the present time the writer is inclined to consider the Phytoptus galls the most abundant. A Coceid gall was found on the twigs of the fig and the native anonas.

\section{SOME OBSERVATIONS ON THE COTTON BOLL WEEVIL.}

By E. Dwight Sanderson, Durham, N. H.

In the following paper the writer wishes to give but a brief summary of the more important conclusions resulting from two years' study of the cotton boll weevil and its relation to cotton production in Texas.

Inasmuch as the most important means of control have to do with the hibernating weevils, and as the mortality of those hibernating and the time of their emergence in the spring is a most important factor in the injury during the subsequent season, we have given considerable attention to all phenomena connected with their hibernation.

Messrs. Hunter and Hinds hare stated that the weevils enter hibernation when the mean average temperature falls to between $55^{\circ}$ and $60^{\circ} \mathrm{F}$. Our observations entirely corroborate this rule. By confining several hundred weevils in cages once a week after October 1 we ascertained that in 1903 none hibernated until about Norember 18, when there was a freeze; and about that time the mean average temperature dropped below $60^{\circ}$. Furthermore, those confined some time before this died before hibernating, almost without exception, showing that they can not be forced into hibernation; that the time of hibernating depends on the average temperature; and that by depriving the wrevils of all food early in the fall they can be starved to death in large numbers. 
By platting the temperature curres for different points it will be seen that the mean daily temperature falls below 60 about December 1 at Victoria. Tex. (which agrees with the observations of Hunter and Hinds), at College Station about Norember 10 to 15. at Dallas several days earlier. and for the northeastern part of Texas about Norember 5 . From a brief study of the arailable data. which we are having tabulated and expressed graphically, we believe that these dates will be found to coincide rery closely with those of the first killing frosts for these sections, although the frost dates will fluctuate much more widely from year to year than does the mean daily temperature.

In carefully observing the numbers snd activity of the reevils every day during the fall. it was interesting to note that the activity was immediately arrested whenever the mean daily temperature dropped below $60^{\circ}$. and a comparison of this daily record with the temperature curve platted for College Station shows this strikingly.

The number of weerils entering hibernation will depend almost entirely upon the food supply during the fall. Whether there are one or two more broods in one part of the State than another matters not, for after the third brood the weerils become so abundant that their numbers are limited only by the arailable food supply. Therefore, with a normal or excessive rainfall during September and early October. which would cause the plants to snuare freely, there would be an abundant food supply and many more weevils entering hibernation than in a dry year when but few squares are formed. The weather of the fall, then. has a considerable influence on the number of weevils which conmence reproduction the next spring.

At present one of the most important natural factors in reducing the food supply of the weerils in the fall is the leaf worm, or so-called "army worm " (Atebrine argillacea, Hübn.). It is a most interesting entomological phenomenon that this insect. which formerly did so many million dollars worth of clamage to the cotton of the South and which was the subject of much inrestigation. has now become one of the Texas cotton planter's most valued allies and is welcomed by him wherever the reevil occurs. That the defoliation of the plant by these caterpillars has an important influence on the number of weerils hibernating is certain.

Of course, the same results are accomplished by thoroughly grazing the cotton. or better. by cutting and pulling the stalks, and the latter forms the most important feature in the fight against the pest, as discussed hereafter. As far as re can ascertain. the number of Teevils entering hibernation will arerage about one per stalk; in badly infested fields it will often be two per stalk. and it may be as low as one to two stalks. with cotton planted an arerage distance apart.

Where the stalks are allowed to stand. many of the injured bolls remain on then unopened during the winter, and in these the imma- 
ture stages continue to develop after frost. At College Station we were unable to ascertain that any of these come to maturity or survive the winter under normal conditions, and we believe this to be the case generally in central and northern Texas. In southern Texas, especially the more southwestern part, the conditions are different, however. In February and March, 1903, we received a large number of bolls Irrom Devine, Tex., containing larvæ, pupx, and adult weevils, mostly newly transformed. Some of these were found within the seeds, but there is comparatively no danger that they would ever be disseminated in the seed, since practically none of the cotton in which they entered the seeds would ever be picked and ginned. Many of these weevils were alive early in April, and in southern Texas would have emerged before that time. Out of 200 bolls picked at random 20 per cent contained living or dead weevils in some stage, and of these 55 per cent were alive. Mr. W. P. Allgood, who sent the bolls, at the writer's request, made careful counts, which showed that in the fields from which the bolls were secured there were about 10,500 weevils per acre. If but 20 per cent of these had survived and had emerged in the spring, there would have been 2,100 per acre, and this is approximately the number which survived during the last winter (190:3-4) in Laraca County, when the number surviving hibernation was unprecedented. Furthermore, the rainfall at Devine was nearly double the normal during this winter and weather conditions were exceedingly unfarorable for the hibernation of weevils had they been hibernating in the fields in the usual situations; but inside the bolls they were well protected from dampness and the temperature was never so low as to injure them. The importance of the absolute destruction of the stalks in southern Texas, even if deferred until midwinter, is therefore apparent, although in the rest of the State it is valueless after killing frost.

Regarding the places of hibernation we have been able to secure but little direct evidence. Just after hibernation commenced Mr. Conradi was able to find four weevils under leaves in a cotton field and under bark of a $\log$ adjoining it, but later in the winter absolutely none were found. Though many days have been spent in the most careful examination of the places where the weevils are supposed to hibernate, we have found but one individual in midwinter. As this has been our experience in hunting for other hibernating insects, however, we are not surprised. There is, nevertheless, abundant indirect evidence that most of the weevils hibernate in the cotton fields and in adjoining woodlands. Infestation usually commences in the spring along a woodiand or hedge row, and is worse in a field which has been in cotton than one in corn. It is worse where sorghum adjoins cotton, as the sorghum stubble or stacks seem to form a safe shelter for the reevils. Furthermore, we are compelled to believe that the 
exceedingly small number of weerils on Brazos bottom plantations in 1903 must have been clue to the flood late in the winter preceding. which undoubtedly killed large numbers of the reerils hibernating on the ground below the water level in the fields or elsewhere. Had this flood occurred after the emergence of the weerils it would probably not have materially reduced their numbers. A larger number of weevils always appear about outbuildings and barns and. very noticeably, near gins.

The mortality of the hibernating reevils is a matter of considerable importance. for. were it not for the large number which fail to survive the winter. it would be impossible to grow cotton in the infested region. Of 500 weerils going into hibernation in cages where they were largely protected 7 per cent survired. Hunter and Hinds have indicated that about 15 per cent survire at Tictoria. and the data arailable wonld indicate that this is msully abont the percentage for southern Texas. At College station. hotrerer. extensive observations show that normally only about 2 per cent. and rarely orer s per cent, surrive in the field: or. in other words, but one-fifth as many as in southern Texas. 'That this is a most important factor in reternining the possible amount and time of damage the next season is apparent. If a similar difference is found between central and northern Texas it will be a matter of great importance for the latter section of the State and other portions of the cotton belt. Carefnl estimates of the number surriring in southern Texas during the last winter show that in Lavaca County fully 30 per cent. or twice as many as usual. survired. With this number appearing in the spring. amounting to about 2.500 per acre by actual count. it is imposible to raise a profitable cotton crop by any means now known. As a result. for the first time since they hare been infested. the counties of southern Texas, which have heretofore showed no marked decrease in production owing to the weeril. produced almost no crop.

The method used for determining the number of weerils surviring was to count a large number of stalks in the fall at time of hibernation and determine the number of weerils per stalk: chen, in the spring. to count them in a similar way until the first summer brood commenced to emerge. In this way the number of reerils per acre, both in fall and spring. can be very accurately determined. provided large numbers of stalks are counted in several fields in one ricinitr: and re beliere this to be the most accurate method of determining the actual mortality which takes place in the field under natural conditions.

The time of the greatest mortality is a matter of some interest. As nearly as can be judged from the meager data now available. the largest number died in December coincident with the greatest rainfall of the winter, which was above normal for that month. Usually the 
greatest rainfall is in January at College Station, and probably the largest number usually succumb in that month.

That the rainfall is probably the most important factor in determining the mortality of the hibernating brood is very apparent upon studying the platted curves for rainfall and temperature for different points where we have made observations as to the abundance of the weevil for several years. After a wet winter weevils are fewer, and after an open dry one they are exceedingly abundant. This has never been more strikingly illustrated than last winter, which in southern Texas was unusually dry and open, whereas during the previous winter there had been a marked excess of rainfall. As a result, in the spring of $190 t$ the weevils appeared in enormous numbers and a crop failure resulted, whereas in 1903 this section made a crop in many cases above the average, although this was partially due to weather conditions in summer. A study of the normal mean temperature and rainfall of southwestern, southern, and central Texas shows that undoubtedly the larger mortality in the last section is due to the more unfavorable winter weather.

Hunter and Hinds have stated that the weevils usually emerge from hibernation after the temperature has been over $60^{\circ}$ for some time, and that in 1903 they emerged after it had been at $68^{\circ}$ for some time. After studying the available data with the aid of temperature curves, platted for various points where the time of emergence was known, I am convinced that this is approximately correct and that when the mean daily temperature becomes $68^{\circ}$ the first weevils commence to emerge. Thus the weevils would normally commence to emerge at Victoria about April 1 and at College Station April 15. Usually the weevils will commence to emerge ten days earlier in southwestern and coast counties than in central and eastern Texas, and about twenty days earlier than in northern and northwestern counties.

The weevils do not all emerge at once, however, but continue to appear for from four to six weeks. Usually the greatest number of weevils appear about the time the cotton commences to square, and the beginning of oviposition is but a few days later, as it has been shown by Hunter and Hinds that a female must feed upon the squares before she will commence oviposition. After this time very few of the hibernating brood appear. That the time of this maximum emergence, as well as the squaring of the cotton plant with which it seems to be largely coincident, is dependent upon weather conditions may be taken for granted. But what are these conditions? Hunter and Hinds have shown that the average mean temperature at which the weevil is active and reproduces throughout the season is about $78^{\circ} \mathrm{F}$. Thus it might seem that when the mean daily temperature had become $78^{\circ}$ the maximum emergence would take place, but com25524-No. 52-05 м- 3 
paring the dates upon which the maximum emergence was known to have taken place at different points in rifferent years with a curre of the mean monthly temperature for that year and the normal mean monthly temperature for a series of years, it was found that such was not the case. In some rears the time of maximum emergence was before the normal date at which the mean daily temperature became $75^{\circ}$, and in others later, depending upon the departure from normal of that individual season. But the date of maximum emergence did not depart from the normal theoretical date upon which the mean daily temperature becomes $i 8^{\circ}$ to the same extent as the departure from normal was indicated by the mean monthly temperature curve for that year. The temperature may have reached $78^{\circ}$ on June 1, for instance, where nominally it would have reached that point May 1, and still in that year the weevils emerged in maximum numbers but a few days after the normal time. Sufficient accurate clata are not at present a vailable to make a positive statement as to what governs this date of maximum emergence. but, from all data available and from a careful study of the temperature curves, I wish to offer the following hypothesis, which I believe will be found to come rery close to determining this date and possibly that of other insects hibernating as adults. ${ }^{a}$

The date of maximum emergence from hibernation, or the date of oriposition, will depart from the normal date-which for the boll weeril may be considered the date when the temperature reaches $78^{\circ}$ F. or thereabouts-by the amount of the accumulated difference in temperature between the normal daily mean and the daily mean for that year; or we might term it the accumulated departure from normal for that year during the period commencing one month prior to the point of departure of the rearly line from the normal after the point of first emergence and the date upon which the total accumulated temperature for that year will equal the amount of accumulated temperature in the normal year between the first date of this period and the date of maximum emergence. ${ }^{b}$

a The writer proposes to make studies of other insects to determine whether any general lats mar be defined upon this point, and will be glad of any cooperation possible from others. as obserrations at sereral points distant from one another are necessary to make such work of value.

$b$ It seems desirable to insert a figure illustrating the hypothesis proposed, as was done with drawings before the Association. For this the normal monthly mean temperature curve for Victoria, Tex., and the monthly mean temperature curve for the same place for 1904 have been selected. The figures are those of the Lnited States Weather Bureau. In platting the curres re hire used the 15 th of the months for which the mean temperature is giren. The "mean monthly temperature" as reported is the arerage for the whole month. It is evident that in most cases the 15th of the month would more correctly approximate this temperature than the 30th, upon which date it is 
The period of time prior to the date of normal maximum emergence during which the accumulated temperature must be ascertained in order to determine the total amount of accumulated temperature

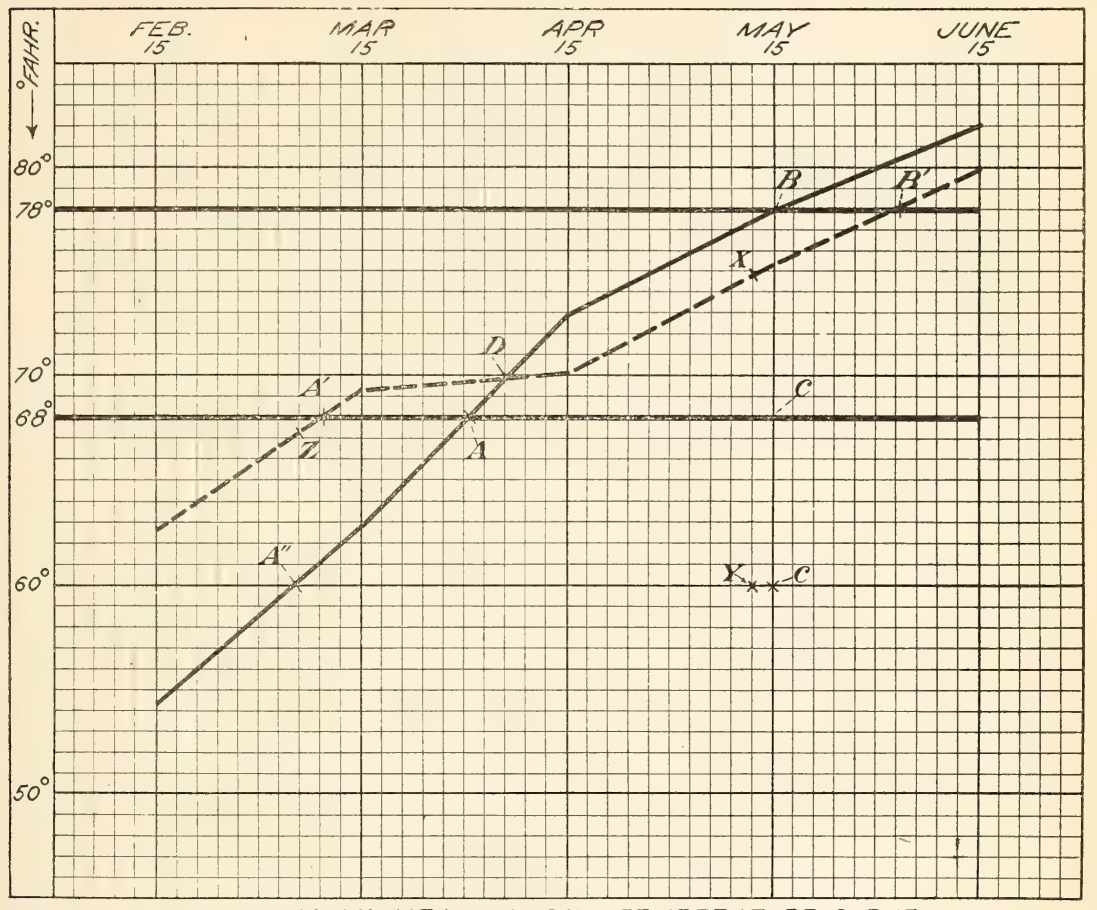

- NORMAL MEAN MONTHLY TEMPERATURE CURVE

- - - - - 1904 MEAN MONTHLY TEMPERATUPE CURVE

FIG. 1.-Diagram showing normal mean monthly temperature and the mean monthly temperature during 1904 at Victoria, Tex. (original).

necessary for maximum emergence, and the average temperature of the date on which this accumulation must begin both for the normal and any individual year, must be determined and will doubtless

estimated, for in the spring the latter half of the month will be warmer and in the fall cooler than the first half. An examination of the daily temperature curves for any year corroborates this view.

Considering that the veevils first commence to emerge normally at $68^{\circ} \mathrm{F}$., and that the maximum emergence is normally at $78^{\circ} \mathbf{F}$., then the amount of temperature necessary to accumulate after the first einergence before the maximum energence will be represented by the area ABC, and the maximum emergence will be at the point $B$, where the normal mean temperature line crosses $78^{\circ} \mathrm{F}$., or, approximately, May 15. In 1904 the first emergence would theoretically have taken place at $\mathrm{A}^{\prime}$, where the mean temperature crosses $68^{\circ} \mathrm{F}$., or about March 12. After that for about a month there was an excess of temperature and then a deficiency until July. The mean temperature line did not cross $78^{\circ}$ F. until about June 3 .

But if we ascertain the date of maximum emergence in 1904 by the hypothesis proposed we would proceed as follows: The point of departure of the 
differ with species. Assuming this hypothesis to be true we can readily determine the date of the appearance of an insect in the spring by keeping record of the accumulated temperature and its departure from the normal with the aid of the formula worked out for that insect. By considering the degrees of temperature per dar as heat units the desired date can be readily computed by mathematical formula: or if the temperatures be platted the determination may be made more readily with the aid of a planimeter.

If this hypothesis be true. we can readily see that a marlied excess of temperature for a week or two afier the daily mean had passed is $\mathrm{F}$.. at which time the first weevils would commence to appear. follomed by a slight deficiency in temperature subsequently until the mean daily temperature had reached $\mathrm{s}^{\circ} \mathrm{F}$.. nould result in the date of maximum appearance occurring before the normal rather than after it. and rice rersa, in a case with the opposite conditions. These conilitions are much more readily appreciable by the study of temperature platted in curves.

That the rainfall is aloo a factor gorerning the time of emergence is probable. but it will be largely reflected in the temperature. Endoubtedly the proper combination of the departure from normal of temperature and rainfall reduced to a formula in which both were included in a single " unit of weather " would gire us the exact method of computation.

I offer this hypothesis merely tentatively. It may be old for aught I know, although I have nerer seen it applied to insects. Hotrever. in fish hatcheries the time of hatching of the egs is deter-

1904 (nure from the normal after passing the point of first emergence (68 $\mathrm{F}$.) is at D. One month prior to that would be $A^{\prime \prime}$ on the normal curre and $Z$ on the 1904 curre. The normal temperature accumulated betreen this date and the normal date of maximum emergence ( where the normal curve crosses $7 s^{\circ} \mathrm{F}$.) at F would be the area $\mathrm{A}^{\prime \prime} \mathrm{BC}$. Then the date of maximum emergence in 1904 rould he that date on which temperature had been accumulated equiralent to that represented by $\mathrm{A}^{\prime \prime} \mathrm{BC}$, which would be determined by an area I"ZXI. in which the position of the line XI must be letermined br computiltion. With mathematical formule: and upon establishing its position so that it confines an area in A'ZXI equal to $A^{\prime \prime} B C^{\prime}$. the point $\mathrm{X}$ mill be the date of maximum emergence for 194. which in 1944 was $\mathrm{I}^{\prime \prime} \mathrm{I}^{\prime}$. or Mar 12. This may be readily done by the aid of a planimeter.

The curves giren are of interest in that prior to the presentation of this faper the date of maximum emergence in 190t had been determined by the abore method as being betreen Mar 9 and 12. according to slight rariation from abore in method of letermining. Since then, in Januarr. 190.5. the author has received Farmers Bulletin 211. in which Mr. W. D. Hunter shoms. on page 21. that the maximum emergence of the weerils in 1904 was on Mar 11. Which filct ras previously unknown to the writer. The close approximation seens to lend support to the probability of the hrpothesis in general. as it has similarly proren correct in at least three other instances. 
mined by the amount of accumulated temperature during their development, and, according to a recent report of the Fish Commission, the time of hatching can be predicted or controlled to a considerable extent in this way. There can be no donbt that the time of emergence of insects from hibernation and the date upon which they begin oriposition or normal activity is dependent upon certain well-defined physical laws which can be determined only by many careful observations and a judiciois interpretation of the data collected. It seems to the writer that this offers a promising field for entomological investigation and one which may very possibly be of much practical importance in our warfare against insect pests.

Though a much larger number of weevils survive the winter in southern Texas, the hot dry summers kill the larva in the fallen squares so that the rate of increase is slower, and often a good crop is made in spite of them. This shows that the rate of increase and the factors governing the mortality of the summer broods are of importance.

In the study of an insect pest we must first secure as accurate and elaborate a knowledge as possible of its life and habits under laboratory or insectary conditions. Then, it seems to me, we must go into the field and ascertain what are the conditions; whether or not our artificial environment has changed the life history, rate of reproduction, etc., and what factors influence these phenomena in the open. This is what we have essayed to do in as far as our limited means would permit, assuming, for the most part, the correctness of the most excellent and careful laboratory studies of Messrs. Hunter and Hinds at Victoria. Our method in field work has been to make frequent counts of large numbers of plants in the same fields through the season, making note of the number of weevils on each plant and the numbers of squares, bolls, and blooms, and the percentage of these which are perfect, or injured by the weevil, and the number of squares fallen as a result of weevil injury. Counts were also made of thousands of fallen squares at different times to determine the percentage injured by the weevil and the stage of the insects contained. Of course, as the season advanced we were compelled to examine a smaller number of stalks owing to the size of the plants, but always a sufficient number to gire several thousand squares from each plot. In this way hundreds of thousands of plants have been carefully counted and the results tabulated, during the last two years.

The first three summer broods seem to be fairly well defined, the first occurring during the last half of June, the second about the middle of July, and the third about the second week in August in central Texas. There is an interesting relation between the normal rate of formation of squares on the cotton plant and the increase of the weevil. The rate of formation of squares is so exceedingly variable 
and dependent upon so many factors that it is difficult to make any generalizations regarding it, but from the many observations made we have diawn the following conclusions: Under the conditions for the last two years at College Station the critical period in the relation between the natural increase of squares and the increase of injury by the weevil is during the first six to eight weeks after squaring commences, which usually coincides more or less closely with the time between the second and third broods of weevils. Therefore, if we consider six weeks as the arerage time for cotton to square after planting, the bulk of the bolls must be set between eighty-five and ninety days after the time of planting. In other words, to escape injury by the weeril cotton must be grown so that the first bolls will commence to open about one hundred days after planting, and that all the fruit which will probably be secured must be set forty-five days after the squares form. The adrantages of early rarieties, other things being equal, is therefore apparent.

But should the weevil increase more rapidly than observed we would have injury even though the cotton were early. The rate of increase of the weeril is therefore most important. From the studies of Innter and Hinds we learn that a female normally lays about 150 eggs in about fifty-four days (average figures), and that nearly half are deposited during the first third of the period. Allowing twentyfour days for development, they estimate the total normal period for a generation to be forty-two days. By comnts of thousands of squares at different seasons we have determined the average rate of mortality of weerils in squares to be about 65 per cent. The sexes are practically equal in numbers. With these facts it is easy to compute that if there be 2 weevils per 100 stalks on June 1 -about the number at College Station-on the appearance of the second brood in mid-July there rould be 50 weevils, and these would produce by September 1 1.250 adults. In other words, the second brood would be twenty-fire times and the third six hundred and twenty-fire times the number of the first. But although we have three broods in the field during this time the increase is by no means so great. Were it so no cotton could be raised. The increase of the second brood orer the hibernated brood is considerably less than twenty-five times, usually not orer fifteen times, and the total increase from June 1 to September 1 is only about fifty times-certainly not over sixty-îve times-instead of six hundred and trenty-fire times, as it should be theoretically. The reason for this discrepancy is unknown to the writer, but for it the planter may be exceedingly thankful. It may be that (1) the mortality of the inmature stages is greater than determined, which we decidedly doubt: (2) many of the adult weerils die or are destroyed before reproducing; or (3) the number of eggs laid and the length of period of oviposition actually occurring in the field are 
much less than observed in the laboratory. We are inclined to the view that it is due either to the last two factors or to some other factor which has not been recognized. 'This discrepancy emphasizes the necessity for accurately observing the actual conditions on a large scale in different fields in different sections of the State, constantly throughout the season, if we are to obtain accurate knowledge of the true habits and rate of increase of the boll weevil and the amount of injury wrought by it; and I doubt not the same principle will apply to the study of many other insects.

Regarding remedies there is but little new to say. $\Lambda$ great furore has been raised over the alleged discovery that Paris green is a remedy for the weevil when dusted, but extensive experiments have failed to show that it may be of any great value. in the control of the weevil. Where the weevils are abundant enough for it to be of benefit-for it will kill weevils when they are thick enough in the spring before the cotton begins squaring-they could better have been prevented by destruction the previous fall, and where the weevils are few in number it is of no value at all, so far as we can ascertain, and the progeny of but two weevils on June 1 will be numerous enough by early in August to stop blooming and prevent further fruiting. The fact is that Paris green appeals to the farmer because it is claimed to be a "remedy." Now, the average farmer, the country over, cries for a remedy, when by the use of a simple and inexpensive preventive he would have no need for it. Therefore, although Paris green may be of some value when weevils occur in enormous numbers on stubble cotton allowed to stand, or where the stalks have not been removed, it seems to me that the less said as to its partial efficacy the better. Neither Paris green nor any other poison will ever control the weevil, but with slight encouragement the farmer will waste much money in trying some one of them. We need in such cases more entomological hygiene and less remedial treatment It seems to the writer, therefore, that the holding out of any hope to the planter that a "remedy" for the weevil may be discovered is doing him an injury. The press is ever ready to magnify any possibility of a "remedy." I have yet to meet the entomologist who thinks the finding of a "remedy" other than those now known probable or possible. It does seem, therefore, that the quicker everyone in an official position authoritatively states that he is not working to find new "remedies" but to perfect the methods of control already known, the better it will be for the farmer.

The past season has demonstrated to me that the "cultural methods," by which we mean growing cotton so early that a crop will be made before the serious injury occurs, are not alone sufficient to insure a crop. If the previous winter be dry and open and an unusual num- 
ber of weevils survive the $\pi$ inter. unless the stalks hare been destroyed the previous fall and the number going into hibernation has thus been reduced. I doubt if the best cultural methods will arail to make an average crop. On the other hand, if midsummer be ret and the fruit formed drops, the best of methods can not make a crop. With normal weather conditions-if there be such in Texas-a crop can be made simply by the best so-called cultural methods, but it is absolute folly to rely on them alone. The only real means of checking the reeril economically is by the destruction of the stalks in the fall. When this is generally done the reevil will cease to be feared in Texas. That it has not been done before is because it has never been demonstrated to the planters on a scale large enough so that they could clearly see the resulting benefit. Te entomologists may be satisfied from our field studies and small experiments that it is of value. but we hare not as ret convinced the arerage planter sufficiently to secure his arloption of our recommendations. It will take a demonstration on a scale so large as to secure the cooperation and subsequent indorsement of a whole community before it can be entirely demonstrated to the unbelieving that the destruction of stalks in the fall is a necessity for the entire State. I am persuaded that the only real method for controlling the spread of the boll weevil is by this fall destruction of the stalks. Were it generally practiced in Texas and in the infested spots in Louisiana. I can see no reason why any large number of weevils should spread to uninfested territory and the few sprearing could be prevented from becoming numerous by adopting the same method. But all the laws of the Medes and Persians wili not stop the spread of the boll neevil or any other similar insect by any method of quarantine ret derised. much as I stmpathize with the adoption of these measures in the Southern States. If the natural conditions are such as to permit and encourage its gradual spread along the Gulf coast, it will spread in spite of all that man can do. All he can do is to deter its spread and control its injury. But if unchecked at its source and throughout the infested region, it will spread at a maximum speed, and it will be much more difficult to bring it under control. It seems, therefore, that the greatest benefit to the uninfested States would come from the passage in Texas and Louisiana of laws compelling the destruction of the stalks in the fall, and any influence that other States can bring to bear toward this end will do more than anything else to prevent the weevil's entry and subsequent depredations in their States.

And, in closing. permit a brief digression to consider a more genural aspect of the case. The boll weevil in Texas and the gypsy and brown-tail moths in New Lngland are raising some points in the relations between States which before long will need careful discus- 
sion and broad-minded treatment. Here we have insects which the infested States fail to control, either through inability or neglect, and they spread beyond their boundaries. Quarantines against them are comparatively useless unless the insects are controlled in the badly infested region. The National Government makes appropriations partly to aid in study of the pests for the information of the inhabitants of uninfested States and partly to prevent spread, but it can have no authority in the latter respect without State legislation. Tndoubtedly at least one of the two moths in New England-the gypsy moth-might be controlled were the States infested willing to spend sufficient money to confine it within their borders; and the same is largely true of the boll weevil, were it generally controlled by destruction of the stalks as outlined. But why should one State tax itself to subdue a pest which is causing it loss and others gain from increased prices, as in the case of the weevil, to prevent it from spreading to them? On the other hand, if it is possible for the State to do so, is the General Government justified in assuming the task if it had the authority? These are questions of a broad nature which it seems to the writer are rather new and which must be met sooner or later. In their solution an association such as this should take a leading part.

Mr. Skinner remarked that certain newspapers had published a statement that an attempt was being made among cotton growers of the Sonth to combine and destroy a portion of this year's crop in order to raise the price of cotton. In view of this, might we not look upon the boll weevil as a beneficial insect in years like the present, when the crop is larger than usual?

Mr. Hunter said that the results reached by the Department of Agriculture agreed fully with those presented in Mr. Sanderson's paper. Climatic conditions are so important that methods that fail to take account of their influence are likely to give widely different results in different seasons. A fairly good remedy is at hand, viz, the actual destruction of large numbers of the weevils in the fall; but the general indifference of the people to suggestions makes it difficult to get cooperation in this. They grasp at any possibility, such as the use of mineral paint, attracting to cotton-seed meal, and other quack nostrums which have been shown to be of no use whatever. As to the suggestion that the boll weevil might be a benefit in raising the price of cotton, it is a fallacy to suppose that the increase in price was due to the boll weevil. It seems an important possibility that predictions of great commercial value in regard to prospective injury may be based on the principle suggested by Mr. Sanderson. 
Mr. Homard said that the Department frequently had great difficulty in counteracting the influence of men prominent locally, who come to believe from accidental causes in some method of no general value, and because of their belief in it strongly adrocate its use in their omn section. A promulgation of the idea of Paris green as of use against the boll weevil was mostly the work of one prominent man. Dnring the past season a rery considerable amount of money was spent in Texas for the purchase of Paris green by people who were impressed by the standing of the individual in question and by his forcible claims. At the recent national cotton convention at Shrereport, La., howerer, so strong a presentation of the case was made by an equally prominent gentleman. who had conducted a large experiment with the substance and with negative results, that no further rerbal statements were necessary from members of the force of the Bureau of Entomology, which, howerer, has published a bulletin deroted to this specific subject, under the authorship of Mr. W. D. Hunter.

The following paper was read:

\section{THE FALL WEBWORM PARTIALLY DOUBLE-BROODED IN CONNECTICUT.}

By W. E. Britrox, Nev Haven, Conn.

In 1901 the fall webrorm (Hyphantria cunea Drury) was more abundant in Connecticut than for many years, and, although still present in destructive numbers. has decreased each year since. For some time I have considered the species to be double-brooded. or partially so, in Connecticut, but had not been able to make any definite observations that rould help to settle the matter. A statement to this effect was made in my first report as State Entomologist. ${ }^{a}$ A similar statement was made at the annual meeting of the Connecticut Pomological Society, at Hartford. Conn., February 4. 1902. ${ }^{b}$

In the Tearbook of the Department of Agriculture for 1895. page 376. and also in Farmers Bulletin No. 99. page 20, Howard states that the species is double brooded south of New York City.

According to Fernald, there is no satisfactory evidence of more than one brood in Massachusetts. ${ }^{c}$ and Mr. Kirkland informs me that the insect has been carefully studied at Amherst and that only one brood occurs.

On June 23, 1904, the first nest of the season was found in a pear tree in Westrille, near New Haven. The nest was small, and the

\footnotetext{
a First Report State Entomologist of Connecticut, p. $2 \pi 1$.

${ }^{b}$ Fourth Report Connecticut Pomological Society, p. 20.

$c$ Hatch Experiment Station, Bulletin No. 20, p. 11, 1893.
} 
larræ had evidently been hatched but a few days. They were taken to the laboratory and fed upon pear leaves. We were too busy with other work to watch them closely, therefore I have no record or descriptions of the different molting stages. On July 29 all but three of the caterpillars had pupated, and two adults emerged August 1. The moths continued to emerge until August 5, when there were 30 in the breeding cage, and two masses of small greenish eggs had been deposited on the side of the cage. Most writers refer to the eggs as being golden yellow in color, but these were quite a brilliant light green. All of the adults, including both sexes, had immaculate wings.

August 15 the eggs had hatched. We fed the larvæ until about the middle of September, when we had to go out inspecting nurseries and could not give them the food needed, and all died before pupating. I do not believe there were two complete broods of the insect throughout the State, because the early nests were extremely rare, most of the nests appearing about a month later. The latitude of New Haven, while not very different from that of New York City, varies by over half of $1^{\circ}$ and probably marks about the northern limit of the double-brooded occurrence of the fall webworm.

Mr. Felt said that the first nests were found in New York the latter part of June. He was convinced that there was a partial double brood.

Mr. Smith said that throughout New Jersey it is fully double brooded.

The following paper was presented:

\section{PRELIMINARY REPORT UPON WORK AGAINST A DESTRUCTIVE LEAF-HOPPER (EMPOASCA MALI Le B.).}

By F. L. Washburn, St. Anthony Park, Minn.

I came to the last meeting of the Association, at St. Louis, with an unsolved problem in my mind as to how we could control this leafhopper, which was making its presence felt in a very destructive way in the murseries of Minnesota. I have found it on many trees other than the apple. The assistant under whom the work was conducted last summer reports that its attacks are least apparent on the Northwestern Greening and most evident on the Repka, Charlamoff, Lyman, Minnesota, and Transcendent varieties. After the Repka, according to his observations, comes Scott's Winter, which appears to be quite badly affected, and in a diminishing ratio Patten's Greening, Early Strawberry, Sweet Russet, Malinda, Longfield, Duchess, Hibernal, Wealthy, Whitney, Peerless, Anisim. 
So far as I know, the life history of Empoasca nuti has not been thoroughly worked ont. As far as the apple is concerned, it rould appear that the egg is laid by the adult in the tissue of the leaf. for young of such a tender age as to preclude the possibility of their haring migrated after hatching are found on the under side of the leaf. In the absence of conclusive evidence, however, I hesitate to regard the abore probability in the light of a fact. As you all know. the leares of nursery trees, as well as the more tender leaves in orchards, are curled by this pest, and the growth of the tree checked for the time being. Last summer in Minnesota the insects began their work early in July and soon grew very abundant.

Mr. Stedman, of Missouri. who was present at the meeting in St. Louis, chanced to remark upon his work along this line in his State. This coincidence was a great help to me, for I at once proceeded to get suggestions from him, which were most cheerfully given. The general plan of his spraying machine I carried home with me, finding. upon considering the matter, that this plan should be changed somewhat to better subserve our purpose in Minnesota.

It is to be noted that 3-and t-rear-old trees in Minnesota are not as tall as they are in Missouri, hence we were not obliged to have the cart quite so high above the ground. We found it best. also, to bring the container off the platform which stood above the wheels in order to make the cart more stable. The wheels of this cart are $5 \frac{1}{2}$ feet in diameter, with $t$-inch tires, and the platform, which is $S$ by $+\frac{1}{4}$ feet in size. is 14 inches above the wheels and firmly balanced on the axle, so that practically all the weight comes on the axle and not on the horse.

A giance at the accompanying illustration (fig. 2) will give one an idea of the details. The pipe $(D)$ is a 1 -inch pipe 10 feet long. On this pipe four nozzles are attached. pointing directly downward and so placed as to be $3 \frac{1}{2}$ feet distant from each other. This spacing brings each of the nozzles directly over a nursery row, where, as in Minnesota, the rows are usually $3 \frac{1}{2}$ feet apart. This pipe can be raised or lowered mechanically to suit high or low trees. The horizontal pipe $(C)$ is $1 t$ feet long and projects 10 inches back of the platform. thus clearing the wheels. The five verticals from this pipe $(E)$ are made of $\frac{3}{5}$-inch piping, 5 feet $t$ inches long, and there is also a $3 \frac{1}{2}$-foot space between these. The crosspieces at the bottom are so arranged that a nozzle in each end of each piece points up at an angle of about $45^{\circ}$. This spacing and arrangement of the nozzles on both pipes results in a copious spray coming both from above upon the tops of the trees and from below against the lower surface of the leaves-the latter, as you know, being rery important. In actual practice the trees are completely surrounded by a fine spray, 
so that the insects, whether upon the upper or lower surface, or whether, disturbed by the spraying, they seek to fly away, are sure to be caught by the deadly mist. 'Two pumps were used, one with kerosene emulsion and the other with kero-water-not at the same time, of course. These pumps were placed on a small raised platform in order to bring the handles within easy reach of the man pumping. The hose can be so connected with the horizontal pipes as to throw all the liquid forced up by one pump into the two

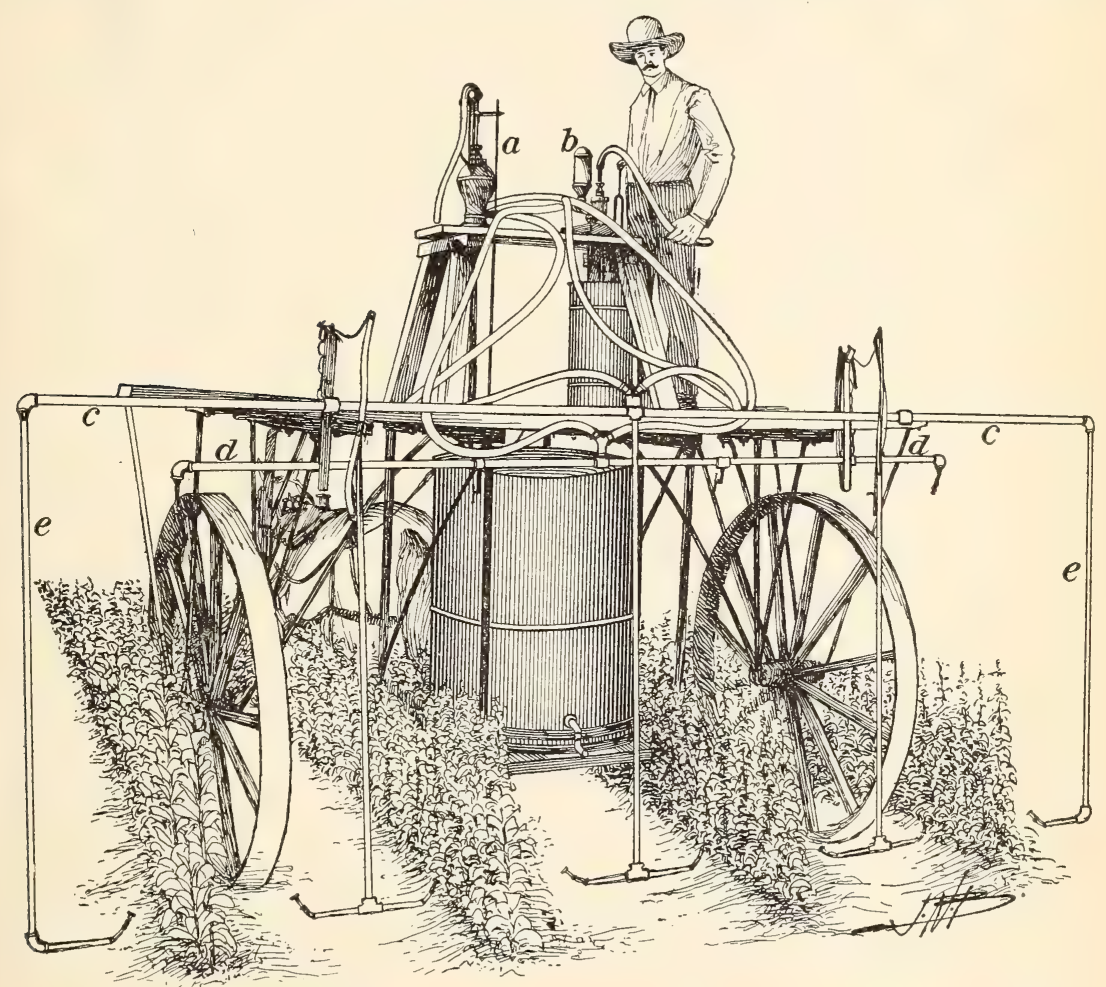

FIG. 2.-Outfit used for spraying young apple trees for Empoasca mali (original).

horizontals when one pump is used alone, or into one horizontal under the same condition; or when both pumps are used the liquid is forced equally into the entire system of piping. As a matter of fact, we found that in using kerosene emulsion one pump could easily make a good spray from all the nozzles. It is evident that this outfit can be used with any spraying compound. The tank, resting on the platform between the wheels, was made of strong galvanized iron and was 2 feet 10 inches in diameter and $3 \frac{1}{2}$ feet high. holding about 165 gallons. The faucet in the bottom behind permitted the emptying of the tank at any time, and there was a hole 14 inches square in 
the top for filling it. We used a heary horse, and placed on the back of the animal an old saddle. which seemed to relieve his back of any undue stram. Howerer. as before stated. the weight was so well balanced on the axle that the outfit mas not at all serere on the horse and was drawn with apparent ease when the tank was from one-half to two-thirds full.

We had planned to spray early in July, but osting to delay in getting the cart completed the first spraring was not giren until July 1. At that time kerosene emulsion mas used at the rate of 1 part of stock emulsion to 12 parts of water. The machine worked perfectly, che man and one pminp being sufficient to enrelop each tree in the row in a complete fog. In this fog were thousands of hoppers flying from the trees. but mable to escape the sprar. This strength of emulsion. hotrerer. while it killed the roung hopiers. did not permanently affect the adults. On July 19. therefore, we increased the strength. using 1 part emulsion to 10 of water. This in no way injured the trees. nor did it. unfortunately. kill the adults, which were rery numerous at that date.

Learning from the Mis-ouri station that they were using a mechanical mixture of kerosene (10 per cent) and water with considerable success. I sent for a kero-mater pump. which is shown in figure 2 (at the right) fitted to the platform. The writer his yet to see one of these kero-rater machines which pumps true to the indicator. Our experience has been that if the indicator points at 10 per cent one is not at all sure of obtaining that percentage of oil in the water: in fact. he is quite sure not to. Then the indicator of our pump " indicated " 20 per cent we found by actual test that we were pumping 10 per cent, and 25 per cent indicated gare only 15 per cent. With the indicator at 30 per cent we obtained 25 per cent, while 50 per cent on the indicator gare nearly 50 per cent by actual test as it came from the nozzles. The indicator: 10 per cent and 15 per cent gare such a small percentage of oil. far below the figure inclicated. as to be practically rorthless for our purpose. We found. further, that when the oil in the oil tank got quite low the percentage materially changed. For instance, with the indicator at 25 per cent we prmped 15 per cent steadily until the tank $\pi$ as nearly empty, when test showed that we mere getting only 5 per cent. This inaccuracy and rariation is common to all the kero-water pumps with which I have had experience, and is a serions objection to their use. Nerertheless, once understood, and frequently tested in the field, thes machines may do good service.

Our kero-nater outfit arrived too late in the season to be of real practical benefit. It was used August $\check{\partial}$ for the first time, and kerowater with 15 per cent of herosene mas applied. At that date the hoppers were becoming decidedly less in number, and, further, the 
pump could only supply liquid sufficient to fill the lower nozzles. This difficulty was overcome by obtaining another pump, so that next season we will be prepared at the rery outset to put up a good and, I hope, a successful fight against this pest, which is costing the nurserymen several hundreds of dollars loss annually.

At Adrian, Minn.. Mr. Fred Mohl, proprietor of a large nursery, has kindly cooperated with the Entomologist, and has been making a series of experiments with the dust spray. Mr. Mohl sprayed twice with the "caustic lime" mixture, and once with the "general formula." At the date of my visit, July 12, the trees were looking very well, though they were not free from leaf-hoppers. Mr. Mohl is of the opinion that, if he had begun earlier, "before the hoppers appeared," as he expressed it, and sprayed three times, he could have kept them well under control. While the writer is quite willing to be convinced, he has not absolute confidence in the efficacy of dust spraying in this connection.

I believe the possibilities foreshadower in the success of the cart as a sprayer are almost inlimited. A cart to straddle one row and spray the straddled row and the two adjoining rows could be easily constructed. These carts, too, including the one we are now using, could be made automatic by connecting the pumps with the wheels by proper gearing.

Mr. Smith concurred in the riew that kero-water pumps were in general unreliable. He hoped that experiments already under way on the production of so-called "soluble petroleum " would solve the difficulty.

Mr. Slingerland said that in New York they had gone through similar experiments for the leaf-hopper on grape vines. With diluted kerosene emulsion or whale-oil soap the young hoppers were easily killed, but the only way to kill the adults was to first get them off the vines. They were knocked down by a 5 per cent kerosene spray, but they would recover from this: consequently it was necessary, while they were on the ground, to spray again with a 25 per cent mixture.

Mr. Sanderson said that he had failed to find any satisfactory form of kero-water pump.

Mr. Osborn said that he had killed some species of hoppers on potatoes with 5 per cent emulsion, but it was necessary to keep them in the air for this to be effective.

Mr. Fletcher called attention to the fact that hoppers might often be fatally injured even though they appeared all right for a time after the spraying, death occurring later. He said that Mr. Lugger had killed grasshoppers by dipping one leg in kerosene. 
The following paper was read:

\section{ADDITIONS TO OUR KNOWLEDGE OF THE CABINET BEETLE (ANTHRENUS VERBASCI Linn.).}

By Henry L. Viereck, New Haven, Conn.

While at the Connecticut Agricultural Experiment Station the writer made some observations on this species which seem to be new. Larræ of Anthrenus verbasci had been kept in a tube with cotton fibers during the winter. After subsisting on the cotton the specimens were transferred, in the spring, to Syracuse watch glasses, lined with black woolen cloth, where they could be readily watched and fed with dried insects.

One day a female specimen was obserred with an egg partly protruding from its oripositor. When first seen it had the ovipositor, with the egg. inserted in the woolen cloth; then it seemed disturbed,

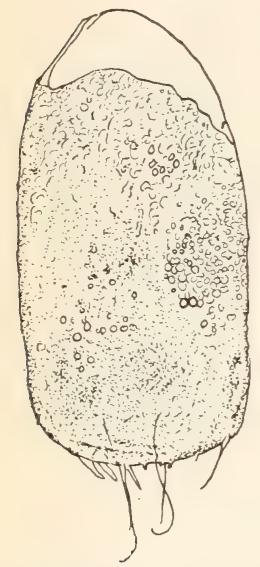

FIG. 3.-Egg of Anthrenus rerbasci, greatly enlarged (original). for it walked around with the egg nearly all the way out, but made no apparent effort to drop it. A short time after this observation the egg had been dropped. The laying of this egg could not have taken more than five minutes. Eggs were first noticed about March 1. On March 15 four eggs were put on a piece of cloth, which was pinned into a Schmitt box with no insecticide in it; another lot of four eggs was put on a piece of cloth and pinned into a box containing three naphthalin cones. April 7 the eggs in the box without naphthalin had hatched and the larvæ were lively. In the box with the naphthalin two eggs had matured embryos or young larvæ; one larra had eaten the end off the egg preparatory to emerging, but there died; the other did not succeed in cutting through the corer, though it was apparently as far advanced in derelopment as the first specimen. The second embryo had evidently inhaled the fumes of the naphthalin through the thin membrane or the micropyle. This experiment seems to demonstrate that naphthalin does not retard the growth of the embryo in the egg, but does prevent the young larva from emerging. When laid, the eggs are soft, with a membranous covering containing the whitish granular fluid, and measures $0.60 \mathrm{~mm}$. in length and $0.29 \mathrm{~mm}$. in width. They are bare, except at the blunt end, where hairs occur. At the time the larva emerges everything in the egg has been taken up and only the thin outer membrane or skin remains as a wrinkled tissue. The accompanying sketch (fig. 3) will help to convey an idea of the characters presented by the egg. 
Mr. Smith said that he had placed naphthalin in boxes that were well infested with Anthrenus; this prevented development so long as any of the material remained, but after it all disappeared, which in one case took over a year, the larvæ developed.

The following papers were then presented:

\section{SPRAYING APPLES AGAINST THE PLUM CURCULIO.}

By S. A. Forbes, Urbana, Ill.

[Withdrawn for publication alsewhere.]

\section{VALUE OF COPPER SULPHATE AGAINST MOSQUITO LARVÆ.}

By C. L. Marlatt, Washington, D. C.

[Withdrawn for publication elsewhere.]

MORNING SESSION, FRIDAY, DECEMBER 30, 1904.

The meeting was called to order at 10 a. m. by President Quaintance. On motion it was decided to defer the discussion on the following series of papers on miscellaneous insects until all of them had been read. The following papers were then presented, the last two by title:

\section{BRIEF NOTES ON OHIO INSECTS FOR 1904.}

\section{By Herber' Osborn, Columbus, Ohio.}

No particularly serious or widespread insect outbreaks have been noted in Ohio during the past season, but there have been a number of cases of local abundance and destruction, some of which may well be placed on record.

The pear slug (Eniocampoides limacina Retz.) was noticed in Huron, near the lake shore, in small orchards of cheny trees, in which many of the trees were so seriously infested as to appear quite brown and burned. This condition was noticeable from a considerable distance, and closer inspection of the trees showed the foliage to be almost completely destroyed by the numerous larva. This occurrence was during the latter part of July, and at this time the larvie were apparently reaching maturity.

The willow weevil (Cryptorhynchus laputhi Linn.). Specimens of this introduced species have been handed to me by Prof. E. H. Edwards, of Cleveland, who tells me that the insect occurrer in large numbers on willows and probably also on poplars in the vicinity of Cleveland. Both larre and adults were observed and the damage. $25524-N o .52-05 \mathrm{M}-4$ 
occasioned was quite noticeable. It will be remembered that the appearance of this species in this State was recorded by Professor Webster three years ago, and it would seem from this occurrence that the species has been spreading and that it is likely to prove of considerable importance where the trees it infests are of any value.

The elm leaf-beetle (Galemeclla luterola Müll.). This species, which has been so injurious in different parts of the eastern United States, has been reported as introduced at Dayton, Ohio, specimens in considerable numbers being secured by Mr. A. F. Burgess, chief inspector of orchards and nurseries. This is the first occurrence of this species in the State, and its appearance at a point so distant from any of the other localities where it occurs is a matter of considerable interest.

The peach borer (Saminoidea exitiosa Say). This common enemy of peaches has apparently been somewhat more numerous than usual during the past season, although regularly a common species in peach orchards.

The occurrence of the screw worm (Chmysomyia macellaria Fab.) is perhaps worthy of notice, although it has doubtless been a common species in the State for many years. It has been found on the beach at Cedar Point as one of the most abundant species, feeding on the dead fish that are thrown ashore. No instances of its attack on man have come to our notice. The species seems at that point fully adlapted to the particular food supply which is furnished it in the drift from the lake.

The Hessian fly (Mayetiola destmuctor Say), which has been somewhat less destructive the last two or three years, seems this year, from reports, to be on the increase. I have not myself had much opportunity of noting its abundance in the fields, and therefore judge simply from reports which have been sent to me.

The chinch bug (Blissus leucoptems Say), while present and coming to light in collections during the year, has not, so far as I know, caused any considerable destruction. No reports of its serious abundance have come to me.

The squash bug (Anasa tristis De G.) has put in its regular appearance, and I have noticed some quite destructive work on squash rines during the latter part of the season. This species is doubtless locally abundant almost every year and must be responsible for no small amount of damage.

The bagworm (Thyridopteryx ephemercformis Steph.) has not, perhaps, been much more abundant than in former years, but has attracted attention. It does not appear to multiply very greatly and its range is probably not changing materially.

The fall web-worm (Hyphantria cunea Dru.) has again been 
noticed as quite abundant, the webs being formed as early as in the first part of July in the vicinity of Sandusky.

The northern corn rootworm (Diabrotica longicornis Say) is apparently increasing in numbers, the adult beetles being quite plentiful during autumn of the present season.

The plum curculio (Conotrachelus nenuphar Hbst.) was probably less abundant than in average years and the crop of plums was abundant and quite free from injury.

The apple maggot (Rhagoletis pomonella Walsh) has not been more abundant than in previous years, so far as observations would indicate. It may be considered, however, as a well-established species in this section and sone damage may be expected from it every year.

The codling moth (C'arpocapsa pomonella Linn.) has not been noticed in detail, but fruit has shown its presence in the usual months and there has doubtless been an average amount of loss except where orchards have been sprayed.

\section{NOTES FOR THE YEAR-NEW YORK.}

By E. P. Felt, Albany, N. I.

The season of 1904 has been notable because of the remarkably small amount of insect injury to agricultural crops. Plant lice and the pear Psylla (Psylla pyri Linn.), so abundant in 1903, hardly attracted attention last year. The San Jose scale (Aspidintus perniciosus Comst.) has becone thoroughly established in a number of localities in the State, and the best method of controlling it in commercial orchards is now an urgent problem. The elm leaf-beetle (Galemcella luteola Müll.) has been remarkable for its scarcity, and the only thing worthy of special note in this connection is its occurrence in considerable numbers in the village of Glens Falls, which, so far as known to us, is its northernmost locality. The violet sawfly (Emphytus canadensis Kirby) attracted some attention about the middle of Jine, because of its depredations on pansies at Nassau. The stalk borer (Papaipema nitela Guen.) has been unusually abundant in some sections of the State, working as usual in thick-stalked plants and injuring tomatoes, potatoes, and corn in particular. An interesting injury by young of what were probably buffalo tree hoppers (Ceresa bubalus Fab.) was brought to notice. They establisher themselves upon the stems of the common balsam and sucked the juices therefrom to such an extent that the plant was unable to support itself, and the part above the point of injury lopped over and eventually died. 
A third shipment of the Chinese lady beetles (Chitocorus similis Rossi) was obtained last June through the kindness of Prof. Wilmon Newell, State entomologist of Georgia, and established in a badly infested orchard at Kinderhook, Columbia Connty. Unfortunately we were unable to find larva or signs of breeding, as had been the case with earier shipments in the rears $1902-3$, and it is possible that most of the insects arailed themselres of their freedom and spread to other trees. It is sincerely hoped that some have found conditions to their liking, where they have bred freely, and that the species will become established in that section and prove of considerable service in controlling the San Jose scale.

It will be well, in this comnection, to allude to some recent work done in continuation of the inrestigations begun in 1902 upon the graperine rootworm (Fidia riticida Malsh). This insect was not nearly so abundant in the Chautauqua grape region during the season of 1904 as it was the preceding rear, and it was somewhat difficult to obtain suitable conditions for experimental work. A badly infested area was most thoroughly sprayed June 30, and a second time. July 6, with arsenate of lead at the rate of $t$ pounds to 50 gallons of water. The treated section was the subject of close observation, and repeated collections with a hand catcher were made for the purpose of determining the number of beetles present upon the rines. Collections July 11 resulted in taking from st to 39 from single rines. on the 14 th from 15 to 46 . and on the 20 th from 5 to 19 . Similar collections on an adjacent untreated area gare on the 1 ith from 18 to 77 , on the 1 tth from 34 to 80 , and on the 20 th from 9 to 14 beetles per vine. It will be seen that there were more beetles upon the unsprayed than upon the poisoned rines, but there was not a very marked difference, and nearly the same proportions held later in the case of egg clusters and also for grubs. The are inclined to believe that the spraying reduced the numbers of the pest abont so per cent. Supplementary indnor experiments showed that many of the beetles taken from the sprayed rines and fed foliage from the same appeared to die as nunch from starvation as from poisoning. The resistance of this creature fo arsenical poisons is somewhat remarkable. There is no doubt that spraying is of some service in keeping the pest in check. though it is not so effective as one could wish.

\section{SOME ECONOMIC INSECTS FOR THE YEAR 1904 IN OHIO.}

By A. F. Burgess, Columbits, Ohio.

The colony of Asiatic ladybirds (Chilocorus simitis Rossi), which was started in an orchard infested with San Jose scale in southern 
Ohio, survived the winter, but the beetles disappeared early in the summer and none have been found since that time. The codling moth (C'urpocapsa pomonella Linn.) has not been as destructive this year as usual, the spring cankerworm (Paleacrita vernata Peck) seems to be on the increase in many sections, and the tent caterpillar (Malacosome americana Fab.) was abundant and injurious in the northwestern part of the State.

Early in May a report was received from Mr. E. E. Richards, who is the owner of a large orchard in Adams County, southern Ohio, that his peach trees were being defoliated by insects. An investigation made by my assistant, Mr. Swezey, on May 15, showed that the buds and young leaves in one part of the 3-year-old peach orchard were being seriously injured by the red-legged flea-beetle (Crepidoder mifpes Linn.), while other parts of the orchard were not attacked. Black-locust thickets are very common in the vicinity of the orchard, and an examination showed that large numbers of the beetles were present in them and were feeding on the young leaves. From the foreman of the farm it was learned that during March a fire ran through the locust thicket nearest the peach trees that were being attacked, and it was found that the leaves had not begun to reappear on the trees in the burned area. This evidently accounts for the injury - the beetles feeding on the peach, owing to the fact that there was no foilage on their natural food plant. Subsequent examinations made in widely separated localities in the State have shown that the beetles were present in greater or less numbers. They have been observed feeding on hazel, dogwood, and plum sprouts that werc growing in locust thickets, but the latter foliage was most seriously injured. The larval and pupal stages are still unknown, but there seems to be no doubt that the insect hibernates at or beneath the surface of the ground, from which the beetles emerge early in the spring. The infested trees were sprayed with disparene late in April, but, as there was practically no foliage to hold the poison, very little good resulted. Later in the season the beetles disappeared and the trees were able to put out a crop of leaves. Outbreaks of this insect were reported in Virginia and Maryland several years ago, and were investigated by Mr. E. A. Schwarz, assistant entomologist of the Bureau of Entomology. His report was published in Insect Life for the year $1893 .^{a}$

In June, 1904, a complaint was received from the Steubenville Traction and Light Company that some of their electric cars were being destroyed by insects. An investigation by Mr. Swezey showed that four cars which had been bought in 1902 had been somewhat 
injured by the powder post beetle (Lyctus striatus Mels.). ${ }^{a}$ Thite ash panels and trimmings were infested and quite a number of small holes were visible. On removing a section of the wood, both beetles and larræ were found. Cars constructed with the same kind of wood and receired from other companies showed no signs of injury by this insect. The infested parts had been treated with creosote and corrosive sublimate, but without beneficial results. Evidently the cars were infested when purchased. and the only remedy seemed to be to replace the infested parts with new wood.

At the request of Mr. C. L. Marlatt, assistant entomologist of the Burean of Entomology, an investigation was made to determine whether the record of Dr. G. B. Smith, indicating that Brood XII of the seventeen-year locust (Tibicen septendecim Limn.) would appear in Vinton County, Ohio, in 1904, was correct. Letters requesting information were sent to the crop correspondents of that county, and my assistant. Mr. E. C. Cotton, interviewed sereral people in each township and made examinations early in June, but no trace of the insect could be found. Larræ were found by one man several feet below the surface of the ground while stripping a coal bank on a hillside, but they were only partially grown and eridently belonged to the brood due to appear in 1914.

An examination of the vineyards along Lake Erie made during the early summer showed that the graperine rootworm (Fidia viticida Walsh) was not as injurious this year as in the past. This was found to be true in sprayed as nell as unsprayed rineyards, and also where the rines had been totally neglected. Some growers are of the opinion that the one reason for the small number of beetles present is that all the roots near the surface of the ground have been destroyed, hence the larvæ on hatching have nothing to feed upon and die before burrowing a sufficient distance to reach the rigorous roots. As the worst infested spots are found where the soil is of a sandy character, and as examinations have shown that considerable digging is required before any tender roots are reached, this may offer a partial explanation of the small number of beetles that dereloped this year.

The grape fruit-moth (Polychrosis viteana Clem.) continues to do considerable damage, especially to vineyards that are not sprayed with poison early in the season.

About June 10 Mr. John Maxwell, of Euclid, noticed that some of the blossom buds on his vines had become somewhat enlarged and were turning red; also that on opening such buds several white or yellowish larvæ were found within. Other growers had noticed the 
same thing in the past, but, supposing that these larvæ were a stage of the berry moth, had taken no further notice of them. The attention of Mr. Swezey was called to the matter by Mr. Maxwell, on June 20, and the insects proved to be a new enemy to the grape and probably one hitherto unknown to science. As affected buds are ruined the clusters are made irregular, and as one-fifth of the buds were found infested in some cases it resulted in considerable loss. Fifteen larvæ have been found in a single bud and as high as twentyfive infested buds have been found in a cluster. The larvæ undoubtedly complete their transformations in the ground, which makes it very difficult to trace their complete life history, but from their structure it is evident that they belong to the dipterous family Cecidomyiidx, and are closely related to the Hessian fly. Later it was learned that this insect had been found also in the Chautauqua grape belt in New York on June 12, 1904, by Mr. Fred Johnson, who was working on grape pests with Prof. M. V. Slingerland. I am informed also by Dr. E. P. Felt that he has found it in New York vineyards this year.

An outbreak of the elm leaf-beetle (Galemcella luteola Müll.) was discovered by Mr. George A. Runner at Dayton, late in August. European elms were badly infested, and, in some parts of the city, American elms were being defoliated. It was impossible to determine how long the insect had been present, but a subsequent examination showed that it was attacking elms in many different sections of the city. This is the first record of its occurrence in Ohio, and careful search in other cities in the State has failed to reveal its presence.

The Hessian fly (Mayetiola [Cecidomyia] destructor Say) has made its appearance in the wheat fields this fall, and according to some of the crop correspondents is more abundant than usual. The present prospect is that considerable damage will result to the next wheat crop.

\section{INJURIOUS INSECTS IN MINNESOTA IN 1904.}

By F. L. Washburn, St. Anthony Park, Minn.

While the year has been uneventful as regards insect outbreaks in the usual looked-for directions, it has nevertheless contained some surprises. There has been practically no trouble from the Hessian fly (Mayetiola [Cecidomyia] destructor Say) in any part of the State, as far as the entomologist can learn, the preceding year, 1903, witnessing the culmination of its increase. We have every reason to believe that it will gradually grow more abundant in the next few 
years, weather conditions being favorable. Owing to its very general alosence in localities formerly infested we have been unable, as we did last year, to secure puparia (flaxseeds) in volunteer wheat, showing the occurrence of an extra brood in this State. Two lots of volunteer wheat plants, from 8 to 10 inches high, were sent us in November, one lot from Marshall County and one from Big Stone County, in both of which counties the fly was thought to be present. Several hundred of these plants were carefully examined, but contrary to last year's experience we found no puparia. ${ }^{a}$

My attention has not been called directly to the presence of the frit-fly (Oscinis soror Macq.) or the wheat-stem maggot (Meromyad americana Fitch) although, from reports of certain ill-clefined injury to wheat from time to time, we have good reason to suspect that both of these are in Minnesota at present. Professor Lugger reported the frit-fly as injurious in 1893 and 1896.

Chinch bugs (Blissus leucopterus Say) have been conspicuous for their absence during the year, no injury whatever being reported in any county. During the wet weather of last fall I found a large number of dead and dying chinch bugs on the station grounds, evidently killed by a fungous growth. This condittion, prevailing in most of the chinch-bug areas, is possibly, in part, the reason why we have been free the past season.

The Mediterranean flour moth (Ephestia Kuehniella Zell.), undoubtedly present and increasing in numbers for the past sereral years in Minnesota, has this year made its presence so conspicuous in certain mills as to call for some special work on the part of the Entomologist, and the publication of a special report on the subject for the benefit of the four hundred or more flour mills in Minnesota.

The leaf-hopper (Empoasca mali LeB.) is becoming more and more evident in nurseries, and causing losses annually. The have done some special work against this pest this season, an account of which forms the subject of a previous paper. The work is purely preliminary. but may prore interesting as illustrating what may be done with certain field apparatus.

The plum curculio (Conotrachelus nenuphar Hbst.) is proving itself almost as great a foe to apples in Minnesota as it is to plums, and is as much of a pest in this particular as is the codling moth.

We have been startled by finding the imported willow curculio (Cryptorhynchus lapathi Linn.) in poplars shipped from New York State with the inspector's certificate to nurserymen in Minnesota,

a Since the above paper was delivered it has been stated to me by a carefully observant entomologist in this State that he found a number of puparia of Hessian fly in volunteer barley plants on Thanksgiving Day, 1904.-F. L. W. 
and then forwarded to parties in the extreme northwestern part of North Dakota. Twenty-fire poplar trees were killed in one locality by these borers, and I have no doubt, although I can not obtain absolutely accurate information, that some of the shipment was distributed within our own State boundary. The nurseryman importing this stock, of course, was in no way to blame in helping on the westward progress of this unwelcome immigrant, since the certificate of the inspector was supposed to be an absolute guaranty that the stock was all right. In complaining of this to the New York commissioner of agriculture I was met with the statement that, while it seems impossible to eradicate this beetle in New York State, measures can and will be taken to prevent infested stock from being sent to other States. Our nurseries in Minnesota have been carefully inspected and found to be practically free from insect or fungous pests. It should be said in this connection, however, that inspection is not compulsory for all nurseries, and not more than two-thirds desire it, namely, those who ship to other States, and others who do not export, yet value the entomologist's certificate as an advertisement of clean stock. Occasional occurrences of woolly aphis in limited numbers are the only especially undesirable features discovered in connection with nursery stock.

Our shade trees, the soft maple and the elm, have been alarmingly affected with the cottony maple scale (Pulvinaria innumerabilis Rathv.) in many of our towns and cities, as well as in those of some of the neighboring States. It has been present in such large numbers as to check the growth of maple trees and weaken their vitality.

Our attention has been called particularly to cecidomyiid gallmakers on the box elder, the soft maple, and a locust, the variety of which could not be given me. Specialists in this group at Washington, D. C., identified specimens mailed them as evidently $C$. negundis Gill., $C$. aceris Shimer, and $C$. robinice Hald., respectively. From $C$. aceris we reared two parasites, Tetrastichus sp. and Meraporus sp.; from $C$. robinice we reared a pteromaline, which Doctor Ashmead pronounces an apparently undescribed genus.

A species of Lecanium has occurred for several years on the conifers in the experiment station forest, and this year has been particularly troublesome on Scotch and jack pines. It evidently can be controlled by spraying with kero-water or kerosene emulsion. After one or two insecticide applications we found a coccinellid (Hyperaspis sp.) in such large numbers, both larve and imagoes, that we deemed it wise to leave the question of the "survival of the fittest" to it and the scale upon which it fed. 


\section{INSECTS OF THE YEAR IN COLORADO.}

By C. P. Gillette, Fort Collins, Colo.

ORCHARD EXEMIES.

THE CONLIYG MOTH.

(Carpocapsa pomonella Linn.)

Our experiments and studies with this insect for the past two years hare been chiefly for the purpose of determining the comparative ralues of early and late spraying, the number of times that it is adrisable to spray. and the best poison to use. Besides conducting experiments in orchards near Fort Collins, the writer has risited many orchards in the different apple-growing sections of the State and has made counts of many thousands of apples in orchards sprayed in different ways to determine percentages of wormy fruit. I have found no reason to change the advice already given out to the orchardists of the State, namely, to spray first as soon as the petals are fairly well off, to repeat the spray in one week. and then make a third spraying about the the of July. If the first and second sprayings are thorough the third will hardly be needed. The first spraying. if thoroughly done at the right time, seems to be worth more than all the applications that are made afterward.

An examination of the fruit in October in many orchards that were sprayed two or three times, as above directed. indicated that less than $\dot{j}$ per cent of the fruit in such orchards was wormy at that date. Unsprayed orchards near by would have from 50 to $9 \check{\text { per }}$ cent wormy.

Arsenate of lead has been used quite extensirely in Colorado the past season and with splendid results. Almost without exception. those who used this poison the past summer say they will continue to use it eren if it is more expensire. Many orchardists hare told me that they no longer fear any serious losses from the codling moth.

PLANT-LICE.

There are a few plant-lice that are serious orchard pests in Colorado every year. The roolly apple aphis (Schizoneura lanigera Hausm.) is one of these. At the present time almost as much complaint is made of it as of the codling moth. Treatment by orchardists seems seldom to be satisfactory. Many who use tobaceo about the roots of the trees think they do not get good results. I should like rery much to hear of the experiences of the members of this society in fighting this insect both on the roots and the branches of the trees. That have you found to be the best treatment?

The black cherry aphis (. Wyzus cerasi Fab.) and the green plum aphis ( 1 phis prunifolice Fitch) are much complained of nearly every 
year; and the same is true of the green apple aphis (Aphis pomi De G.), which is sometimes so abundant as to kill young trees. Mr. H. E. Mather's, horticultural inspector for Delta County, considers these lice as the most serious pests to fruit in his section, and Mr. Thurston White, horticultural inspector for Fremont County, says the black peach aphis (Aphis persicce-niger Sm.) is one of the most serious insect enemies he has to deal with.

Gooseberries and currants suffered quite severely in the northern portion of the State the past summer from the attacks of the gooseberry fruit-fly (Epochra canadensis Loew) and from a fruit-worm closely allied to Zophodia grossularire Riley, but apparently different from that species.

Aulacaspis rosce Bouché was taken for the first time in Colorado last October upon blackberry canes, where it seems to have been fairly common.

The cherry scale (Aspidiotus forbesi Johns.) was reported to me by Professor Cockerell, who took examples near Colorado Springs. I believe this scale has not been taken before in Colorado.

The San Jose scale (Aspidiotus perniciosus Comst.) is still unknown in the State. The scale that gives inost promise of being a serious orchard pest is Aspidiotus howardi Ckll. It is partial to pears and plums and attacks the fruit badly, but does not produce the red discoloration that is so characteristic of perniciosus.

\section{SHADE-TREE PESTS.}

The cottony maple-scale (Pulvinaria innumerabilis Rathv.) is probably our worst shade-tree pest and is about equally bad each year, but Mr. S. Arthur Johnson has a paper upon this insect, and I will not say more about it.

The so-called oak borer (Prionoxystus robinice Peck) is a serious enemy to our poplar and cottonwood trees and is especially destructive to Balm of Gilead. A phytoptus mite (Eriophyes populi Nal. ${ }^{a}$ ) greatly disfigures our poplars and cottonwoods by the production of irregular knot-like swelling upon twigs and smaller limbs, particularly about the buds.

\section{ENEMIES TO GARDEN VEGETABLES.}

A radish maggot that $\mathrm{I}$ have taken to be Anthomyia radicum, but which does not seem to the writer to answer very well to Doctor Riley's description of this species, has been troublesome in radishes in Colorado for a few years past and seems to be on the increase. There were at least two broods of the flies at Fort Collins the past

a Determined by Mr. Nathan Banks, through the courtesy of Dr. L. O. Howard. 
summer. The maggots commonly enter at the center of the crown of the radish and, after burrowing about until full-fed, make their exits at the side. The accompanying illustrations (figs. 4 and 5), by Miss Miriam Palmer, show the injuries of the maggot to a radish in cross and vertical sections.

The destructive pea aphis (Nectarophora pisi Kalt.) was sent me last fall by Mr. J. H. Empson, of the Empson Packing Company,

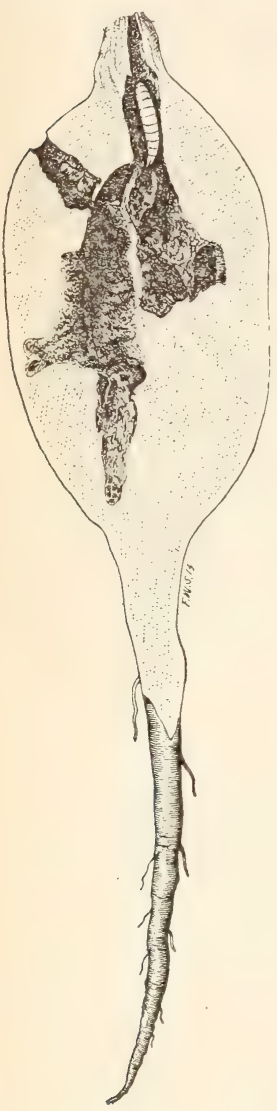

FIG. 4.-Section of radish, showing injury from maggot of Anthomyia sp. (original).

Longmont, Colo. The lice were noticed in a few fields only, and they seemed to be entirely destroyed by their enemies before the season closed. It is my first record of this insect in Colorado. We shall doubtless hear more from it later.

The melon aphis (Aphis gossypii Glover) is troublesome every year in the melon-growing districts, especially about Rockyford. The growers are fighting the louse by covering the vines with dirt as soon as they find lice upon them.

\section{ENEMIES TO FARM CROPS.}

The sugar-beet webworm (Loxostege sticticalis Linn.) has been a very abundant moth at electric lights in northern Colorado for years, but this year was the first that it has done extensive injury to sugar beets. It did some injury in a few limited localities in 1903 , but not enough to occasion much alarm. This year a midsummer brood, the first week in July, did considerable injury to beets about Rockyford, and a later brood was more destructive about Rockyford, Sugar City, and Lamar from the 10 th to the 20 th

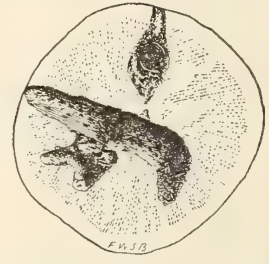

FIG. 5.-Cross-section of radish, showing injury from Anthomyia sp. (original).

of September. The first brood did no perceptible harm in northern Colorado, but the September brood caused thousands of dollars of loss in beet fields about Fort Collins, Greeley, and Sterling. Hundreds of acres of beets during September had all their leaves eaten away except the midribs and a little cluster of new leaves at the center. Wherever the injuries became severe the larvæ matured rapidly. A farmer might think his beets all right on Monday, and by Wednesday be convinced that the worms would take the entire crop. Poisons were used to good effect upon the beets, but the great- 
est benefit was derived from great flocks of blackbirds that congregated in nearly every infested field and ate the worms. The worms that survived burrowed into the dirt and spun silken tubes about 2 inches in length, in which they are spending the winter in the larval condition.

Grasshoppers are always abundant enough in Colorado, but the past summer much of the State has been comparatively free from the introduced species (Melanoplus bivittatus Say, M. differentialis Thos., and $\%$. femur-mbrum DeG.), which are the cause of heaviest losses to farm crops. A native species, Anabms simplex Hald, commonly called "Mormon cricket" or "Idaho cricket." occurred in ninprecedented numbers in portions of Routt County. Many of the ranchmen becane alarmed and inquiries were sent in to the experiment station to know what could be done. In past years the "crickets" have remained almost entirely upon the native ranges, where they did no damage to cultivated crops. For a series of years the cricket armies have been increasing in numbers and have marched steadily eastward until this year, when they entered cultivated regions along the mountain streams and destroyed crops of grain, potatoes, and hay, as well as everything planted in gardens. The infested region, which is over $\delta 0$ miles from the nearest railroad, was visited by both Mr. S. A. Johnson and the writer, and much information was gathered in regard to the habits and past history of this interesting migratory grasshopper. The results of our investigations will appear later in an experiment station bulletin.

The potato flea-beetle (Epitrix cucumeris Harr.) was unusually abundant in the potato fields of the Greeley district the past summer, where it caused many thousand dollars' worth of loss to potato grow. ers. A prominent potato dealer estimated the loss at fully a half million dollars. The beetles were abundant upon the tops, but did their chief harm by boring into the tubers. From larvæ taken in the tubers in September, pupx and adults were obtained. Press Bulletin 23 of the Colorado Experiment Station, treating of this insect, was prepared by Mr. S. A. Johnson. I am calling this insect the potato flea-beetle because it is always found congregating upon potatoes and tomatoes, and seldom occurs upon cucumbers or other cucurbitaceous plants, so far as my experience goes.

A beet leaf-miner, probably Pegomya ricinu Lint., has been abundant enough to attract considerable attention the past summer, particularly in the northern sugar-beet fields of the State. The maggots were noticed in the leaves of young beets the first of June, and they were very abundant in all stages during the last half of August. The white eggs are deposited singly or in groups of two, three, or four upon the under side of the leaves. 


\title{
DISTRIBUTION AND MIGRATIONS OF THE MORMON CRICKET (ANABRUS SIMPLEX Hald.) IN COLORADO.
}

\author{
By S. Arthur Johnson, Fort Collins, Colo.
}

During the past summer there was a serious outbreak of the Mormon cricket in Colorado. The writer spent about two reeks in the infested part of the State, where he collected many data and made observations on the life history of this insect. It has been thought best, in this account, to give, in the first place, a brief summary of the facts obtained in each locality; second, to attempt to trace the great wares of migration: and, third, to give a summary of this information.

Axiel, a tomn in Routt County, Colo., just north and east of the Danforth Hills, was the nearest point we reached to what appears to be the established home of Anubmes simplex. A lady living on a ranch 7 or $S$ miles east of Axiel says that it is necessary to fight the insects almost every rear. The armies come in from the west and travel east and up canyons. The migrations appear to begin soon after the eggs have hatched and continue until egg laying begins again, when the insects locate on the dry hills and devote their energies to providing for their offspring. The pest is kept off the crops here by herding or driving and making noises.

At Hamilton, a town perhaps 20 miles east of Axiel, on the Williams Fork of Bear Rirer, the migrations are less frequent, and we were able to obtain definite clata regarding them. The first observation was made by $\mathrm{Mr}$. T. H. Hamilton and occurred in 1879. Nothing more was seen of the insects until 1895, when a second migration is recorded. Again, in 1900 and 1902, hordes of the insects passed through. In these risits they took all kinds of garden and field crops. Climbing the trees, they collected on the limbs until these bowed with the weight of insect life. The migration from here in each case was northeast. A glance at the map (fig.6) will show that the direction of their trarel took them immediately into the Williams River Mountains. To accomplish this they were obliged to cross the Williams Fork, which flows with considerable speed at this place. Immense numbers were drowned in the attempt and floated down the stream. In one case they came in contact with an obstruction and formed a temporary dam to the water. According to the observations of Mr. Hamilton, the insects traveled about 30 miles in two years. In each case when a brood has passed through, eggs have been laid in this locality. They hatch early in the spring as soon as the snows melt (March or early April). The young are not injured by the rigors of the season. Frequently they are frozen stiff during 
the night and thaw out next day to renew operations. Sometimes they are buried in the snow and remain buried without apparent inconvenience until that is melted.

Hayden is situated on the Bear River north of the Williams River Mountains. Two visitations are recorded at this place. A brood came through in 1882, at which time there were but few settlers in the valley. These protected their crops in part by herding. The second invasion was during the present year, and proved to be much more severe than the first. It evidently came from the Williams River Mountains and appeared at the town about the 1st of June. The insects traveled east and stopped at nothing in their course. In the town they climbed over the board fences and houses with the greatest ease. They entered open doors and made themselves at home by the family fireside. On reaching a ditch they leaped in and many were drowned. The dead and the living which did not succeed in reaching the opposite bank floated on the water, and, lodging against a dam, formed a pile a foot deep, 30 feet long, and 4 feet wide. The brood proceeded on its way until it came to the Bear River, where it was deflected to the north, and, following the course of the river, came about and risited the people of Hayden again a few weeks later. After this they retired to the dry hills 3 or 4 miles south of town, where they were to be found at the time of our visit in the latter part of July laying eggs. A diligent search for eggs failed to disclose them in any considerable numbers.

The most remarkable record was made at Lay, a town nearly west of Hayden and 7 miles north of the Bear River. A brood passed through here in 1895. It came from the sonthwest and went to the north. It was not a rery large one and was never heard from aftermard. This is the only verified instance of the insect having crossed Bear River. The swarm, before it reached the river, must have been enormous, for even the great numbers at Hayden this year farled to effect a passage.

A glance at the map (fig. 6) will show that the number of migrations recorded and the directions traveled support the testimony given by different individuals that Anabrus simplex is permanently located in the Danforth Hills. From this center migrations of insects occur nearly every year. The number of individuals in each band varies greatly and determines, in a large measure, the distance from the home ground that it will ultimately travel before becoming extinct.

The paths of three great migrations are fairly well made out.

A band passed through Hamilton in 1879 and proceeded to the Williams River Mountains, where they became established. Three 
years later they appeared at Hayden, as before stated, having occupied this time in traversing a distance of about 30 miles.

The second migration is indicated by two records only-one at Hamilton, in 1895, and the other the brood which crossed the Bear River and was observed at Lay the same year. Judging from the locations where these records were made and the unusual circumstances already mentioned, the direction of travel of this brood was more northerly than its predecessor. The records were both made in the same year, and the fate of the brood is uncertain, except that it may have become established in the Williams River Mountains. It was reported to us last summer that the insects have been there for

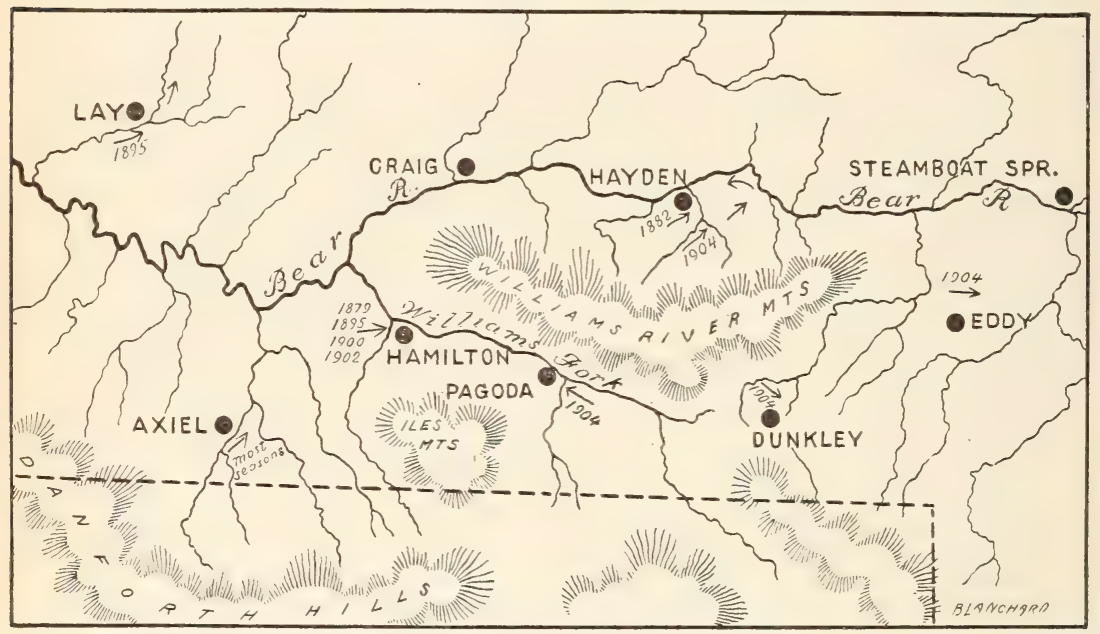

Frg. 6.-Map showing territory infested by Anabrus simplex in Colorado (original).

the past ten years, which would agree within one year with the adrent of this brood.

In the third great wave we may include the two broods which passed through Hamilton in 1900 and 1902. respectively. They both passed into the Williams River Mountains and were not observed again, so far as we discorered, until the umprecedented migration of the past summer.

Some points with regard to this migration must remain in doubt. Whether it was the result of the accumulation of the three broods which passed through Hamilton in 1895, 1900, and 1902. respectively. or two, or only one of these, is uncertain. It would seem as though the last two, at least, must be contributing factors. In any case the individuals of these previous broods succeeded in giving rise to countless numbers this summer.

All of this year's migrants had their home in the Williams River 
Mountains. There rere at least three great divisions of the migrants. One band went northeast through Hayden, as already recorded. A second took an easterly direction and proceeded as far as Erdy and Dunkley, a branch going northeasterly to within 5 miles of Steamboat Springs. A third division reached the IVilliams Fork and followed its course in a westerly direction as far as Pagoda, at which place they were within 12 miles of the point where the former broods crossed the river at Hamilton.

At Pagoda the number of insects was enormous. They were piled sereral inches deep in the road. The cliffs a mile away were seen, with the aid of the telescope, to be black with them. They fell into the ditches mutil these were almost choked with the dead. Those that crossed entered the oats and alfalfa. The former they ate to the ground and stripped the latter of leaves and tender shoots, leaving nothing but the bare stens standing for a distance of 30 or 40 feet from the margin. The coming of the insects was announced by telephone from 5 miles up the creek one week before they reached this place, which was about the Fourth of July. It took the brood two weeks to pass a given point.

At the time of our visit, Angust 9, the insects had retired to the hills, where they were found in great numbers in the act of egg-laying.

\section{CONCLUSIONS.}

To recapitulate, the insects are permanently located in the Danforth Hills. From this place immense swarms migrate in different directions at times. The immigration is probably caused by overproduction of the species. The ultimate destination of the swarm is determined in no small measure by the number composing it. If a swarm succeeds in attaining a favorable locality, a brood may be produced which will cause another migration. The IVilliams River Mountains have more than once served as a temporary breeding ground. Each ware is followed by the enemies of the insect. These, combined with otherwise unfavorable conditions of the new country, would lead to its ultimate destruction.

The insect has been here as far back as our knowledge goes, which is not very far, however. The ranchmen live far apart and the country is altogether new. The advent of civilization has probably had little influence on the destiny of the insect because the percentage of land under cultivation is very small and the localities where there are cultivated fields are only raided during the migratory stage of the insect's life. Its normal home is not in the river bottoms, but on the dry hills. The only change that civilization has caused there is the substitution of the stock of the ranchman for the droves of elk and 
deer. and the herds of buffalo. This change has not, perhaps, greatly affected the insect's food supply.

Migrations will occur in the future as they have in the past, but we do not anticipate that the insects will become more numerous, and there appears to be little danger that they will become an unbearable pest in the near future.

The migration of last summer was. perhaps. chiefly due to the unusual climatic conditions of the preceding winter.

\section{MISCELLANEOUS NOTES FROM TEXAS.}

By A. F. Coxnad, College station, Tex.

With the present interest aroused in entomological work in Texas many varied problems confront the entomologist. Yo attempt will be made here to rerien the work for the rear, as it will be elaborately discussed elsewhere in a short time.

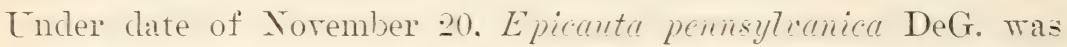
reported to injure onions in southern Texas by eating off the tops near the ground. The injuries this season rere not serious, on account of the small numbers of the insect. but they gire ground for apprehension in case the pest be numerous another rear.

Ourideres cingulute Say has attracted considerable attention, especially during Yorember. Its work is well known, although its Iife history has not been worked out in Texas. Year Independence it attacked pear and rose. doing serions damage. Experiments with trap lights were made here with apparently good results, for many beetles nere thus captured. In this locality it injured apples peach. and per-immon. Year Manor it injured rosebushes, salt cedar, hackiberry. elm. pecan, and cotton. Year Bellville the pear was the chief object of attack. Picking the fallen limbs was a remedr used this season.

The San Jose scale (Aspictictus permiciosus Comst.) is at present definitely knomn in eight different localities in Texas. representing almost erery section of the rell-settled portions of the State. With the rapid growth of the State in fruit groming and with no inspection lans. it will be but a short time before this will become one of the most important of its many insect problems.

The sweet-potato weeril (Cylas fomicains Fab.) is seriously threatening the street-potato industry in sereral localities. It was first reported in Texas in October. 1890. by T. H. Edrards. Bay Vier, Harris County. The same year the sweet-potato crops around Buras, La.. were reported a failure. owing to this insect. At this writing. it is knomn in this State from Bee Cares. Hankamer, Pasadena, Ceilar 
Valley, Bay City, Port Lavaca, Austin, and Hamshire, and it probably occurs at Marlin. No doubt other localities which have not yet come to our notice are infested.

The females lay their eggs on the lower part of the stalk in cavities previously made while feeding. They also oviposit on the tubers in the same inanner, in shallow-planted potatoes or where the tubers are easily accessible. The number of eggs that one weevil is capable of laying could not be ascertained the past season, but in the insectary the number was rery small, which accounted for the slow increase of the pest. The first mating at College Station was May 2. On May 6 mating pairs were common, but the first eggs were found May 20. 'The average time to the hatching of these eggs was twelve days. The life cycle from mating to adult is forty-nine days, allowing fourteen days from time of mating to egg-laying, twelve days for eggs to hatch, sixteen days for larvæ to develop, and seven days for the pupæ. The time from emergence to mating varies from a few minutes to several days. Experiments made in breeding the insects on potatoes that had not yet the tubers formed were successful. The young larva first bored down in the stem, then upward, in most cases the pupx being found several inches above the ground in the center of the stalk. On May 20 the first eggs were found in the insectary. On December 7 of the preceding year specimens of tubers sent in from Port Lavaca had all larra half grown. As the season of activity is longer at Port Lavaca than at College Station, four to five generations would have ample time to develop. Fumigation in the bin with carbon bisulphid has been thus far the main reliance. At College Station the adults fed voraciously on all parts of the growing plants, giving the plant an appearance something like that given to the tomato by the flea-beetle. These adults were all killed with Paris green and arsenate of lead sprays, the latter insecticide requiring a longer time than the former. Tubers in which all stages of the insect were present in a healthy condition were received at College Station at different times of the year. Infested sweet potatoes can be shipperl long distances, and this is an easy way of disseminating the pest. The old practice of allowing the vines and small tubers to remain in the field is unfortunately still in vogue in many localities. Some growers follow the advice given and destroy the remains of the crops after harvesting. They feed the small tubers to cattle, holding that hog refuse to eat them.

Although the adult insects have wings, their chief mode of migration is on foot. This accounts for the relief obtained by planting carefully selected seed remote from the infested territory. It is important that good seed be thoroughly covered with earth when 
planted, some successful growers contending that the weevils are more injurious to shallow-planted potatoes on cloddy land than to deep-planted potatoes on sancly land. A note under date of August 1 gires one infested hill among twenty-fire, the infested tubers being an early variety and projecting from the seed bed.

During the winter careful observations were made on the mosquitoes infesting College Station and vicinity, especially from a sanitary standpoint. These investigations were stimulated two years ago when yellow ferer appeared at San Antonio and seemed to be spreading northward. The comntry about College Station is low and level, the soil of a loamy nature, underlaid at from 6 to 10 inches with a tough hard clay. The streams are so rapid that they will hold water but a short time after a rain. It is, therefore, the common practice to put dams across the gullies and collect the water during a rainfall. Such tanks will rarely dry out during the summer. It was found that no mosquitoes bred in such waters on account of the number of minnows present in all cases. The main breeding place near the college was at the mouth of the sewer where it empties into the brook. Here nosquito larve were so numerous that they formed a solid scum on the water. On account of the annorance duie to mosquitoes during the early spring months, making life on the campus alnost unbearable, relief was sought by treating the cisterns and the sewer. Some relief followed, but it was discorered that the mosquito supply came from another source. Each negro hut scattered orer the country has a rain barrel or a water tub at one or two corners, and here the mosquitoes bred undisturbed through the greater part of the season, the prevailing south wind carrying them for over a mile.

The only mosquitoes at College Station are species of Culex, no Stegompia haring been found. I few specimens of Anopheles, hlown in by a mild east wind from a pond in the valley of Carter Creek, rere taken during July. This is the only breeding ground of Anopheles close to College Station, but the supply is blown northward by the prerailing winds. Although mosquitoes breed there all winter and maintain a high percentage of malaria cases in the neighborhood during the summer, they do not aflect the college, since nearly all winds from that direction are " northers." which rarely carry mosquitoes. The only other breeding place of Anopheles of any importance is 17 miles southwest across the Brazos Rirer. Although the mosquitoes keep malaria alive in that locality they do not affect the college. The fer cases of malaria that appeared at College Station originated in other localities, and such cases were not a menace to the community, as there was no agency for carrying the disease. 


\section{INSECTS OF THE YEAR 1904 IN GEORGIA.}

By Wilmon Newell and R. I. Smith, Atianta, Ga.

Continued experiments with the San Jose scale have demonstrated that a lime-sulphur wash of 21 pornds of lime and 18 pounds of sulphur in 50 gallons of water is fully as effectual as washes containing larger amounts of lime and sulplur, and also that the addition of salt to this wash is umnecessary, so far as the scale is concerned. By first mixing the sulphur with boiling water and then adding the molaked lime the boiling an be completed in from thirty to fifty minutes in an iron kettle over a fire and in from twenty to thirty minutes where a full head of steam is available for boiling. Washes prepared in this way have given fully as good results as the stronger washes, boiled for a much longer time, which were formerly recommended. The lime-sulphur-caustic-soda wash has also given good results when properly prepared. For successful preparation of this wash we have found that it is necessary to first mix the sulphur with boiling-hot water and then to add slowly the caustic soda until all the sulphur is dissolved and a perfectly clear liquid obtained. By adding the stone lime to this clear liquid and allowing it to slake, a preparation is secured which is in no way distinguishable from the regular lime-sulphur wash. The effects of this wash upon the scale have not thus far been quite as satisfactory as those of the regular boiled wash. Experiments with caustic soda solution alone, which substance was highly indorsed by many agricultural papers during last winter, have demonstrated its utter worthlessness as a remedy for this pest.

The Asiatic ladybird (Chilocoms similis Rossi), which in 1903 gave promise of becoming abundant, has proved something of a disappointment. In the majority of the orchards where this species was colonized but few individuals could be found during the past season. In the case of an orchard at Marshallville, where literally thousands of the beetles occurred in the summer and fall of 1903, no specimens were found during 1904. In a near-by plum orchard, however, a few individuals survived the winter, and during early summer and midsummer they fed readily upon Pulvinaria amygdali Ckll., which species was fairly abundant in the orchard in question. Their beneficial work in keeping the latter species in check is much more marked than in the case of the San .Jose scale, owing to the slower rate of breeding of the Pulvinaria.

The plum curculio (Conotrachelus nempher Hbst.) has proven very injurious in the peach orchards in southern and middle Georgia, in some cases from 15 to 20 per cent of the crop being rendered unmarketable. 
Among the unusual insects attacking the peach during the year may be mentioned colaspis facosa Say. which defoliated peach trees in one locality in northern Georgia. Hippodumia conrergens Guér. and Diabiotira 12-punctuta Fab. have both been noticed eating the petals of peach blossoms and also eating into the base of the blooms. Apparently nothing but the relative scarcity of indiriduals prevented serions damage by these two species. Ithycems noveboracensis Forst. did considerable injury by girdling apple twigs in Gilmer, one of the mountain counties.

Throughout the apple-growing section of northern Georgia, embracing practically all of the state north of the thirty-fourth parallel. C'(1,pocal)s pomonetlı Linn. is universally distributed. The prevalence of this insect is doubtless largely responsible for the lack of interest taken in commercial apple culture, and but fer growers have taken the pains to systematically combat it.

Baldnims corya Horn. did serious damage to pecan nuts near Thomasville during 1903. Thile also doing considerable damage Aluring 1904. this species did not appear to be nearly so abundant as in the year prerious.

In a number of localities in extreme sonthern Georgia Hyphantia tewor. Harr. occurred in considerable numbers upon pecan trees. From the summer generation of larre adult moths were reared August 31. Niminglon baxitare Say has been found working in the trunks of roung pecan trees in southern Georgia; and at Vinings, ịn northern Creorgia. Chmysochus auretus Fab. did much damage in a small pecan grove by defoliating the trees.

During the latter part of the summer Alabama argitlacea Hbn. was generally distributed and abundant orer that part of the State south of the thirty-second parallel. and destroyed practically all of the " top crop " of cotton. Cpon late cotton the damage from this insect was rery pronounced. The Paris green and lime mixture wherever applied effectually checked the pest.

Heliothis obsolete Fab. while generally distributed. was not as destructire as in 1903. An unusually large amount of injury was done by this species rery early in the season. the cotton squares in many fields being liberally punctured during June. Only three or four counties suffered excessively from this insect later in the season.

Chalcodermus anews Boh. was quite destructire to young cotton plants in Kandolph and Terrell counties during May. This beetle makes numerous punctures in the tender buds and leaf-stems before the cotton is large enough to commence squaring, these punctures causing the leares, and frequently the entire plant, to wilt and die. Upon some small areas fully 50 per cent of the cotton plants were killed and an arerage damage of 2.5 per cent occurred in a few fields. The first appearance of the beetle in early spring is, so far as has 
been observed, always upon land which had been in compeas the year previous. A rotation in which cotton does not follow cowpeas effectually disposes of the trouble, but such a rotation is not always practicable. In the laboratory the beetles show a marked preference for compeas, when both the latter and young cotton plants are growing side by side. Trap rows of cowpeas, planted between cotton rows when the cotton is planted, would probably serve to direct the attacks away from the cotton almost entirely. However, as many more cotton plants come up than are ultimately utilized, the simplest and cheapest remedy appears to be the delay of the first "chopping" as long as possible, or until the extent of the damage can be approximately forecasted. The first chopping can also be made light, so as to leave plenty of plants, and the damage by the insects will then amount to hardly more than a severe thinning. When the time for the second chopping arrives the period of maximum injury will have passed and a good stand can be secured. Owing to the relative abundance of this species in the localities mentioned, it was mistaken by many for the boll weevil and caused much temporary alarm.

Carpophitus dimidiatus Fab. has several times been found breeding abundantly in cotton bolls which have been destroyed by the cotton anthracnose. Systena blanda Mels. developed an unusual appetite for young cotton plants, and during May did severe damage to cotton near Jackson, Ga.

A somewhat detailed inquiry among the wheat growers of the State has revealed that in previous years the damage by Mayetiola (Cecidomyia) destructor Say has been considerable. In the case of Bartow County alone, which normally produces more wheat than any other county of the State, the damage by this insect in 1903 was estimated by many prominent planters as considerably in excess of 20 per cent of the crop. This was equivalent to a money loss of practically $\$ 19,000$ in that county annually. Examinations in Bartow County revealed the eggs of the spring brood in abundance on April 1. Observations were made from time to time during the summer, and it can now be stated with certainty that in this the southernmost part of its range in the United States the Hessian fly is not more than two-brooded. Plans were made for extensive experiments in sowing wheat in different localities and at different altitudes during the past autumn in order to determine with certainty the dates of egg deposition. Owing to an exceptional and prolonged drought during August, September, and October, early-sown wheat remained in the ground without germinating until about November 5, and did not appear above ground until after the periods for the appearance of the adult flies had passed. The only puparia that can be found at present are in rolunteer wheat, and the indications are that during 1905 the attacks of the insect will be much less than formerly. The advisability of 
further decreasing the numbers of the insect, under these peculiar conditions, by destroying as much of the rolunteer wheat as possible, is self-evident. In the laboratory flies emerged between October 18 and 30 from infested stubble collected at Halls, Ga. (approximately $34^{\circ} 20^{\prime}$ north latitude; elevation 790 feet). In a season of normal rainfall we anticipate that the date of emergence will be several days earlier.

Diatrea saccharatis Fab., after having remained in the background for several years, came prominently to the front near Hawkinsville during early summer, and did considerable damage to corn over a small area. Ligymes rugiceps Lec. appeared as a destructive enemy to corn near Canton, in the northern part of the State.

Cryptocephalus obsoletus Germ., known locally as the "Lincoln bug," has become a rather serious pest to collards in middle Georgia.

Among the interesting cases in which a species rapidly disappears or becomes greatly depleted in numbers we may record the case of Toumeyella turgida Ckll., which in 1900 was so abundant upon Magnolia glauca and fuscate at Thomasville as to thoroughty incrust these trees and kill a considerable number of them. During 1903 and $190 t$ it has been practically impossible to find even isolated individuals of this scale in that locality. So far as known to the writers no systematic treatment toward eradicating the pest has been undertaken and parasitic insects were not noted in greater numbers than are usually found upon other scale insects.

During July Dr. John B. Smith, who was paying an entomological visit to Georgia, found the larvæ of Ephestia kuehniella Zell. feeding in cotton-seed meal.

Dynustes tityus Linn. caused considerable annoyance at Washington, Ga., by its abundance upon ash trees.

During late summer and autumn the larve of Anisota senatoric S. \& A. occurred very generally upon oak throughout the northern prart of the State. While the damage, both in cities and in the native forests, was not excessive, still a great many trees were partially or totally defoliated.

Observations made upon the life history of Melittia satyriniformis Hübn. show the supposition made by Professor Quaintance in 189?, that this insect is double-brooded in Georgia, ${ }^{a}$ to be correct. In central Georgia the second brood of adults emerged between July 1 and 15,1904 , with a few belated individuals coming ont after the latter date. Individuals may be found in the pupal stage during a period of from three to four weeks.

Omorgus (Campoplex) frumentarius Rond. has been reared from 
the larva of Ephestia huehniella Zell., and Phanerotoma tibialis Hald. from pecan nuts badly infested with Balaninus caryo Horn.

To Dr. L. O. Howard and his assistants the writers are indebted for the determination of a considerable number of the species above mentioned.

Mr. Slingerland called attention to the fact that prepared arsenate of lead in wooden buckets dried and caked badiy. He thought it was much better to purchase in tin.

Various speakers complained of its eating through the tin and consequently they preferred the wood, but the members were evidently divided as to which was better.

Mr. Quaintance asked what the effect of arsenate of lead was on peach and plum.

Mr. Smith said that it could be used two or three times on peach at the rate of 1 pound to 25 gallons without apparent injury.

Mr. Slingerland questioned the advisability of the home-made arsenate of lead, because the materials were often adulterated. Messrs. Burgess and Sanderson both believed that the arsenate of soda was often adulterated and unreliable in strength. Mr. Fernald preferred to make his own, but felt it necessary to be very particular rrom what source the arsenate of soda was obtained.

The question of the advisability of using trade names in publication was brought up, and a lively discussion, participated in by almost all of the members, indicated that the general feeling was that the exact truth should be told about materials sold under trade names, referring to them by these names in the publications. In some cases, however, this was in possible on account of the official censorship. Some members, howerer, believed that trade names should not be used in publication.

The question arose as to whether it was desirable to publish the names of people on whose property experiments are made or whose premises are infested with certain insects. Mr. Gillette believed that this should rest in each case with the party concerned. If the owner of the property wished his name mentioned, this should be done, but otherwise not. Mr. Burgess agreed with this view. In Ohio there had been a prejudice against firms who fumigated their trees. A photograph of a fumigating house of one nurseryman was secured, but the owner was consulted as to whether he desired to have his name mentioned before any steps were taken concerning its publication.

Mr. Slingerland asked if entomologists should be expected to test all the nostrums that are put on the market. 
Mr. Gillette felt it a duty to test an insecticide whenever he beliered that it was liable to do injury to the people of his own State.

Mrr. Burgess called attention to the fact that we often knew, before testing, that a remerly would be a failure, and yet, in order to satisfy the people and hare them follow our recommendations, it was necessary to make an actual test. For instance, there had been introduced a panacea for pear blight and peach yellows, which was to be used by washing the outside of the trees. Nlthough, of course, this could not possibly be efficient. it was necessary actually to test it.

Mr. Femald beliered that the testing of proprietary insecticides was a matter for cooperation. Each station can not analyze all of them. yet the people of the country have a right to know of the existence of good preparations. He beliered that in each of the main divisions of the country one station might assume this testing for a certain period, others taking it up afterwards in rotation. $\mathrm{Mr}$. Phillips felt that this should be done. In Virginia it appeared to be necessary to gire this information to the people to protect them from fraud. but it was impossible to test ererything. Mr. Quaintance called attention to the fact that the Association of Official Agricultural Chemists has such a strstem of cooperative tests. Mr. Slingerland believed that eren after these tests were made many people would not beliere in them. They want to find out by their own experience what the truth is. Mr. Surface dissented from this view to some extent. believing that part of the people at least do accept our reports. Mr. Smith said that he receired many adrertisements of curculio remedies accompanied by the question, "Do sou know antthing of this?"

Mr. Fernald mored that a committee of three be appointed to consider the question of cooperation in the testing of insecticides and proprietary preparations. to report at the next annual meeting. The motion was carried. and the chair appointed as such committee Messers. H. T. Fernald. H. A. Surface, and A. T. Burgess.

The following paper was read:

\section{THE PRESENT STATUS OF THE PREDATORY INSECTS INTRO- DUCED INTO NEW JERSEY.}

Ву John B. Sıгтн, New Brunsuick, N. J.

Erer since the introduction of the San Jose or pernicious scale into New Jersey, the question of securing the assistance of predatory insects to exterminate or at least control it has been more or les; continnonsly before the farmers and fruit growers, and of necessity before the entomologist as rell. The subject is an old one. It has been before rarions meetings of farmers. fruit growers, and entomologists, and it has been discussed from all sides. That a measure of 
success, large or small, has been attained in a number of cases is without doubt. The classic case is of course the effect produced by Novius (Vedatia) cardinatis Muls. against the cottony cushion scale (Icerya purchasi Mask.) in California. I have followed in a very general way the records of the successes attained in foreign eountries, including under that term, for convenience, Hawaii. There is no doubt that not only a measure of success has been obtained in many instances, but that the measure has been in a few cases a very satisfactory one, amounting in, the California instance just cited to the almost complete extermination of the pestiferous insect.

At first blush there seems to be no reason why what has been done in one section of the country can not be equally well done in another; and why, if it has been shown that on the Pacific coast a species of coccinellid is found keeping a scale insect in check, that same species shonld not do precisely the same work in the State of New Jersey.

With this idea, I made my first risit to California and the Pacific coast in 1896 ; in the first place to determine whether, as against the San Jose scale, the coccinellids were really effective, and, second, whether it would be possible to acclimate these insects in New Jersey. A few years ago I would have said that what can be done in California can also be done in New Jersey, and that the results of experiments obtained in New Jersey were equally valid in California. The experience of the past few years has modified my opinion on this subject very materially. I am extremely reluctant nowadays to even advise a New Tork or a Pennsylvania fruit grower to make applications based upon what I have found to be effective in New Jersey. In fact, I have discovered that I can not always duplicate results two years in succession; that when I find an application almost completely effective one summer, I am as likely to find it, under apparently similar conditions, absolutely ineffective the year following. Perhaps it does not often occur that such extreme contradictions are noted; but I think every working economic entomologist has seen cases at least similar to the one just suggested.

I do not encourage too great hopes from importations made from California into New Jersey. You are probably familiar with the report made by me in 1897 as to the results of my investigation; how I found that in the more southern parts of the State the pernicious scale was really kept in check by a coccinellid not the species which had been credited with the work, but by a common native form, Chilocorus biculnems Muls. I found, too, that the species that was most generally credited with being the check to the scale could scarcely be found at any time, and that instead of Rhizobius lophantce Blaisd., which is an introduced species, Scymnus marginicollis Mann. is really the effective form. Nevertheless I succeeded in making arrangements by which I introduced into the State of New Jersey dur- 
ing the season of 1896 a number of colonies both of Rhizobius and Scrmmus. In all, several hundred specimens were brought into the State and distributed in the more southern counties, where the climate is mildest and conditions generally more farorable than in the north, and in each instance where there was an abundance of food for them. 'The colonies were scattered so that anything happening in one section might not affect the entire experiment. The results were absolute failures. Nothing more was seen of either species at any subsequent period.

At the same time I entered into correspondence with Professor Matsumura, of Japan. This resulted in the introduction into New Jersey of a small series of Chilocoms simitis Rossi, the Asiatic lady beetle of which we have heard so much during the past year or two. Some eighty specimens were contained in the sending and of these nineteen were alive and in apparently good condition. I placed them out nyself under farorable circumstances on May 24, in a locality where food was abundant and where conditions might be supposed to be of the best. For a few days afterwards the insects were seen, some of them were noted as feeding, and there is no doubt that they lived for a short period. There is no doubt, either, that they died off, for nothing was seen of them in that same orchard after midsummer, or at any time since. Nothing more was done in this matter until after Mr. Marlatt had suceeded in securing specimens from China and Japan and had actually established them in Washington, D. C.

During the latter part of 1902 I secured, through the courtesy of the Iepartment of Agriculture, sufficient specimens of Chilocoms simitis to colonize on two infested trees in my own garden, where they were under constant observation. These insects multiplied to some extent during the year, hibernated rery fairly, and had only one dramback - they became pretty well parasitized before the season "was over. In 1903, while the parasites were rery active, I succeeded in getting increase enough to send out 15 colonies, and with what was receired from Washington some 400 individuals rere distributed in different parts of southern New Jersey. It will be noted that the rate of increase is not especially great. Out of perhaps 30 ladybirds received, only about 360 were actually obtained after a year under the most favorable circumstances.

The winter of 1903- $t$ was an unusually hard one, not that the temperature was lower than usual, because, as a matter of fact, it did not reach the lowest point of the year before; but the cold was continuous and there were sereral unusually heary late frosts. Whether on this account or for some other reason which I have not been able to discorer, the colonies in all parts of the State were completely exterminated. I have not seen anywhere eren a single example of this species. This report is not based altogether upon statements 
made by the parties to whom the insects were sent. It is made partly upon the results of my own examination and partly upon those of my assistant, Mr. E. L. Dickerson. Nevertheless I have not given up hopes of securing some better results even yet.

I) uring the summer of $1904 \mathrm{Mr}$. Wilmon Newell, State entomologist of Georgia, was good enough to give me a week of his time and to guicle me through those sections of Georgia where in 1902 this coccinellid had occurred in enormous numbers. As to the status of affairs in Georgia, Mr. Newell is the only one competent to speak; but I may say that after a pretty thorough collecting orer the various communities where the beetles had been most abundant I succeeded in getting a sufficient quantity to start a new colony in New Jersey. Mr. Newell was good enough to divide with me in order to give New Jersey an even start with Georgia on the new deal. This time all the specimens that were obtained were placed in one orchard, not far from New Brunswick, and this comes about as near to being an ideal place for insects of this kind as could well be imagined. The orchard consists of apple, peach, pear, and plum trees, several hundred trees in all. Almost every tree is scaly and some trees are dying. Nothing has been done to destroy the scales, and as the estate is in chancery it is very certain that nothing will be done during the current winter. 'There is plenty of rubbish to serve as hiding places, also plenty of loose bark. Scales occur in abundance, and although Pentitiu misella Lec. occurs on these trees by the thousands, it has not succeeded in making any impression upon the scales. All the specimens were introduced during the latter part of July. The orchard was visited from time to time and at all times sone specimens were seen feeding upon the scales; and in the latter part of the season larvæ and pupæ were found, indicating that the insects had made themselves at home, to some extent at least. A small number that were kept in the laboratory and plentifully supplied with food laid eggs in small numbers. Such larvæ as hatched from these eggs were taken into the orchard to give them normal winter conditions. I can not say that I hope for very much as the result of this last experiment; nevertheless there is a chance that something will be seen of the insects next year, and if they do breed they will have an opportunity to do so under the best possible surroundings.

Some time before 1900 a mantid, Paratenodera sinensis Sauss., introduced from China had established itself in the vicinity of Philadelphia and had been doing well, hundreds of egg masses being seen rluring the winter, while the insects themselves were not at all uncommon during the summer. Mr. Philip Laurent recorded the presence of this insect and figured it in Entomological News.

During the winter of 1900-1901 I secured through Mr. Laurent a small lot of specimens, altogether about 100, which I distributed 
mostly in southern New Jersey, retaining only a few myself. Adults from these masses were seen during the summer of 1901 at a number of places, and during the following winter I added materially to the supply by further lots of eggs obtained through Mr. Laurent. In addition. Professor Slingerland sent me a number of egg cases of the European species, which had established itself, in northern New York, also the result of an accidental importation. There were thus in New Jersey during the early spring of 1902 a large number of eggs of Paratenodera sinensis Sauss., some of which had been placed there by insects that might be considered native to the State, since they were born and bred there: and an additional lot of eggs of Mantis retigiosa Linn., natives of New York State, and which might have been expected to do fairly well in the somewhat milder climate into which they were introduced. Hatching was pretty general from all the egg masses of the Chineve species: but so far as I could make out none of the European egg cases produced young.

During 1902 the adults were seen everywere that the introduction had been made: but nowhere in any rery large numbers. Still they were there, and again, during the early spring of 1903. I added some 350 egg masses, secured from Mr. Laurent, to the previous sendings. 'The result in $190 t$ was not in proportion to the work that had been done. Ferrer examples were seen in most of the places than ever before. In one locality only was any considerable number of specimens noticed. In one place that had received sendings each year, and which was almost a duplicate of the locality near Philadelphia where they had first established themselves. not a specimen could be found. I sent Mr. Dickerson through one of the places that he had seeded down, and where the location of erery egg cluster had been mapped, and. while many of the $\pi$ hole clusters were found, the eggs apparently hatched. the net result seems to hare been one new egg mass and nothing else. As the result of introductions continued three years in succession there is no one point where I could go at the present time with any reasonable hope of finding even a single egg mass.

For some reason New Jerser seems to be a reritable paradise for the injurious species that are introduced: but something very much to the contrary for such beneficial insects. or rather predatory forms, as have been introduced to control them. So far as the records go, they offer very little encouragement to those who are inclined to depend upon fighting injurious species with natural enemies.

Mr. Mashburn asked whether any coccinellid was found working on Lecanium.

Mr. Smith said no, but that Lecaniums were rare in New Jersey. 
Mr. Marlatt said that this work was very interesting to him because of the care with which the experiments had been carried on. His own course had been to try to allay undue enthusiasm regarding the San Jose scale coccinellid. Its introduction was an experiment that seemed at first promising. In many sections the experiment failed, but frequently this was due to the starvation of the coccinellid, because sulphur-lime wash was used at the same time and destroyed most of the scales. Predaceous insects of general feeding habits should be introduced with care. They may destroy beneficial as well as injurious species. Mantis, for instance, seemed to take a special delight in destroying the aphid-eating coccinellid.

The following paper was presented:

\section{REPORT ON THE "NEW ORLEANS" ANT (IRIDOMYRMEX HUMILIS Mayr).}

By E. S. G. Titus, Washington, D. C.

In July of 1904 the Bureau of Entomology of the Department of Agriculture received a letter from Prof. H. A. Morgan, of Louisiana, inclosing a letter from Mr. E. Baker, superintendent of Audubon Park, New Orleans, La. Mr. Baker's letter gave an account of an ant that occurred in enormous numbers in that city and was causing serious trouble.

Under instructions from the Entomologist, Dr. L. O. Howard, I reached New Orleans from New Iberia, La., October 15, and proceeded to the sugar experiment station in Audubon Park. Mr. R. E. Blouin, vice-director of the station, and Mr. E. Baker gave me such information regarding the presence, distribution, manner of spreading, and ravages of the ant as they had collected during the past few years.

Mr. Baker first noticed the ants in 1896, at which time he moved into Carrollton, near the Southport docks. They then extended over but a small area, reaching approximately from Southport docks to Carrollton avenue and from the river back to Poplar street. At that date the residents in that section had been troubled with them but a short time. I could find no one who could positively remember noticing them before 1895 .

In 1899 the ants were first noticed in Audubon Park, and by the next summer had become quite numerous. They are now practically all over the park, the nests more commonly occurring at the bases of trees. On the experiment-station grounds the ants' nests are very (nmmon around and beneath buildings, in flower beds and cultivated fields, beneath sidewalks, and even on the lawns. In wet weather, Mr. Baker stated, the ants deserted their ground nests and carried pupæ, larvæ, and eggs into the trees. Here they constructed nests by 
bringing dirt from the ground. I found several inhabited nests as high as 15 to 20 feet above the ground in the forks of live-oak trees. 'These nests appeared to be entirely independent of the nests at the foot of the tree.

The ants were noticed aiding in the distribution of the following insects on the grounds of the station and in other parts of the park:

Aphides on fig, citrus trees, sycamore, live-oak, cedar, arbor-rita, Durenta plumieri, and ornamental plants in greenhouses, and on the grounds.

Ceroplastes floridensis Comst., occurring on fig, persimmon, orange, lemon, and on many plants in the horticultural greenhouses.

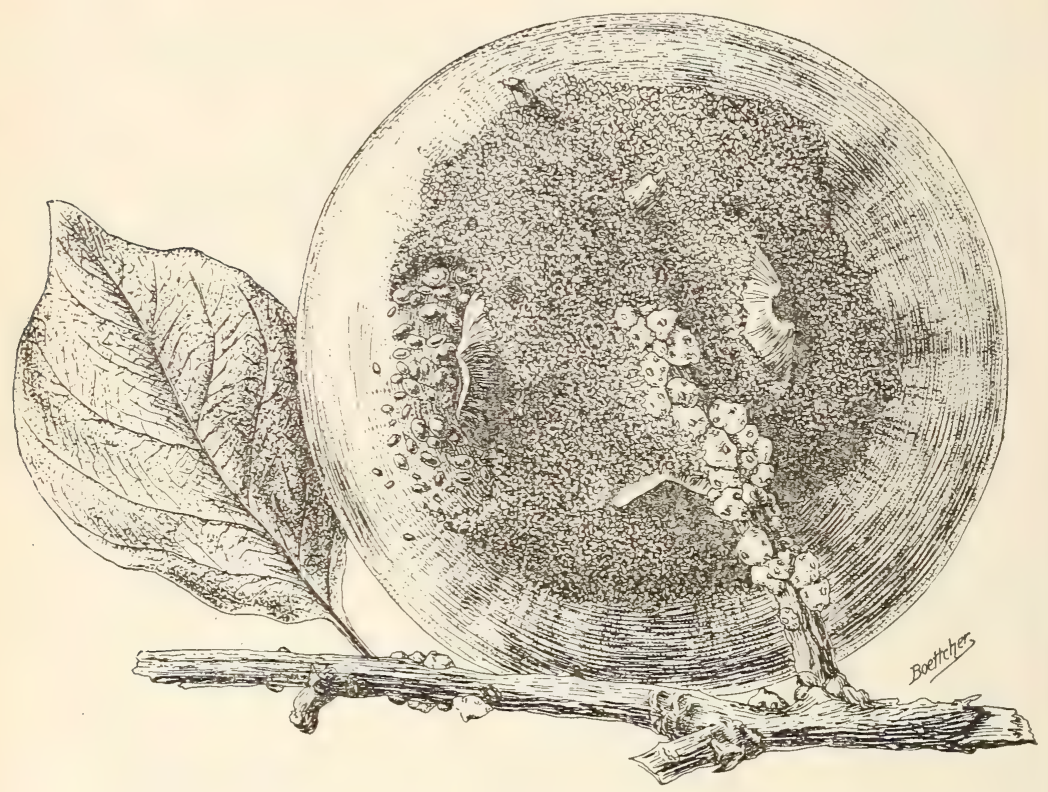

F'IG. 7.-Persimmon showing protective covering made by Iridomyrmex humilis (original).

Pseudococcus citri Risso, occurring on all citrus-fruit trees, fig, persimmon, plum, sycamore, live-oak, willow, and other trees, palms and ornamental shrubbery of almost all kinds, chrysanthemums, dahlias, golden-rod, and rarious plants in the greenhonses, including ferns, palns, coral-tree, coffee-tree, and a species of Hibiscus.

Scale-lice of sereral other species are being taken care of by these ants. They occur in such great numbers that they have apparently become care-takers for all kinds of scale and plant-lice present in the regions they infest. Where possible to do so, they build a covering, composed of dead lice, cast skins, dead ant remains, and dirt orer the insects for which they are caring. On fruit this is first built near the base of the stem and gradually extended outward as the colony 
grows. This was especially noticeable on persimmons and oranges. At the stem end, or wherever two specimens of fruit touched, the projecting covering had been extended for a considerable distance.

On twigs of arbor-vitæ the ants were able to build a covering for the plant-lice by extending it outward onto the rough, flat leaves of the plant, and in one instance they had built on both the upper and lower sides of the leaves.

The entrance to these shelters over colonies on fruit was always near the stems, but ants could usually be seen at some place on the outer edge repairing or extending the covering or removing young scales to new territory.

The mealy-bugs infesting citrus trees and other fruits and on the palms appear to be the same species as the one commonly found in the greenhouses in the city-Pseudococcus citri Risso.

The mealy-bug affecting the sugar-cane on the sugar experiment station grounds is, so far as I can ascertain, the same species. Careful comparison has been made with mounted specimens of Pseudococcus caleolarice Mask. on sugar-cane from Florida, $P$. adonidum Targ. and $P$. citri Risso.

This sugar-cane mealy-bug has increased very rapidly in the last two years, and this year a large percentage of the cane was affected. The woolly secretions were present in the greatest numbers in the leafsheaths, but occurred on the stalks from the base up to from 3 to 6 feet above the ground, and often far out on the leaves, where two or more leares were touching or rested against a cane stalk. Very few were found in the ground among the roots, but the older specimens could often be seen traveling over the rough dirt from stalk to stalk. The ants were everywhere present among them and were several times seen establishing new colonies on cane.

Ants were found, also, with mealy-bugs on several weeds in the cane fields, on grasses, and rarely on ramie.

I found the ants in boxes of crackers and candies sent directly from New Orleans, and while in that city noticed them being packed up with several kinds of groceries for shipment to outlying towns.

A Louisville and Nashville construction-department cooking car was visited in New Orleans. This car was in daily use and had been for several days located at the point where I saw it. The cook told me the ants worried him nearly to death. "Why, they are so thick that I don't get rid of them till I've been out on the road two or three days."

Their present distribution is probably limited by the distance that wholesale goods are shipped locally from New Orleans. While as yet they do not extend all over the city, it is a matter of only a few years, at the outside, when the entire residence district will be infested. 
The ant is nom knom to occur in the following localities outside of the city of Xew Orleans: Across the river in Algiers and adjoining small settlements: at West End. Spanish Fort, and Milneburg. summer resorts on Lake Pontchartrain: Bay St. Louis, Miss., a summer resort between New Orleans and Mobile; along the Texas and Pacific Railroad at Donaldsonville, Cheneyrille, and Alexandria; along the Southern Pacific at Thibodaux, Schrierer, Houma, Berwick, Morgan City, Franklin, New Iberia, and Lafayette; and at Opelonsas.

It will be noticed that these points are all, excepting Opelousas and the three first-named summer resorts, on main lines of the railroads leading out of New Orleans. They doubtless occur at many other smaller places along these lines and in localities on other railroads leading into Mississippi, Alabama, and Louisiana. Their distribution to -ummer resorts occurs through baggage and clothing as well as in supplies sent from New Orleans to these points.

In the lower part of the city one woman told me that the ants appeared in her house late in June, 190t. Her baby was taken sick soon afterwards and they had a great deal of trouble keeping the ants away from him. The ants seemed especially attracted to the child. perhaps from some odor of the sick room, and would cross coal-oil bands on the bed and on chair legs in order to reach the baby. After the child's death they were eren more persistent in their efforts to reach him. The coffin was set on a stool the legs of which were placed in dishes of water with a coal-oil film. This would deter the ants for only a short time, when some would get on the oil and, others following, there would soon be a bridge of dead ants.

Sereral instances were related where ants dropped from the ceiling in order to reach food or other substances they desired. An experiment was tried with some sugar sirups on a table which stood against the wall. The ants came up the wall to reach the table. When it was remored from the wall they came up the legs. Next morning the legs were wrapped with cloths soaked in coal oil and the table remored some distance from the wall. That day the ants were persistent in their efforts to reach the food, constantly climbing up and down the legs, but only-a ferr attempted to cross the oiled bandages and these were not successful. The following morning the table was well corered with ants. They had gone up the wall orer the first trail and passed on up to the ceiling, then orer that diagonally until they were orer the table, when they dropped down onto it. Tery few ants were noticed returning from the ceiling, but a constant stream of them was going up. At the point where the table had formerly toucher the wall quite a number of ants were clustered, evidently at a loss to know where to go. The ants, in learing the table, usually went down one of the legs and were crossing the coal-oil bandages with apparently 
little or no injury to themselves. Some dropped directly from the table top to the floor.

One large colony of ants, on the ontskirts of a portion of the infester area on Carrollton avenue, had paths running in several directions; over these paths thousands of ants were hurrying all day long. A willow tree standing alone in a very bare piece of hard ground orer 200 feet from the colony was thoroughly infested. The pathway from the colony was about 2 inches wide, going fairly straight through a weed patch, then directly across the barren ground to the tree. The outgoing ants from the colony were usually not laden; a few were noticed carrying ant pupe, and these were followed to the tree, where they entered a hollow in the trunk. Almost all the returning ants had distended abdomens, evidently being filled with the excretions from the plant lice. A few were seen carrying young lepidopterous larva that were dead at the time I found them. To this same nest was traced one large foraging party that was destroying a nest of other ants.

Not only at New Orleans, but at several other towns in the State, I heard complaints of the destruction of flowers by the ants. The calyces and bases of the petals of several kinds of composite ornamental flowers were found to have been so thoroughly destroyed that a slight jar would cause the petals to fall. Lemon blossoms on trees of B. M. Young, at Morgan City, La., were eaten so badly that the trees failed to set fruit. I heard accounts, also, of their establishing colonies of plant lice on the flower buds of shrubs in yards to such an extent that no flowers opened. I found them attending colonies of the "black aphis of chrysanthemum " at Doctor Stubbs's residence, in Audubon Park, and in other yards to such an extent as to dwarf or deform almost half the flowers.

Hard umripened pears left in barrels on a house porch were found several days later to be honeycombed by these ants, almost all the interior being eaten.

Lunch-counter, soda-fountain, candy-store, and fruit-stand proprietors are kept continually on the watch to prevent their stock in trade from being ruined. A grocer in the lower part of the city told me that when the ants first appeared they seemed to come in by thousands in a single day. He stated that he threw away over half a barrel of sugar and several boxes of evaporated fruits.

These ants have driven or killed out all other ants in the regions infested by them. I witnessed two battles between them and other ants on the outskirts of the infested area. The new ant, although much smaller, overcame the other by sheer force of numbers, column after column of them arriving on the scene of battle, while long files were carrying away dead ants, pupæ, and larvæ. 
They are extremely active: the residents of Nerr Orleans have christened them " the crazy ant." since when a column is disturbed it breaks up, the ants ruming aimlessly about in every direction. Professor Wheeler. of the Imerican Museum of Natural History, has rery kindly examined specimens of the workers and states that they appent to be identical with Iridomyrme humitis Mayr. This species has been hitherto reported only from tropical regions. The genus is quite closely related to Tapinoma. but this species can be separated by the presence of a distinct. erect. sharp-edged scale and by the fact that the abdomen does not project forward, nor in any Way conceal this sale. The workers are from $:$ to $2.50 \mathrm{~mm}$. in length. pale brown in color. head and thorax rugose, abdomen shining, but slightly pubescent.

The Yew Orleans trade-men early took adrantage of the annoyances caused by the ant. and now every grocery and drug store in the infested area has for wale one or more " ant killers." " ant poisons." " ant preventives." etc. These consist of tapes saturated with corrosive sublimate: corrosive sublimate solutions to be painted on walls and legs of tables and chairs: hydrocyanic-acid preparations; coal-oil mixtme-: and others having trate names. the compositions of which are kept secret by the manufacturers.

The use of corro-ive-ublimate tapes and of cloths saturated with coal oil appears to be the mo-t -ncec-ful means of keeping the ants anay. The use of carbon bisulphid to destroy the nests will be futile unles it can be taken up br the whole community. A nest will be reoceupied in a few day after having been dosed with carbon bisulphid. and cleaning out the ants in any section will be a waste of time and money unles all other -nrrounding sections are immediately treated.

Mr. Sanderon said that he could corroborate the statements in the paper as to the sererity of the attacks. In Morgan City they were at times simply unbearable.

Mr. Surfacerasked how these ants are diseminated by the methods described. which would presumably apply only to the workers. If the queens were not present they could not become established in the new locality unles the workers reproduce parthenogenetically.

Mr. Titus said that the life history had been little studied and that many of these points were still not clear. but it might be a fact that in this group queens were not alwars necessary to establish colonies.

In the absence of the author, the following paper was read by $\mathbf{M r}$. Gillette: 


\title{
THE COTTONY MAPLE SCALE: AN UNUSUAL OUTBREAK, AND EXPERIMENTS WITH INSECTICIDES.
}

\author{
By S. Arthur Johnson, Fort Collins, Colo.
}

Contrary to general experience the cottony maple scale (Pulvinaria imnumerabilis Rathr.) has done serious injury in Denver for several years past and gives promise of renewed ravages ruring the coming summer. The scale is widely distributed over the city on the soft maple (Acer saccharimm ) shade trees in the parks and streets. In a number of localities the permanent injury has been severe. Two winters ago the time of one man was employed for two weeks cutting out and remoring the dearl limbs from a park covering one block. In this same park last winter the under surfaces of many limbs on the soft maples and black locusts (Robinia psendacario) were literally coated with the scale. Here the Colorado Agricultural College, in conjunction with the superintendent of parks, conducted a number of experiments for the purpose of discovering an effective winter treatment. So far as the writer is aware very little thorough work has been done in this line.

The advantages of a winter treatment are indicated both by the condition of the trees and by the life history of the insect. 'The immense numbers of the pest would make it necessary to spray thoroughly both surfaces of the leares in summer. which is a practical impossibility with trees of dense foliage which are often 30 or more feet in height. Moreover, it would seem that the life history of the insect would necessitate ninere than one application of the spray. Doctor Howard, "in giring the jife history, says:

The soung hatch early in summer. usually in the month of June, but occasionally at least as early as Mas 22. The hatching period usually extends on into early July, but may last until August. *** In the course of a month they undergo a molt and begin to secrete a certain amount of wax from the dorsal surface of the body.

It thus appears quite possible that some of the first-hatched insects may molt and become protected with scales before the last of the eggs have hatched. Professor Gillette has expressed the opinion that after the wax is formed sprays of greater strength will be necessary. The leaves of the soft maple appear to be quite sensitive to the greater strengths of contact insecticides.

\section{EXPERIMENTS WITH INSECTICIDES.}

Shortly after I came to this station a quantity of badly infested maple twigs were received from Colorado Springs. At that time, under the direction of Professor Gillette, I made a number of experi- 
ments for the purpose of determining the effect of insecticides on the insect. The notes I have tabulated belor. The results obtained from these experiments indicated the lines of attack which were followed out a year later in Curtis Park, Denver.

Preliminary laboratory experiment in 1903 for determining the effect of different insecticides on the cottony maple scale.

[Treated January 17, 1903; examined January 23, 1903.]

\begin{tabular}{|c|c|c|c|c|c|}
\hline Insecticide. & Strength. & Alive. & Dead. & $\begin{array}{c}\text { Per cent } \\
\text { dead. }\end{array}$ & Remarks. \\
\hline $\begin{array}{l}\text { Do } \\
\text { Whale-oil soap (hardi } \\
\text { Do } \\
\text { Do } 2 . . . \\
\text { Do } \\
\text { Check }\end{array}$ & $\begin{array}{l}12 \frac{1}{2} \text { per cent kerosene } \\
1 \text { pound to } 1 \text { gallon.. } \\
1 \text { pound to } 2 \text { gallons }- \\
1 \text { pound to } 4 \text { gallons } \\
1 \text { pound to } 6 \text { gallons }\end{array}$ & $\begin{array}{c}44 \\
12 \\
53 \\
512 \\
62\end{array}$ & $\begin{array}{r}67 \\
140 \\
23 \\
-60 \\
55\end{array}$ & $\begin{array}{l}49 \\
70 \\
71 \\
61 \\
90 \\
92 \\
\\
60 \\
92 \\
30 \\
83 \\
47\end{array}$ & $\begin{array}{l}\text { Possibly all dead. } \\
\text { Those in protected } \\
\text { places alive; others } \\
\text { dead. } \\
\text { All dead, except occa- } \\
\text { sional protected ones. } \\
\text { Little, or no effect. }\end{array}$ \\
\hline
\end{tabular}

Results of a second experiment in 1903.

[Treated January 31, 1903; examined February 10, 1903.]

\begin{tabular}{|c|c|c|}
\hline Insecticide. & Strength. & Remarks. \\
\hline $\begin{array}{l}\text { Kerosene emulsion ................ } \\
\text { Do } \\
\text { Whale-oil soap } \\
\text { Lime-sulphur-salt (IIlino is } \\
\text { formula). }\end{array}$ & $\begin{array}{l}50 \text { per cent kerosene. } \\
25 \text { per cent kerosene. } \\
1 \text { pound to } 1 \text { gallon.. } \\
\text { Full }\end{array}$ & $\begin{array}{l}\text { Seems to hare killed all. } \\
\text { Seems to hare killed about all. } \\
\text { Seems not to have killed any, but there } \\
\text { may be different results later. } \\
\text { Seems not to have killed any. }\end{array}$ \\
\hline
\end{tabular}

It will be seen by consulting the tables that the mortality of the untreated scale during the winter reaches probably 50 per cent. This is indicated by the counts on the check branches and those on which the treatments were so reak as to have had little or no effect. The numbers counted in the laboratory experiments were too small to have positive ralues except where the percentage of dead was very high, because the difference in mortality on different twigs is a conspicuous feature on looking orer the hibernating insects.

The only effective remedies appeared to be kerosene emulsion, 25 per cent or more in strength, and whale-oil soap at the rate of 1 pound to the gallon. The laboratory experiments indicated that further tests with kerosene emulsion, rarying in strength from 10 to 50 per cent. and the stronger solutions of whale-soap should be made to ascertain more accurately the location of the "dead line." 
Results of applications of insecticides made in Curtis Park, Denver, for the cottony map'e scale.

[Treated November 23, 1903; examined February 27, 1904.]

\begin{tabular}{|c|c|c|c|c|c|c|}
\hline $\begin{array}{c}\text { No. of } \\
\text { tree. }\end{array}$ & Insecticide. & Strength. & Alive. & Dead. & $\begin{array}{c}\text { Per cent } \\
\text { dead. }\end{array}$ & Remarks. \\
\hline $\begin{array}{r}2 \\
3 \\
4 \\
5 \\
6 \\
7 \\
11 \\
13\end{array}$ & $\begin{array}{l}\begin{array}{l}\text { Kerosene emulsion } \\
\text { do } \\
\text { do do }\end{array} \\
\text { Tobacco stems } \\
\text { Tree soap } \\
\text { Check do }\end{array}$ & $\begin{array}{l}50 \text { per cent oil } \\
20 \text { per cent oil } \\
12 \text { peí cent oil } \\
10 \text { per cent oil } \\
1 \text { pound to } 1 \text { gallon } \\
1 \text { pound to } 3 \text { gallons } \\
2 \text { pounds to } 1 \text { gallon } \\
1 \text { pound to } 2 \text { gallons }\end{array}$ & $\begin{array}{r}\text { None. } \\
\text { None. } \\
1 \\
35 \\
217 \\
\end{array}$ & $\begin{array}{r}\text { All. } \\
\text { All. } \\
73 \\
273 \\
89 \\
\end{array}$ & $\begin{array}{r}100 \\
100 \\
98 \\
88 \\
29 \\
60 \\
25\end{array}$ & $\begin{array}{l}\text { No benefit. } \\
\text { Scales all dead } \\
\text { and shriveled. } \\
\text { A b o t t w o- } \\
\text { thirds dead. } \\
\text { One-fourth dead. }\end{array}$ \\
\hline
\end{tabular}

Results of later applications in Curtis Park.

[Treated February 19, 1904; examined March 1, 1904.]

\begin{tabular}{|c|c|c|c|c|c|}
\hline Insecticide. & Strength. & Alive. & Dead. & $\begin{array}{c}\text { Per cent } \\
\text { dead. }\end{array}$ & Remarks. \\
\hline $\begin{array}{l}\text { Lime-sulphur-salt (Illinois for } \\
\text { mula). } \\
\text { Kerosene emulsion } \\
\text { Do Do } \\
\text { Do } \\
\text { Do } \\
\text { Do } \\
\text { Whale oil soap (hard) } \\
\text { Do Do } \\
\text { Do } \\
\text { Do } \\
\text { Check }\end{array}$ & $\begin{array}{l}50 \text { per cent } \\
33 \text { per cent } \\
25 \text { per cent } \\
17 \text { per cent } \\
12 \text { per cent } \\
10 \text { per cent } \\
1 \text { pound to } 1 \text { gallon }- \\
1 \text { pound to } 2 \text { gallons } \\
1 \text { pound to } 3 \text { gallons } \\
1 \text { pound to } 4 \text { gallons } \\
1 \text { pound to } 8 \text { gallons }\end{array}$ & $\begin{array}{r}87 \\
0 \\
0 \\
5 \\
1 \\
14 \\
299 \\
3 \\
117 \\
26 \\
128 \\
118 \\
256\end{array}$ & $\begin{array}{r}404 \\
310 \\
274 \\
153 \\
229 \\
688 \\
171 \\
563 \\
81 \\
154 \\
154 \\
421\end{array}$ & $\begin{array}{r}70 \\
100 \\
100 \\
98 \\
99 \\
94 \\
69 \\
98 \\
84 \\
76 \\
55 \\
57 \\
62\end{array}$ & - \\
\hline
\end{tabular}

\section{PREPARATION OF INSECTICIDES.}

The kerosene emulsion was emulsified with whale-oil soap. The tobacco stems were very dry when weighed and were boiled one hour in enough water to cover them, after which the concoction was diluted to the strengths given. The tree soap employed was used in the first series of experiments and hard whale-oil soap, purchased at a drug store, in the second. The lime-sulphur-salt wash was prepared according to the Illinois formula and boiled three hours.

\section{APPLICATION OF THE INSECTICIDES.}

Both seneca and vermorel nozzles were used. The latter did good work and is rather to be preferred on account of economy of material. Only the lower branches of the trees were sprayed and in some cases two applications were made on different parts of the same tree. With the lime-sulphur-salt wash two entire trees were treated. 
A glance at the percentage column shows that the effective remedies stand out prominently. They are kerosene emulsion in strengths of over 10 per cent and whale-oil soap at the rate of 1 pound to the gallon. Tobacco-stem decoction and lime-sulphursalt wash appeared to be ineffective. The lime-sulphur-salt wash was especially disappointing. After sereral weeks the scales under it appeared bright and healthy, and it almost seemed as if they enjoyed the protection of an extra covering during the cold weather. The insects take little or no nourishment during the winter and might thus be able to withstand for a time an application which deprived them of their food supply.

As a result of these experiments kerosene emulsion in strengths of 1 to 6 or 1 to 8 was recommended. Applications were made by the park anthorities on Ipril 16. The trees were examined on May 13 by Professor Gillette, who made the following note:

Where Mr. Smith applied kerosene emulsion that was one-sixth kerosene the scales appeared to be all deat orer the greater portion of the trees. Some limbs hare scattering living sales and occasionally limbs were found where the scales rere quite abundant. From the fact that the lice are all dead in places where they were rery abundant, it seems evialent to me that the living lice were those that were not well treated. Mr. Smith was also of the same opinion.

The entire park was not sprayerl last winter, and as a result the infested trees have deluged the whole grove with the scale. Treatment is being made at this writing with kerosene emulsion in the strength of one-sixth lierosene. Judging from twigs sent to the laboratory, the application is all that could be desired, the scales all being killed.

Some scales will doubtless be missed by the spray, but these can be trimmed out as sorn as the max becomes conspicuous in the spring and before the eggs have hatched.

In the absence of the atithor, the following paper was read by the secretary :

\section{SOME EXPERIENCES WITH PULVINARIA.}

By Howard Evarts Weed, Chicago, Ill.

The entomological literature regarding Pulvinaria innumerabitis Rathv. contains so many misleading statements that it is certainly time for attention to be called to them. The two principal misstate- 
ments are: (1) That "the insect is rarely injurious in two consecutive years," a and (2) that the remedy consists in a "summer spraying with a dilute kero-ene-soap enulsion." " $b$ These, or similar statements, have appeared in every article heretofore written on this subject, and during the past summer I have been shown a score of letters from entomologists making these statements.

Early in June of this year I received a note from the chairman of the North Shore Park Commission stating that a committee of the Rogers Park Improvement Association had been appointed to devise means for the elimination of the cottony maple scale. This committee asked me to investigate the subject and undertake the work of spraying in the territory of Rogers Park-a Chicago suburb, but within the city limits. Upon investigation I found the soft or silver-leafed maple (Acer dasycorpum) to be the principal shade tree here, and every tree was covered with the white egg masses of the Pulvinaria. 'These insects have been present in this territory in large numbers each year since 1856 at least. In 1897 a large number of the trees were severely pruned, the supposition being that this would eliminate the scale, and the beauty of the trees was thus largely spoiled. The insects have been so numerous that they have destroyed the lower and smaller branches and killed hundreds of trees outright. The work of the Pulvinaria, together with the pruning in an effort to get rid of it, has caused the trees to look anything but beautiful. This same condition exists at other places around Chicago, especially at Eranston and Irving Park. To soft maples are now being planted in this territory on account of the ravages of the insect.

During the past summer the eggs were slow in hatching, as the season was very backward. Up to June 25 practically no eggs were hatched. Two quite warm days occurred about July 10, and this served to bring them ont. At this time the larger limbs and branches were fairly alive with the young going from the egg masses to the leaves. Persons pruning the trees at this time would get the insects in the hair and upon the person and clothes in the same manner as chicken mites. The insects rere scattered to surrounding shrubs and flowers in various ways, erpecially by the falling of the weakened leares, so that during August they were to be found on practically every shrub.

The list of plants upon which I have found the Pulvinaria is considerably larger than heretofore given. Of course a distinction should be made as to what constitutes the normal food plants, or those upon which it occurs in both summer and winter forms and the food plants upon which it may have drifted for the summer. My own observation gives the following as the normal food plants of the 
species, those most affected heing mentioned first in the list and those least affected last: Soft or silrer-leafed maple (-Lcer dasycarpum), box elder (Acer negmido). linden (Tilia). Tirginia creeper (AmpeTopsis quinquetolia). bittersweet (Celastmescandens), sumac (Rhus), grape (Titis), and willow (Salix). The summer food plants observed have been sipian Ten Hontteii. s. arguta. and S. prunifotiu: Phitadelphus arandifloms and P. coronarius: Cormus mascula.

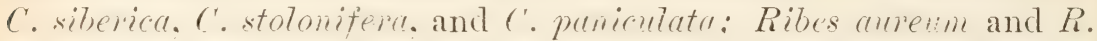
sanguineum; Hydrangea: Rudbeckia: Symphoricarpus racemosus and s. rulgaris; Srringa. sereral rarieties: Viburnum. several varieties. I hare not found it upon either the sugar maple (Acer saccharimini ) or the Norway maple (A. platanoides), even where these trees were surrounded by the soft maples. except in such small numbers as to be very inconspicuous.

The work of spraying began the middle of July and continued until september 1 . The work was done under my constant supervision by some senior student of the Michigan Agricultural College. Two outfits on wheels with hand pumps were used. these being the most convenient in getting around from tree to tree. Both the vermorel and bordeaux nozzles were nsed. The trees sprayed were mostly quite large. requiring a $6(0$-foot hose to reach the top. The operators wore fireman s oiled suits and began the spraying at the top by climbing the tree. finishing at the bottom limbs. 'The work was thoroughly done, so far as possible erery leaf being corered.

When I first took hold of this mork I had expected to kill the insects readily " with a meak kerosene emulsion." All the entomologist-sid this was the remedy, and my own fourteen years" experience in practical spraying work told me the same thing. I began with an 8 per cent kerosene emulsion. which was increased within a few days to 10 per cent, then to $12 \frac{1}{2}$. and finally to 15 per cent. Practically none of the insects were killed with either the $\delta$ or 10 per cent emulsions. An examination at Professor Forbes's office of leares sprayed with $12 \frac{1}{2}$ per cent. some days after. showed that something over 50 per cent were killed. but the death of some of these was doubtless from natural causes. The 15 per cent emulsion killed the greater portion of the Pulrinaria, but as this strength took practically all the leares off the box elcters, all from the lindens, and fully one-half from the maples, the remedy was at least equal to the disease. A 10 per cent emulsion is all that can with safety be applied to the linden or box elder, while a $12 \frac{1}{2}$ per cent is all that can safely be applied to the maple.

In this connection some experience in the making of the emulsion may be of interest. With 2,500 large trees to spray, scattered orer a large territory, the matter of making the emulsion was of considerable importance. But, as "necessity is the mother of invention," it 
so happened that a sample of soft soap containing 50 per cent of naphtha was sent me for trial. A single trial convinced me of its merits, and 500 pounds were ordered. This soap readily dissolves in cold water and takes up the kerosene very readily when pumped through a bucket force pump. I found that the best proportion was 1 pound of the soap to $2 \frac{1}{2}$ gallons of kerosene. In the making of a 10 per cent emulsion in this way I first dissolved 1 pound of the soap in $2 \frac{1}{2}$ gallons of water. I then added $2 \frac{1}{2}$ gallons of oil and pumped the whole through a bucket sprayer and added it to 20 gallons of water.

Toward the end of the spray work Professor Close, of the Delaware station, visited me and told of the experiments which he had just completed with the hydrated-lime emulsion. I obtained some of the hydrated lime at once, intending to give it a trial, but as the season was then rather late and my landscape work took up my entire time, I was unable to conduct the desired experiments. During the coming spring I expect to spray extensively with the hydrated-lime emulsion.

I have endeavored to ascertain the experience of the other entomologists with Pulvinaria so as to compare results, but without exception the reply has come, "I have had no experience with this particular insect." My experience leads me to conclude that the Pulvinaria is as hard to down as the San Jose scale. It also teaches that we can not reason from analogy as to the remedies for insects. If we have had no personal experience with an insect we really know nothing about it, and we should be extremely careful in making statements recommending remedies. The comment of a resident of Rogers Park, after the receipt of a letter reading "remedies are not necessary, as the insects are rarely numerous," was, "He can't make me believe that." I trust that no such letters will hereafter be written.

Mr. Titus said that there had during the past few years been much trouble from Pulvinaria in the Chicago city parks. He had risited there frequently and had found employees using sponges saturated with kerosene. These sponges were rapidly passed along the infested limbs. Apparently the method was very efficient, so far as it reached the scales. Those on the leaves were, of course, missed.

\section{AFTERNOON SESSION, FRIDAY, DECEMBER 30, 1904.}

The president called the meeting to order at $2 \mathrm{p}$. m. The committee on nominations reported as follows:

For president, H. Garman, Lexington, Ky.

For vice-president, E. Dwight Sanderson, Durham, N. H.

For second vice-president, w. L. Washburn, St. Anthony Park, Minn. 
For secretary-treasurer, H. E. Summers, Ames, Iowa.

For members of the council. C. L. Marlatt, Washington. D. C.; Herbert Osborn, Columbus, Ohio.

Respectfully submitted.

M. V. Slingerland, Chairman. HERBERT OSBORN.

J. L. PHiLlips.

On motion, the secretary ras instructed to cast the ballot of the association for the officers nominated. and they were duly elected.

The committee on membership recommended the following for membership, and on motion they rere declared elected:

For foreign members: H. A. Ballou. Imperial Department of Agriculture. Barbados, West Indies; W. E. Collinge, Lnirersity, Birmingham, England.

To be changed from associate to actire members: F. C. Bishopp. Washington, D. C.; C. T. Brues, Washington, D. C.; A. A. Girault, Washington, D. C.; S. Arthur Johnson. Fort Collins, Colo.; G. W. Martin. Nashrille, Tenn. : E. P. Taslor, Urbana, Ill.

For actire members: J. C. Crawford, jr., Dallas, Tex.; Edgar L. Dickerson, New Brunswick. N. J. : C. O. Houghton. Newark. Del. : W. J. P'hillips. Crbana, Ill, : W. Dwight Pierce, Dallais. Tex. : George I. leeves, Witshington, D. C. : C. E. Sanborn, College Station. Tex. : H. L. Viereck. Ner Haren. Conn. : B. H. Walden. New Haren, Conn.

For associate members: Gordon MI. Bentley, Raleigh, N. C.; F. D. rouden, Washington. D. C.: Harper Dean, jr.. Blackshurg. Ta. : Enos B. Engle. Harrisburg, Pa.; W. A. Hooker, Amherst, Mass.; John 'Isaac, Sacramento, Cal. ; A. D. MacGillirray, Cornell Tnirersity. Ithaca, r. Y.: Leslie Martin. Washington, D. C.; A. C. Morgan, Dallas Tex.; E. F. Phillips, Philadelphia, Pa.; H. J. Quayle. Bexkeley, Cal. John II. Rankin, Washington. D. C. : W. A. Riles, Ithaca, N. Y. ; J. G. Sanders, Washington, D. C.

Jofix B. Sunth, Chairman.

C. E. Chambliss.

E. S. G. Tites.

The folloming rere reported as having been added to the list of active members during the rear by the secretary. in accordance with the constitution:

Frank Benton. Washington. D. C.: Mel T. Cook. Santiago de Jas Tegas. Cuba; D. L. Van Dine, Honolulu, Harraii.

The committee on resolutions, Messrs. Felt. Burgess. and Tashburn, reported resolutions thanking the Secretary of Agriculture for his courtesy in publishing the proceedings of previous meetings, and asking him to continue that courtesy : and thanking the Unirersity of Pennsylvania, the Zoological Society of Philadelphia. the Academy of Natural Sciences of Philadelphia, and the American Entomological Society for farors and courtesies extended.

The secretary called attention to the limitation of size of the proceedings and suggested the appointment of a committee to edit these, with power to require the preparation of abstracts from members 
where it was deemed necessary. On motion the president appointed as such committee Messrs. Summers, Smith, and Marlatt.

On motion the following amendments to the by-laws, laid on the table at the last meeting, were adopted:

That in the interpretation of the paragraph of the constitution regarding the election of new members it be understood that an " economic entomologist" is a person who has been trained in entomological work and whose known work or published papers show him to be capable of conducting original work in economic entomolog.

That the term "practical entomologists," referring to associate members, be held to indicate persons who have done general work in entomology and who Lave, by published papers or otherwise, given evidence of their attainments in such work.

That associate members be listed separately in the published roll, or the fact that they are associate member's be indicated in the list.

The committee on nomenclature made the following recommendations :

That there be published a list of species, siving a single name, the one current for a large part of the world or throughout the range of the species, and that every entomologist be urged to use this name, and this only, for an English name in his publications, and that the Latin name be included but once, and in as inconspicuous a manner as possible.

That copies of this list be furnished to the learling agricultural papers of the country, and that the editors of such papers be requested to use these names, and these only, in all articles referring to such species.

That a second report, to inciude other names in current use, but which are less firmly established, less definite in aplulication, or limited to less territory, be privately distributed among the members, the name first given to be the preferred name and its use alone urged wherever the entomologist believes it can be dowe with due regard to his constituency, and a second local or other name used where deemed neressary for the service of his State.

That in choice of scientific names for any species in purely economic papers, care be taken not to change from a long-used and current name to a new or resurrected mane until its continual use in scientitic papers or adoption in a monograph or catalogue of authority shall furuish evidence that it will remain in use.

LIST OF NAMES RECOMMENDED FOR EXCLUSIVE USE.

American cockroach, Periplaneta americana Linn.

Angoumois grain-moth. cerealella L.

Apple-leaf skeletonizer, Canarsia hammondi Riley.

Apple-aphis, Aphis pomi $\mathrm{L}$.

Army-worm, Heliophila unipuncta Haw.

Asparagus beetle, Crioceris asparagi L.

Bag-worm, Thyridopteryx ephemeraformis Haw.
Bean-weevil, Bruchus obtectus Say. Bedbug, Clinocoris lectularia L.

Boll-weevil, Anthonomus grandis Boh. Boll-worm, Heliothis obsoleta Fab.

Brown-tail moth, Euproctis chrysorihoea L.

Buffalo tree-hopper, Ceresa bubalus Fab.

Cabbage aphis, Aphis brassice $\mathbf{L}$.

Carpet-beetle, Anthremus scrophulario. I.

Carpet-moth, Trichophaga tapetzella Linn. 
Cattle-tick, Boophilus anmulatus Say. Cecropia-moth, Samia cecropia L.

Chinch-bug, Blissus leucopterus Say.

Clover-hay worm, Hypsopygia costalis Fab.

Codling-moth, Carpocapsa pomonella $\mathrm{L}$.

Colorado potato-beetle, Leptinotarsa decemlineata Say.

Cotton-stainer, Dysdercus suturellus H.-Sch.

Cottony maple-scale, Pulvinaria innumerabilis Rathr.

Cottony cushion-scale, Icerya purchasi Mask.

Fall canker-worm, Alsophila pometaria Harr.

Fall web-worm, Hyphantria cunea Drury.

Granary-weeril, Calandra granaria L. Grape-phylloxera, Phylloxera vastatrix Planch.

Grpsy-moth, Porthetria dispar L.

Harlequin cabbage-bug, Murgantia histrionica Hahn.

Hessian-fly, Mayetiola destructor Say. Honey-bee, Apis mellifera L.

Hop-aphis, Phorodon humuli Schrank. Horn-fly, Hamatobia serrata R.-D.

Horse bot-fly, Gastrophilus equi L. House-fly, Musca domestica L.

Indian-meal moth, Plodia interpunctella Hübn.

Larder-beetle, Dermestes lardarius $\mathbf{r}$.
Leopard-moth. Zeuzera pyrina L.

Iediterranean flour moth, Ephestia kuehniella Zell.

Onion thrips, Thrips tabaci Lind.

Oyster-shell scale, Lepidosaphes ulmi L.

Peach-borer, Sanninoidea exitiosa Say.

Peach-scale, Eulecanium persica Fab.

Pear-slug, Eriocampoides limacina Ratz.

Pea-weeril, Bruchus pisorum L.

Plum-curculio, Conotrachelus nenuphar IIbst.

Plum-gouger, Anthonomus prunicida Walsh.

Ricè-reevil, Calandra oryza L.

Red-legged locust, Melanoplus femurrubrum DeG.

Rose-chafer, IIacrodactylus subspinosus Fab.

San José scale, Aspidiotus perniciosus Comst.

Scurfy scale, Chionaspis furfura Fitch.

Silkworm, Bombyx mori Linn.

Spring canker-worm, Paleacrita vernata Peck.

Squash-bug, Anasa tristis DeG.

Striped blister-beetle, Epicauta vittata Fab.

Tarnished plant-bug, Lygus pratensis L.

Tomato-worm, Phlegethontius sexta Joh.

Nore.-The list of common names of insects published above differs radically from that in use in the Bureau of Entomology as regards the system of hyphenization. hence it should be understood that it is not authorized by this Bureau.-ED.

Mr. Sanderson spoke of the possibility and desirability of there being some publication which could be regarded as the semiofficial organ of the Association and in which members could publish economic notes and papers. It was mored and seconded that a committee of four be appointed to consider the feasibility of making an arrangement with Entomological News, similar to that now existing between Science and the American Association for the Adrancement of Science.

The motion was carried, and the chair appointed as such committee Messrs. Skinner, Sanderson, Smith, and Titus.

The following paper was presented: 


\section{LABORATORY EXPERIMENTS WITH CARBON BISULPHID.}

By F. L. WAshburn, St. Anthony Park, Minn.

[Withdrawn for publication elsewhere.]

The committee on bibliography presented the following resolution relative to the publishing of a bibliography of current economic entomology :

To facilitate the more prompt distribution of information on the literature of economic entomology, the Association of Economic Entomologists respectfully request the Office of Experiment Stations of the United States Department of Agriculture to enlarge its present bibliographical work in this direction, in accordance with the following suggestions:

(1) That the bibliography now being published by the Office of Experiment Stations in the Experiment Station Record be issued also as a separate, and that a copy be mailed to each member of the Association.

(2) That copies of this bibliography be printed on stiff paper in such form that they may be cut apart and used as a card catalogue, a copy of this style of issue to be sent to each member of the Association desiring it.

(3) That the monthly reports be combined at the end of each year, properly classified by subjects, and reissued as a special bulletin with full index. This rearly bulletin to be published by the Office of Experiment Stations or by the Bureau of Entomology, as may be arranged, and to be in effect a continuation and supplement of the Bibliography of Economic Entomology, published hitherto from time to time by the Bureau of Entomology.

\section{L. Marlatt, \\ H. T. Fernald, \\ E. D. SANDERSon,}

Committee.

On motion the report of the committee was adopted.

Mr. Sanderson reported for the auditing committee that the report of the treasurer has been examined and found correct. On motion the report of the committee was adopted.

The following paper was read:

\section{SOME NOTES ON THE FUMIGATION OF HOUSEHOLD INSECTS AND THEIR EGGS WITH HYDROCYANIC-ACID GAS.}

By J. L. Phillips, Blacksburg, Va.

Some buildings used as living apartments near Blacksburg were found in the early summer of 1904 to be plentifully supplied with Clinocoris lectularia Linn. in all stages of development. It was finally decided to fumigate one of these buildings with hydrocyanicacid gas. The building is a four-story brick and contains approximately 150,000 cubic feet of air space distributed in eight sections. The windows were tightly wedged, and then calked with old cloth to prevent as much as possible the escape of the gas. The quantities used were 80 avoirdupois pounds of potassium cyanide, 96 pounds of sulphuric acid, and 240 pounds of water. The water and acid were first put into the jars, of which there were one or more to each section, 
and the cyanide was weighed out and placed by the jars. Everything being in readiness, the attendants put in the cyanide by beginning on the upper floors and passing rapidly to the lower floors. The doors were then closed, locked, and kept so for two days. Brick walls being porous, and the windows not as tight as desired, much of the gas escaped. Persons walking within 100 feet of the building, on all sides except that from which the wind was blowing, could detect the odor of the gas the entire time. This made it desirable to leare the building closed for a period longer than usual. Whan the building was opened two days later most of the gas had escaped.

The insects were very abundant and in all stages of growth, and in many cases the egos almost coated the slats on the beds. Many of the egos had hatched several weeks earlier, howerer, and it was necessary to pick them orer carefully to find good ones for observation. 'This was done. and 10 apparently sound egos were taken to the laboratory and placed in "stender" dishes for examination before the charges were placed. The day after the building was opened 101 r.gs that had not hatched were collected, and these also were placed in "stender" dishes for examination. All of the eggs in the first lot (i. e.. those taken before fumigating the building) hatched within ten days. The egos collected after the building was fumigated rere (xamined every few days for two weeks. but not a single one hatched, and they shriveled up and lost their plump appearance after a few weeks.

In examination of the insects the day after the building was opened proved that all were read and no eggs appeared to hatch afterward, although examinations were made frequently for a period of sereral weeks. Though this work was done in sune, scarcely an insect could be found in the building as late as December 22. This appears to be conclusive evidence that fumigation with hydrocyanicacid gas will destroy some classes of insect eggs. It is likely to be most effective on those with a large micropyle, like that of the eggs in question, and might not be effective on those with heary shells suited to stand weather conditions in the field. We are now arranging to study its effect on the eggs of the scurfy scale (Chionaspis furfura Fitch).

Rooms used for storing food products have been treated by fumigating with hydrocyanic-acid gas under our directions also. These rooms had become seriously infested with the croton bug (Blattella aemanica Linn.). Before fumigating these rooms all food products that had been opened, such as butter, lard, etc., in fact, all materials with a moist exterior, were remored from the building. Such materials as boxed oatmeal, coffee, flour. sugar, canned goods, sealed packages of preserves, etc., were left inside. 
The charges were placed at night after the workmen had left, but one room above was not fumigated. The next morning, after airing the building for a couple of hours, the insects were brushed up and destroyed. Quite a number of these insects were found on the upper floor where no charge was placed. They appeared to have been stupefied, and staid in that condition till they could be swept up and destroyed.

Mr. Sanderson had found such fumigation for fleas effective, even under circumstances where eggs must have been present.

Mr. Titus reported, however, that he had known instances where even two or three trials had failed to eradicate fleas.

The following papers were then read:

\section{INSECTS COLLECTED FROM THE FLOWERS OF TREE AND BUSH FRUITS.}

By W. E. Britton and Henry L. Viereck.

[Withdrawn for publication elsewhere.]

A DESTRUCTIVE PTINID NEW TO NORTH AMERICA.

By James Fletcher, Ottava, Canada.

[Withdrawn for publication elsewhere.]

INJURIOUS INSECTS OF THE YEAR IN CANADA.

By James Fletcher, Ottawa, Canada.

[Withdrawn for publication elsewhere.]

The following paper was then presented:

THE AMOUNT OF INJURY FROM THE COTTON BOLL WEEVIL.

By E. Dwight Sanderson, Durham, N. H.

[Withdrawn for publication elsewhere.]

\section{THE COFFEE LEAF-MINER (LEUCOPTERA COFFEELLA Stain.).}

By Mel. T. Cook, Santiago de las Vegas, Cuba.

Probably the greatest enemy of coffee in the IVest Indies, and especially in Cuba, is a small moth, the coffee leaf-miner (Leucoptera coffeella Stain.). According to the Annual Report of the Office of Experiment Stations (1903), United States Department of Agriculture, from 20 to 40 per cent of the leaves on each tree in Porto Rico were affected. The coffee on the farm of the Cuban experiment sta25524-No. 52-05 м- 7 
tion consisted entirely of small trees and these were seriously affected. Examination of trees on neighboring farms showed that frequently as much as $\check{5} 6 \frac{1}{2}$ per cent of the leares were affected and that those plants growing in the shade, or very clese together, were more seriously affected than those in the open. Howerer, the small trees upon the experiment station farm were suffering more than the large trees upon the neighboring farms.

\section{LIFE HISTORY.}

The adult insect is about 2.5 millimeters in length and of a silvergray color, tipped with black on the posterior end. When not in flight the rings are folded close to the body. The length of life in the adult stage is probably not more than forty-eight hours, and it is improbable that the insect trarels to any great distance, unless carried by air currents. Within twenty-four hours after emerging from the pupa the female insect punctures the upper surface of the young leaf and deposits her eggs. In fact the adults usually emerge from the pupa during the night and deposit their eggs during the following night. It is possible with the unaided eve to see the small slits in the leares, and they are clearly visible with the aid of a small hand lens. Within four or five days small black spots surrounding the punctures make them clearly risible to the unaided eye and indicate that the eggs hare hatched and that the larra are working within the mesophyll of the leaf. The larra lives within the mesophyll of the leaf for about three weeks, causing large, black, irregular spots, which indicate the area through which the mesophyll has been destroyed. Frequently the punctures are so close together that the galleries become united into one very large area. In some cases every leaf on a plant is affected and many of them are entirely destroyed. Young trees are often entirely defoliated.

After about three reeks within the leaf, the larræ cut their way out through the upper epidermis and in a very short time seek a protected place on the under surface of the leaf and pupate. The larvæ are 3 to 4 millimeters in length, and in pupating first weare a delicate web in the form of a letter $H$ with a very broad crossbar. Between this web and the surface of the leaf the small pupa is formed. The web and the pupa are rery delicate and are so placed on the under surface of the leaf that they are protected from the excessive rains of the rainy season. Within three to seven days the adult moth comes from the pupa, and the life cycle is complete.

TREATUENT.

The location of the larva within the leaf makes any treatment at this stage practically impossible. However, the delicate character of the pupa furnishes a vital point for attack, and experiments were 
commenced on August 15, using a kerosene emulsion made with 1 part of kerosene, 1 part of whale-oil soap, and 8 parts of water. This was applied to a few plants to note the effect of the emulsion upon the plants. A few applications showed practically no effect, but repeated applications showed the burning of small spots, and also the burning of the tips of the leaves. However, the injury is not sufficient to be of any great importance.

An experiment to demonstrate the effect of the emulsion upon the pupæ was conducted as follows: Two lots of leaves were selected on which were a large number of pupæ. One lot was treated with the emulsion and the other not treated, and both lots put into breeding cages. From the leaves not treated a large number of insects were hatched, while from those treated only two emerged.

Accordingly, on August 18, experiments were commenced upon the coffee on the Experiment Station farm. The coffee field contained 231 plants, ranging from 6 inches to 6 feet in height and well shaded by bananas. All the plants were badly affected at this time. At first the plants were sprayed on Mondays and Thursdays. This was continued until October 3. After that date they were sprayed on October $13,17,21,26$, and 31 , and on November 5 . The trees were numbered, and a careful record was kept of the number of affected leaves on each tree. From time to time the injured leaves were picked from such trees as were entirely free from recent attacks. Care was taken not to pick the leaves from a tree until it was evident that the leaves had been deserted by the larva. These leaves were placed in breeding cages and careful records were kept of the number of adults which came from them; thus we know that only a very few insects were removed in this manner.

The picking of these deserted leares facilitated the work in two ways: (1) The absence of the old leaves made it very much easier to look for newly affected leaves; and (2) trees that were not affected were not sprayed.

For the first six weeks the trees yielded to the treatment very slowly, and September 26 only about one-third of the trees were unaffected. After that date the trees yielded to the treatment more rapidly, and on November 5 they were absolutely free from the insects and were in excellent condition. The small trees responded to the treatment much more rapidly than the large ones.

The writer is reasonably sure that the treatment above described is a good one, but it is impossible at this time to say how effective it will prove, owing to the fact that at this season of the year the insect enters a quiescent period which prevents our continuing the experiments or determining to what extent the reduction was due to natural causes and to what extent to our treatment. 
The following paper was presented:

\section{GYPSY MOTH AND BROWN-TAIL MOTH CONDITIONS DURING 1904.}

Bg C. L. Marlatt, Washingtom, D. C.

[ Tithdramn for publication elsewhere. $\left.{ }^{a}\right]$

The following two papers were read by title:

\section{BLACK-FLY STUDIES.}

By A. F. Coxbadi, College Station, Tex.

The blacis-Ay (simulimm renustum say) is responsible for much annoyance in many part of $\mathrm{Xer}$. England. especially about inland summer resorts. For some time it has threatened the business of summer hotels in such localities. This pest becomes tronblesome about May 1 in couthern New Hampshire and about May 20 in the northern part- of the state. according to data gathered from different hotel managers interested in the extermination of the scourge.

There is no distinct definition of broods: all stages can be found during the entire snmmer. The life history lasts from fire to nine week-. depending upon the conditions of the breeding places. Shallor. sunlit water rippling orer a pebbly botton forms the ideal breeding ground. The first experiment - for the purpose of exterminating this insect that rere mate in Yew Hampshire were at Dixrille Yotch. in the northern part of the state. The results rere recorded in the -ixteenth annual report of this Association. Since that time experiments have been continued by the writer in sereral parts of the State. all of which go to show that this species can be reduced to an inconsiderable pest in all localities where it occurs.

The methods of extermination consist: (1) In applying phinotas oil to the breeding grounds: (立) scrubbing with stable brooms where the breeding place corers a small area. and especially when the bottom of the stream is composed of solid rock: (3) damming streams; (4) raking with iron rakes.

The last three methods are to be employed when there is danger of lilling the fish in such streams as feed lakes reserved for fish culture.

The first oil experiments rere conducted at the Hotel Balsoms, Dixrille Yotch. X. H., in the waste way of the hotel lake. which is the source of Mohark Creek. The breechng ground from which the hotel $\pi$ as infested $\pi$ as about is feet $\pi$ ide and 20 feet long in the sunlit waters of the waste way. Here the inmature stages were present at the rate of $6 \pm$ to the square inch. making a total of about 
$1,000,000$ specimens. With one-half gallon of oil this breeding place was destroyed, whereupon almost complete relief at the hotel followed.

In shallow streams several feet wide and half a mile long the hottoms were so densely covered with larvæ as to give them the appearance of a dense covering of moss. Here sufficient black-flies emerged daily to make life unbearable for an entire community. It required only a few minutes to put dams across the streams to check and deepen the water, as a result of which the larvæ and pupæ died.

In Mount Washington brook the problem presents a different aspect. Damming would be out of the question in most places on account of the boulders and the great velocity of the current. Miles of such breeding ground can be swept with a stable broom or raked with iron rakes in one day. When such larvæ are loosened and carried to deep water, they will die, but where shallow, noninfested water is ahead the operations may simply transfer the breeding places. If in such cases a cheese-cloth net is stretched across the stream, nearly all larvæ can be captured. If a stick pointed at one end is fastened to each end of the cloth, it can easily be adjusted to streams of any width by winding.

Through experiments made at Dixville Notch and at Durham, N. H., it was found that a gallons of oil poured in at the source of a stream averaging 10 feet wide and containing many shallow breeding places wonld kill so many of the larva as to leave only an inconsiderable number for a distance of $3{ }_{+}^{1}$ miles, and the water at the end of a mile would not be too offensive for cattle to drink. Fish apparently escaped down the stream.

As this species will shift its breeding grounds, it is not advisable to make permanent dams, but instead cheap water gates may be constructed which can be opened and closed at will.

\section{THE FUMIGATION OF A FRUIT HOUSE FOR CONTROLLING THE CODLING MOTH.}

By A. F. Burgess, Columbus, Ohio.

Many larræ of the second brood of the codling moth (Carpocapsa pomonella Linn.) (lo not energe from the fruit until after it is picked and placed in storage; hence it is usually possible to find cocoons in the fruit boxes or in crevices in the fruit house during the spring. Last April an examination of the boxes in which apples were stored in a fruit house at Delaware, Ohio, disclosed the fact that many larre were present within their cocoons, and, as the building was. well constructed, an excellent opportunity was offered for testing the effect of hydrocyanic-acid gas on this insect. After removing the fruit the empty boxes were allowerl to remain in the house 
and the doors and rentilators trere kept open for sereral dars, so as to allow it to become as rarm as possible. in order to render the larræ more actire.

The maximum temperature from April 25 to May 12. the date when the house was fumigated. was $s t^{\circ}$ and the minimum $33^{\circ} \mathrm{F}$. May 11. the night before the treatment was applied. the thermometer dropped to $33^{\circ}$. but rose rapidly the following dar. registering $80^{\circ} \mathrm{F}$. in the afternoon.

Before charging the house. my assistant. Mr. Strezer, who mas sent to do the work. examined many cocoons. and actire larra. but no pupæ, were found.

The formula used ras 1 ounce of potassium cranide 98 per cent pure. 1 fluid ounce of suiphuric acid. and 8 fluid ounces of rater to each 100 cubic feet of space. As the house measured 32 by $2 \pm$ by 14 feet. $6 \frac{3}{4}$ pound of cranicle mere required: this was dirided into three equal parts and placed in separate jars. The rentilators mere tightly closed and the house charged at 3 p. m.. and the door mas opened at the expiration of trenty hours. The odor of gas mas then rery strong: and, after airing for one hour. Mr. Strezey made an examination of cocoons taken from -ereral boxes. Sixty-nine worms were remored and placed in a jar. and as about one-third of these shored sign of life when they rere taken the house was closed and allowed to remain so for orer a week.

An exanination of the $\pi$ orm - in the jar. which was made fire hours after ther were taken. showed that 39 rere alire and 30 mere apparently dead. I final examination made June o gare the following data: 28 worm- and 3 pupa dead. and 1 larra. 6 pupa. and 23 moths alire. Eight larræ had escaped from the jar.

Taking this count as a basis. it is erident that the gas killed less than 4.) per cent of the rorms. In remoring the larra from the boxes. it was alnost impossible to prevent injuring the cocoons. and in many cases the larra placed in the jar left the old cocoons and spun entirely netr ones. This mould undoubtedly have some influence on the death rate. and under normal conditions. where the cocoons were undisturbed. the treatment rould not be as effective as in this instance.

In examination of cocous in the fruit hou-e May 26 shored that less than $t$ per cent of the larra were dead. although the house had been tightly closed sine the day it $\pi$ as first aired out. and the odor of the gas ras still rer' perceptible. Computing the price of the cranir?e at 30 cents and the acid at 5 cents per pound. the cost of this treatment was $\$ 2.36$. Had it been effective in destroring the larra it mould have furnished a simple and comparatively cheap method of treating fruit houses and rould have been preferable to the use of screens on the door and rentilators. which are liable through carelessness or accident to be left open and gire the moths an opportunity to escape. 
Fumigation for a longer period may be satisfactory, but from the above experiment it appears that screens should be used.

The following paper was presented:

\section{THE IMPORTATION AND BREEDING OF HONEY BEES OF VARIOUS TYPES.}

By Frank Benton, Washington, D. $C$.

In these later times when the tendency is to specialize more and more in all lines of industry, there are among bee keepers many who devote themselres to one particular line of their pursuit, such as the production of comb honey to the exclusion of extracted honey, or, on the other hand, to the production of extracted (or liquid) honey wholly; others turn the whole strength of their apiaries to the rearing of queen bees of various breeds, which are supplied to those engaged in honey production; others push the multiplication of their colonies at the expense of honey production, in order to have full colonies of bees to sell, either singly, in lots of 100 colonies, or even whole carloads, which are shipped into great honey-producing regions to yield tons upon tons of beautiful nectar for eastern and foreign markets. Then we have the medium-sized and smaller apiaries, many of which are devoted to two or more of these lines of work, some even combining all of them.

It would seem quite natural that if any difference in traits could be discovered between various breeds or varieties of honey bees great care would be taken to propagate those types possessing qualities which fitted them in a more eminent degree than others for any particular purpose desired to be accomplished, and, in truth, exactly this has been done. Bees have been found which are naturally more suited to a given purpose than are other types, which, however, are equally valuable in still different lines. In fact, the differences among bees are exactly comparable to those noted by the raisers of other farm stock. Among horses there are the large cart horses and Percherons for use as draft animals, the fleet Arabian for the turf, the carriage horse, the general-purpose horse for the farm, etc.; among cattle the Jersey, Alderney, and Holstein for producing milk and butter, the shorthorn as a beef animal; the shorthorn and Devon as draft animals; and similarly with sheep and swine; while even a poultry raiser has his egg breeds and meat breeds, fancy fowls. and general-purpose fowls. It is, therefore, small wonder that for more than forty years past great efforts have been made to secure the rarious types of honey bees found wild, and cultivated to a greater or less extent, in various regions of the earth.

Although about a score of types, more or less distinct in markings, qualities, and habits-some of them no doubt deserving varietal rank, 
others perhaps to be regarded only as subrarieties or even to be looked upon as mere artificial breeds-have been obtained and tested, there still remain great regions yet to be explored in this respect. The honey bee is believed not to have been a native of the New World, so that in the unexplored portions of South America no varieties nor new species of the genera Apis, Megapis, nor Micrapis are to be looked for. The interior regions of Africa may yet present some new types. It is possible, although hardly probable, that Australia may possess some. The field in the East Indian Islands, however, is far inore promising, while the great central regions of Asia have not been touched.

\section{IMPORTATIONS OF VARIOUS BREEDS.}

The first importations of bees were doubtless made from England in early colonial times, and perhaps from Holland and Spain. These were the common black or brown bees so generally spread throughout the Eastern States previous to the middle of the last century, but which only reached the Iracific coast in the fifties. They were folIowed by the introduction, in the early sixties, of the yellow race from Italy, imported by the United States Department of Agriculture. Then followed. in 1880, Cyprian, Syrian, and Palestine hees, brought from their respective native lands by the writer and Mr. D. A. Jones, of Canada. In 1883 the peculiar type known as "Carniolan" bees, from the province of Carniola, in southwestern Austria, was introduced in large numbers by the writer. A few queens of this race had reached this country some years before, but they were not multiplied to any extent, hence the race had gained no hold here previous to my own extensire importations of 1883 .

Just as happened in the case of the Carniolans, a small number of Caucasians had reached America a decade or more before their extensive introduction: but, quite in the same manner as occurred with the earlier importations of Carniolans, the efforts attracted no general attention and the cultivation of Caucasians was neglected, resulting, of course, in their complete disappearance. About 1900, however, Rauchfuss Brothers, of Colorado, with the assistance of German shippers, made fresh importations. The writer's importations direct from the Caucasus followed these, and last year the United States Department of Agriculture, at my suggestion, imported still more. As ret, howerer, the Caucasians exist in America in but limited numbers.

QUALITIES OF THESE TYPES.

Common black or brown bees.-This familiar type possesses some excellent traits, such as hardiness, willingness to enter surplus honey receptacles, and activity luring abundant honey flows; but, united with these traits, is a greater disposition to rob during times of 
dearth, due to easy discouragement when a honey flow slackens. They defend their colonies less energetically than various other types. Spitefulness and a ready disposition to fly at passers-by, as well as to resent greatly any manipulation of the combs, are among their undesirable traits.

Itclians.-These are more active, more prolific, much gentler under manipulation, defend their hives better against various bee enemies, and in general are better economic managers.

Cyprian and other Eastern types.-The record for the largest yield of honey ever obtained from a single colony is held by the Cyprians. This is due to a combination of certain excellent traits, such as great prolificness, relatively great wing power, most wonderful energy in honey collecting, rapid breeding in early spring, persistent and continuous field work, even though the return at times be somewhat slow, together with the best possible defense of the hive against enemies which may tend to reduce its effective force. With these traits the Cyprians combine, however, a degree of irascibility which renders their general introduction as a pure type inadvisable. Their disposition to produce laying workers is also great, and operates against them. Another feature, which condemns them for the production of comb honey of the very highest finish, is the tendency which they have of filling the individual cells quite to the brim with honey, so that the wax cap rests flat upon the liquid and presents, therefore, a soaked or watery appearance instead of the clear snow-white surface which certain other races give to their finished combs. The other eastern types possess the same general characteristics, yet the excellent traits here indicated are in the main less pronounced with them.

Carniolans.-These are radically different from the bees just under consideration, both in appearance and characteristics. Large-bodied, gray in color, somewhat droning in flight, they present a great contrast to the slender, yellow, and nimble-winged Cyprians. The Carniolans, having reached their derelopment in an elevated Alpine legion, are distinguished for great hardiness, the individual workers being able to stand a considerably lower temperature than those of the next hardiest type--the blacks. The queens are very prolific, and early brood-rearing is the rule, so that the decimation of colonies, so noticeable with blacks and Italians of pure blood, is reduced to a minimum when only pure Carniolans are present. They possess the excellent peculiarity of capping their combs in such a mannex as to give them a snowy-white and very attractive appearance. The amount of propolis, or bee glue, gathered by them is small; hence the tendency to daub sections and combs is less than with any other type. Their disposition is most excellent, enabling anyone to handle them easily by the use of a small amount of smoke.

Caucasians.-Chese bees have hardly been tested sufficiently to 
enable me to state exactly what their relative ralue will be as a pure breed. It seems, howerer, rather erident that as crossing material they will find a certain place, since they hare at least proved themselves to be excellent workers and most marrelously gentle. Tithout smoke or bee reil and with no protection whaterer, the hires may be opened at all times and under any circumstances with no danger whaterer of stings. Caucasians are particularly mell adapted to city bee keeping, to manipulation by ladies and amateur bee keepers, and to the purpose of studying bee life--one of the most fascinating subjects for inrestigation in the whole realm of animated nature. I beliere that the general introduction of these remarkably gentle bees - the Caucasians - mould do more to extend and popularize the culture of bees in this country than hare all of the importations of other races or all of the bee-keeping inventions since that of the Langstroth frame hive.

SECLRING DESIRABLE TRAITS BY CROSS-BREEDING.

Since each one of the abore types also possesses, along with its excellent qualities. some faults which thus far have not been entirely eradicated by selection in breeding these types pure, the thought is natural that by some out-cross. or series of out-crosses, followed, perhaps. by continned selection, types might be dereloped and established which should present the chief among the excellent traits in a pronounced degree without the undesirable qualities or with these greatly minimized. Thus we find that erer since the introduction of the Italian bees there hare been efforts along this line. and since the spread of the Italian bee has been so general throughout the country. especially among the professional bee keepers, there are now few apiaries where the original black or brown bee exists in its purity. Special strains of the Italians have also been produced in different parts of the country by continued selection. and queens of supposed pure Italian blood are often sent from this country to Tarious portions of Europe, and occasionally eren to Italy itself. The progeny of these queens differ in important colorational features, as well as in qualities, from the original type found generally in northern Italy. The most striking difference in appearance is that in place of the three bands on the first. second, and third anterior segments of the abdomen a rellow color corering the whole of these segments, and often the fourth and fifth segments. is to be seen. This result is strikingly illustrative of what can be done with such plastic material as honey bees by careful and continued selection.

The writer conceired nearly trenty rears ago the idea that, notwithstanding the bad traits of the Crprian race (this being taken as the hest of the Eastern types) - it mould be a rery desirable thing to fix in a new trpe-hardier and gentler than Cyprians-the funda- 
mental and strong characteristics, as regards honey-gathering powers, prolificness, energy, and general activity, which are inherent in this race. Yet, in accomplishing the result just indicated, it was particularly desirable to avoid the extreme irritability of the eastern type. A series of experiments was begun by the writer in the years 1883-84 in Munich, Germany, and continued in subsequent years in Carniola, Austria, looking to the production of a type which should possess the traits just indicated. After many crosses between the queens and drones of each race, starting at times with the Cyprian and again with the Carniolan, it seemed apparent that the temper and constitution were largely derived from the male side, while prolificness and energy in honey production seemed likely to be transmitted from the female side. The proposition was, therefore, laid down that in all crosses the drones must come from a gentle, hardy race, while the mothers were to be selected from a race noted for prolificness, early breeding qualities, and whose worker bees showed the highest energy in honey collecting. As representing, at that time, the two types which had best be utilized in this combination the Cyprians were selected for the blood of the queens and the Carniolans to produce the males; the resulting product, in order to indicate its origin, was named the Cyprio-Carniolan. Since the year 1885 these bees have been bred and tested under most varying conditions, with the result that wherever the principles above mentioned have been followed in their selection and breeding they have given great satisfaction as to the quantity of honey obtained. Indeed, a practical honey producer in southern California stated recently that, while he was obliged to feed his Italian bees during this dry year to keep them from starring, the crosses obtained with the Cyprian race had some 30 to 40 pounds in each of their colonies. In form and coloration the Cyprio-Carniolans approach more nearly the Cyprian type than the Carniolan. Likewise in their manner of flight and many other peculiarities they resemble the Cyprians; but in hardiness and, to a great extent, in temper, particularly in their readiness to yield to smoke, they resemble, to quite a degree, the Carniolan race.

These experiments, which have been carried on in recent years in my private apiaries in and near the city of Washington, have frequently enabled me to secure considerable material illustrating variability in the crossing of different types; and this has been of some service, also, to various worker's in zoology who have taken up problems of this nature.

\section{FU'TURE WORK.}

In view of the results obtained by the use of males of a gentler race, the plan is, during the coming year, to utilize in this respect the newly imported Calsasians, producing thus the Cyprio-Caucasian type and 
likewise, as a further test of the principle, the Carnio-Caucasian type. We may confidently expect excellent combinations from the crossing of females of either of these prolific races (the Carniolan and Cyprian) with males of the extremely geritle Caucasian race. The mating of the Cyprian with the Caucasian particularly will, it is believed, produce a type even gentler than mating Cyprian with Carniolan; while in mating a Carniolan queen to a Caucasian drone bees will be produced that, while exceedingly gentle, will, I feel confident, be well adapted to the production of comb honey of high grade.

It is proposed, in the future work of the United States Department of Agriculture along this line, to carry forward, in an apiary which the Department has recently acquired, further investigations and breeding of various races of bees now in this country; and also to extend the work so as to include an examination, test, and possible importation of the giant bee of East India (Megapis dorsata) and that of the Philippine Islands (Megapis zonata), as well as the common East Indian species (A pis indica), which is now cultivated to a limited extent. The first and last mentioned of these bees were quite imperfectly investigated by the writer in India in 1881, previous to his connection with the Department of Agriculture. Unfortunately, a severe attack of jungle fever cut short his work at that time and obliged him to leave India at once.

I look forward with great interest to the possibility-I might say the probability-that additional valuable types of honey bees, of which we have as yet only rague accounts, will be found in the great central Asian area eastward and southeastward from Persia, particularly in the elevated ralleys of the Himalayan Mountains and in the plateaus to the north and northeast of the main range.

Mr. Mashburn asked whether the honey bees were chiefly responsible for the distribution of pear blight.

Mr. Benton answered that he beliered not, because other insects did the same work, and if honey bees were not present the blight would be spread quite the same.

On motion, Mr. F. M. Webster was elected to succeed himself as a member of the committee on nomenclature, for three years.

On motion, it was resolved that the next meeting be held in conjunction with the American Association for the Adrancement of Science, the exact date to be left to the executive committee.

The meeting was then adjourned.

H. E. Summers, Secretary. 


\section{LIST OF MEMBERS OF THE ASSOCIATION OF ECONOMIC ENTOMOLOGISTS.}

\section{ACTIVE MEMBERS.}

Aldrich, J. M., Agricultural Experiment Station, Moseow, Idaho.

Alwood, William B., Charlottesville, Va.

Ashmead, William H., U. S. National Museum, Washington, D. C.

Baker, C. F., Agricultural Experiment Station, Santiago de las Vegas, Cuba.

Ball, E. D., Agricultural Experiment Station, Logan; Utah.

Banks, C. S., Bacolod, Negros, P. I.

Banks, Nathan, U. S. Department of Agriculture, Washington, D. C.

Bethune, C. J. S., 500 Dufferin avenue, London, Ontario, Canada.

Benton, Frank, U. S. Department of Agriculture, Washington, D. C.

Bishopp, F. C., U. S. Department of Agriculture, Washington, D. C.

Bogue, E. E., Agricultural College, Mich.

Britton, IV. E., New Haven, Conn.

Bruner, Lawrence, Agricultural Experiment Station, Lincoln, Nebr.

Brues, C. T., Milwaukee Public Museum, Milwaukee, Wis.

Burgess, Albert F., State Department of Agriculture, Columbus, Ohio.

Busck, August, U. S. Department of Agriculture, Washington, D. C.

Caudell, A. N., U. S. Department of Agriculture, Washington, D. C.

Chambliss, C. E., Clemson College, S. C.

Chittenden, F. H., U. S. Department of Agriculture, Washington, D. C.

Clifton, R. S., U. S. Department of Agriculture, Washington, D. C.

Cockerell, T. D. A., Boulder, Colo.

Comstock, J. H., Cornell University, Ithaca, N. Y.

Cook, A. J., Pomona College, Claremont, Cal.

Cook, Mel. T., Agricultural Experiment Station, Santiago de las Vegas, Cuba.

Cooley, R. A., Agricultural Experiment Station, Bozeman, Mont.

Coquillett, J. W., U. S. Department of Agriculture, Washingten, D. C.

Cordley, A. B., Agricultural Experiment Station, Corvallis, Oreg.

Crawford, J. C., jr., Dallas, Tex.

Dickerson, Edgar L., Agricultural Experiment Station, New Brunswick, N. J.

Dyar, H. G., U. S. National Museum, Washington, D. C.

Ehrhorn, E. M., Mountainview, Cal.

Felt, E. P., Geologic Hall, Albany, N. Y.

Fernald, C. H., Agricultural College, Amherst, Mass.

Fernald, H. T., Agricultural College, Amherst, Mass.

Fiske, W. F., U. S. Department of Agriculture, Washington, D. C.

Fletcher, James, Central Experimental Farm, Ottawa, Canada.

Forbes, S. A., University of Illinois, Urbana, Ill.

Fowler, Carroll, Duarte, Cal.

French, G. H., Carbondale, Ill.

Garman, H., Agricultural Experiment Station, Lexington, Ky.

Gibson, Arthur, Central Experimental Farm, Ottawa, Canada.

Gillette, C. P., Agricultural Experiment Station, Fort Collins, Colo.

Girault, A. A., U. S. Department of Agriculture, Washington, D. C.

Gossard, H. A., Agricultural Experiment Station, Wooster, Ohio.

Gregson, P. B., Blackfolds, Alberta, Northwest T'erritory, Canada.

Hargitt, C. W., Syracuse University, Syracuse, N. Y. 
Ilart, C. A., University of Illinois, Urbana, Ill.

Heidemann, Otto, U. S. Department of Agriculture, Washington, D. C. Hinds, W. E., L. S. Department of Agriculture, Washington, D. C.

Hine, J. S., Ohio State Unirersity, Columbus, Ohio.

Holland, W. J., Carnegie Museum, Pittsburg, Pa.

Hopkins, A. D., U. S. Department of Agriculture, Washington, D. C.

Houghton, C. O., Agricultural Experiment Station, Newark, Del.

Howard, L. O., U. S. Department of Agriculture, Washington, D. C.

Hunter, S. J., University of Kansas, Lawrence, Kans.

Hunter, W. D., U. S. Department of Agriculture, Washington, D. C. Johnson, S. Arthur, State Agricultural College, Fort Collins, Colo.

Kellogg, Vernon L., Stanford University, Cal.

Kincaid, Trevor, University of Washington, Seattle, Wash.

Kirkland, A. H., Malden, Mass.

Kotinsky, J., Honolulu, Hawaii.

Lochhead, William, Guelph, Ontario.

Marlatt, C. L., U. S. Department of Agriculture, Washington, D. C. Martin, George W., State Entomologist, Nashville, Tenn.

McCarthy, Gerald, care of Crop Pest Commission, Raleigh, N. C. Morgan, H. A., Agricultural Experiment Station, Baton Rouge, La. Morrill, A. W., C. S. Department of Agriculture, Washington, D. C. Murtfeldt, Miss M. E., Kirkwood, Mo.

Nerell, Wilmon, La. Crop Pest Comm., Shreveport, La.

Osborn, Herbert, Ohio State Unirersity, Columbus, Ohio.

Parrott, P. J., Geneva, N. Y.

Pergande, Th., U. S. Department of Agriculture, Washington, D. C.

Perkins, G. H., Agricultural Experiment Station, Burlington, Vt.

Pettit, R. H., Agricultural Experiment Station, Agricultural College, Mich.

Phillips, J. L., Agricultural Experiment Station, Blacksburg, Va.

Phillips, W. J., U. S. Department of Agriculture, Washington, D. C.

Pierce. W. D.. Dallas. 'Tex.

Piper, C. V., U. S. Department of Agriculture, Washington, D. C.

Popenoe, E. A., Agricultural Experiment Station, Manhattan, Kans.

Pratt, F. C., U. S. Department of Agriculture, Washington, D. C.

Quaintance, A. L., U. S. Department of Agriculture, Washington, D. C.

Reeres, George I., U. S. Department of Agricuiture, Washington, D. C.

Rumsey, W. E., Agricultural Experiment Station, Morgantown, W. Va.

Sanborn, C. E., College Station, Tex.

Sanderson, E. Dwight, Agricultural Experiment Station, Durham, N. H.

Saunders, William, Centr. Expt. Farms, Ottawa, Canada.

Schwarz, E. A., U.-S. Department of Agriculture, Washington, D. C.

Scott, W. M., U. S. Department of Agriculture, Washington, D. C.

Sherman, Franklin, jr., Department of Agriculture, Raleigh, N. C.

Sirrine, F. A., Agricultural Experiment Station, Jamaica, N. Y.

Skinner, Henry, 1900 Race street, Philadelphia, Pa.

Slingerland, M. V., Agricultural Experiment Station, Ithaca, N. Y.

Smith, J. B., Agricultural Experiment Station, New Brunswick, N. J.

Snow, F. H., Lawrence, Kans.

Stedman, J. M., Agricultural Experiment Station, Columbia, Mo.

Summers, H. E., Agricultural Fxperiment Station, Ames, Iowa.

Surface, H. A., State Zoologist, Harrisburg, Pa.

Symons, T. B., Agr. Expt. Sta., Collegepark, Md.

Taylor, E. P., University of Illinois, Urbana, Ill.

Titus, E. S. G., U. S. Department of Agriculture, Washington, D. C. 
Van Dine, D. L., Government Entomologist, Honolulu, Hawaii.

Viereck, H. L., Agricultural Experiment Station, New Haven, Conn. Waldron, B. H., Agricultural Experiment Station, New Haven, Conn. Walker, C. M., Amherst, Mass.

Washburn, F. L., Agr. Exp't Sta., St. Anthony Park, Minn.

Webster, F. M., U. S. Department of Agriculture, Washington, D. C. Weed, C. M., Agricultural Experiment Station, Durham, N. H. Wilcox, E. V., U. S. Department of Agriculture, Washington, D. C. Woodworth, C. W., Agricultural Experiment Station, Berkeley, Cal.

\section{ASSOCIATE MEMBERS.}

A.dam, M. F., City Bank Building, Buffalo, N. Y.

Barber, H. S., U. S. National Museum, Washington, D. C.

Beckwith, H. M., Elmira, N. Y.

Bentley, Gordon M., Department of Agriculture, Raleigh, N. C.

Bullard, W. S., 301 Lafayette street, Bridgeport, Conn.

Burke, W. E., U. S. Department of Agriculture, Washington, D. C.

Campbell, J. P., Athens, Ga.

Collins, Lewis, 177 Remsen street, Brooklyn, N. Y.

Conradi, A. F., College Station, Tex.

Couden, F. D., U. S. Department of Agriculture, Washington, D. C.

Currie, R. P., U. S. Department of Agriculture, Washington, D. C.

Dean, Harper, jr., Blacksburg, Va.

Doran, E. W., Champaign, Ill.

Engle, Enos B., Department of Agriculture, Harrisburg, Pa.

Frost, H. L., 21 South Market street, Boston, Mass.

Gifford, John, Mays Landing, N. J.

Gould, H. P., U. S. Department of Agriculture, Washington, D. C.

Green, E. C., College Station, T'ex.

Harrington, W. H., Post-Office Department, Ottawa, Canada.

Hooker, W. A., Amherst, Mass.

Hudson, G. H., Normal and Training School, Plattsburg, N. Y.

Isaac, John, Sacramento, Cal.

Johnson, W. G., 52 Lafayette place, New York, N. Y.

Johnson, S. Arthur, Fort Collins, Colo.

King, George B., Lawrence, Mass.

Mann, B. P., 1918 Sunderland place, Washington, D. C.

Martin, Leslie, U. S. Department of Agriculture, Washington, D. C. MacGillivray, A. D., Cornell University, Ithaca, N. Y.

Morgan, A. C., Dallas, Tex.

Mosher, F. H., 283 Pleasant street, Malden, Mass.

Niswander, F. J., 2121 Evans street, Cheyenne, Wyo.

Palmer, R. M., Victoria, British Columbia.

Phillips, E. F., U. S. Department of Agriculture, Washington, D. C. Price, H. L., Agricultural Exweriment Station, Blacksburg, Va.

Quayle, H. J., Agriculturai Experiment Station, Perkeley, Cal.

Rane, F. W., Agricultural Experiment Station, Durham, N. H.

Rankin, John M., U. S. Department of Agriculture, Washington, D. C.

Reed, E. B., Esquimault, British Columbia.

Riley, W. A., Cornell University, Ithaca, N. Y.

Rolfs, P. H., Miami, Fla.

Sanders, J. G., U. S. Department of Agriculture, Washington, D. C.

Smith, R. I., Atlanta, Ga.

Southwick, E. B., Arsenal Building, Central Park, New York, N. Y. 
Stimson, James, Watsonville, Cal.

Swezey, O. H., Columbus, Ohio.

Thaxter, Roland, 3 Scott street, Cambridge, Mass.

Toumey, J. W., Yale Forest School, New Haren, Conn.

Tomusend, C. H. T., El Paso, Tex.

Webb, J. L., U. S. Department of Agriculture, Washington, D. C.

Young, D. B., Albany, N. Y.

\section{FOREIGN MFMBERS.}

Ballou, H. A., Imperial Department of Agriculture, Barbados, West Indies. Berlese, Dr. Antonio, R. Stazione di Entomologia Agraria, Firenze, Italy. Bordage, Edmond, Directeur de Musée, St. Denis, Réunion.

Bos, Dr. J. Ritzema. Willie Conmelin Scholten, Amsterdam, Netherlands. Carpenter, Dr. George H., Royal College of Science, Dublin, Ireland. Cholodkosky, Prof. Dr. N., Institut Forestier, St. Petersburg, Russia. Collinge, W. E., University, Birmingham, England.

Danysz, J., Laboratoire de Parasitologie. Bourse de Commerce, Paris. France. Enock, Fred, 13 Tufnell Park road, Holloway, London, N., England. French, Charles, Department of Agriculture, Melbourne, Australia. Froggatt, W. W., Department of Agriculture, Sydney, New South Wales. F'uller, Claude. Dept. of Anriculture. Pietermaritzburg. Natal. South Africa. Giard, A., 14 Rue Stanislaus, Paris, France.

Goding, F. W., Newcastle, New South Wales.

Grasby, W. C., Grenfell street, Adelaide, South Australia.

Green, E. E., Royal Botanic Gardens, Pundalnoya, Ceylon.

IIelms, Richard, 136 George street, North Sydney, New South Wales.

Horvath, Dr. G., Musee Nationale Hongroise, Budapest, Austria-Hungary. Jablonorski, Josef, Budapest, Hungary.

Lampa, Prof. Sren, Statens Entomologiska, Anstalt, Stockholm, Sweden. Lea, A. MI., Department of Agriculture, Hobart, Tasmania.

T.eonardi, Gustayo, Portici, Italy.

Lounsbury, Charles P.. Department of Agrieulture, Cape Torn. South Africa. Malls, C. W., Department of Agriculture, Grahamstorn, Cape Colony.

Marchal, Dr. Paul, 16 Rue Claude, Bernard, Paris, France.

Iusson, Charles T., Hawkesbury Agr. College, Richmond, New South Trales. Nara, Yasushi, Gifu, Japan.

Newstead, Robert, Univ. Sch. of Tropical Medicine, Liverpool, England. Peal, H. W., Indian Museum, Calcutta, India.

Porchinski, Prof. A., Ministere de l'Agriculture, St. Petersburg, Kiussia. Reed, E. C., Rancagua, Chile.

Reuter, Dr. Fnzio,-Fredriksgatan 45, Helsingfors, Finland, Russia.

Sajo, Prof. Karl, Güdöllö-Teresegyhaz, Austria-Hungary.

Schoren, Prof. W. M., Zoological Museum, Christiana, Norway.

Shipley, Prof. Arthur E., Christ's College, Cambridge, England.

Simpson. C. B., Pretoria, Transvaal, South Africa.

Tepper, J. G. O., Norwood, South Australia.

Theobald, Frederick V., Wyecourt Wye, Kent County, England.

Thompson, Rev. Edward H., Franklin, T'asmania.

Tryon, H., Queensland Museum, Brisbane, Queensland, Australia.

Urich, F. W., Victoria Institute, Port of Spain, Trinidad, West Indies.

Vermorel, V., Villefranche, Rhone, France.

Whitehead, Charles, Barming House, Maidstone, Kent, England. 


\section{INDEX.}

Pace.

Abstracts of papers, committee, names
Agricultural methods, reduction of insect losses -13

Agriculture, benefits from entomology and other sciences____._._._._._. Alabama argillacea, Georgia report for 1904 (see also "Army worm") _.-Anabrus simplex. See Cricket, Mormon.

Anasa tristis, squash bug, Ohio report for $1904 \ldots \ldots \ldots \ldots \ldots \ldots \ldots \ldots \ldots$

Anisota senatoria, Georgia report for $1904 \ldots$

Ant, Iridomyrmex humilis, distribution and depredations (see also Ants) _ 81-84

of slave insects _............. 80,81

life history, notes _.-_...

nests, eggs, etc., remarks__._.

“New Orleans," report by E. S. G. Titus

Anthomyia radicum, Colorado report for $1904 \ldots$

Anthonomus grandis. See Boll weevil.

Anthrenus verbasci, cabinet beetle, observations_______________...

Ants, common, destruction by ant, Iridomyrmex humilis (see also Ant) -.-

Cuban, destructive habits

remedies for prevention and destruction

Aphides, distribution and care by ants.

Aphis, apple, Colorade report for 1904

Aphis gossypii, melon aphis, Colorado report for $1904 \ldots$ persice niger, peach aphis, Colorado report for $1904 \ldots$ pomi, green apple aphis, Colorado report for $1904 \ldots \ldots \ldots \ldots$ prunifolia, plum aphis, Colorado report for $1904 \ldots$ Apis indica. East Indian bee, study

Apple aphis, Colorado report for 1904

infestation with codling moth in Colorado in 1904

injury by insects in Georgia in 1904_....... maggot, Ohio report, $1904 \ldots$ varieties affected by leaf-hopper, Empoasca mali "Army worm," or leaf worm, value in control of cotton boll weevil_____Arsenate of lead, handling and usefulness use against codling moth in Colorado in $1904 \ldots \ldots \ldots$ grapevine rootworm in New York_....... soda, insecticide use, note.

Arsenates, use against sweet potato weevil Ash trees, injury by insect, Dynastes tityus, in Georgia, note Aspidiotus forbesi, cherry scale, Colorado report for $1904 \ldots$ howardi, Colorado report for $1904 \ldots$ perniciosus. See San Jose scale.

Atta insularis, Cuban ant, habits.

Audubon Park, La. olservation of first appearance of ant Iridomyrmex humilis

Aulacaspis rose, Colorado, 1904, report of first appearance

Bagworm, Ohio report, 1904 
Bees, desirable traits secured by cross-breeding

Page.

future work in improvement

106-107

giant, East India and Philippine, possible importation

$107-108$

hones, rarious trpes, importation and breeding. paper br Frank

Benton

types or breeds, characteristics

$103-108$

various breeds, importation

Beet leaf-miner Colorado report 104

webworm, Colorado report for $1904-61$

Beetle. leaf, elm, appearance at Darton, Ohio

powder post, injury to electric cars

See also Ladybird and Flea.

Bextox, Fraxk, paper on "Importation and breeding of honey bees of

rarious types"

Bibliography, committee report, adoption_______ 95

Blackberry, infestation by fulacaspis rose. Colorado report for $1904 \ldots$

Black-fly, methods of extermination__.___._. 100 studies, paper by A. F. Conradi

Blatella germanica, fumigation with hydrocyanic-acid gas

Blissus leucopterus. See Chinch bugs.

Boll weevil, cotton, broods, occurrence

37,38

control, relation of winter

Cuba, occurrence

cultural methods for control

29

destruction in hibernation by rain

emergence, relation of weather conditions

extent of infested area of Louisiana and Texas_._._-_

farming methods as means of control

$39-40$

33

33

15

hibernation, frost effects, food supply, etc

14-17

hrpothesis for date of maximum emergence

$29,30,31$

identification, confusion with Chalcodermus ceneus.--

increase in numbers with adrance of season

legislation for restriction, remarks.

$34-37$

71

38

20

numbers hibernating and kinds of shelter.

31

observations, paper by E. Dwight Sanderson

problems of interstate relations:

remedies, remarks

$29-41$

$40-41$

39

stalk destruction as only remedy

40

16

$\$ 50,000$ reward for control, results of Texas offer

Bordeaux mixture, use for San Jose scale

Borer, oak, Colorado report for 1904

Box elder, infestation with gall-makers, note

Breeding and importation of honey bees of rarious types. paper br Frank

Benton

cross, for bees, securing of desirable traits

ground, black-fly

100,101

mosquitoes, Texas observation

sweet potato weevil, Texas observation

Breeds, various, of bees, importations
BritTon, W. E., paper on "The fall webworm partially double brooded

in Connecticut-,

Broods, boll weevil, occurrence-

Hessian fly, southern United States, note-

Iormon cricket (Anabrus simplex), notes

sugar-beet webworm, comparison of injuries

$62,63,64$

Buffalo tree-hopper, New York report, $1904 \ldots$

Burgess, A. F., paper on "Some economic insects for the year 1904 in

Ohio" "

"The fumigation of a fruit house for control-

ling codling moth

By-laws, Association of Economic Entomologists, amendments

Cabinet beetle, Anthrenus verbasci, additions to our knowledge, paper by

Henry L. Tiereck

Cankerworm, spring, Ohio report, 1904

Carbon bisulphid, use against ants, note 
Camiolan bees, characteristics

Carpocapsa pomonella. See Codling moth.

Carpophilus dimidiatus, Georgia report for 1904

Caterpillar, tent, Ohio report, 1904__ 53

Caucasian bees, characteristics _-

Caustic soda solution, experimental use against San Jose scale_____ 26, 69)

Cecidomyia spp. See Gall makers.

Cecidomyiidx, member of family as enemy of grape_____________ 54-55

Ceresa bubalus, New York report, 1904_______ 51

Ceroplastes floridensis, distribution and caro oy ants____________- 80

Chalcodermus aneus, Georgia report for 196; injury to cotton_____

Cherry aphis, black, Colorado report for $1904 \ldots 58$

scale, Colorado, 1904, report of first appearance__________ $\quad 59$

Chicago, work against cottony maple scale

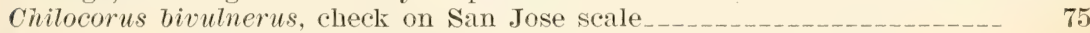
similis. See Ladybird.

Chinch bugs, Minnesota, report for $1904 \ldots$

Ohio report, 1904

Chionaspis furfura, proposed cyanide fumigation ______________ 96

Chrysochus auratus, Georgia report for 1904

Chrysomyia macellaria, occurrence in Ohio in $1904 \ldots$

Cicada, Ohio report for 1904

Citrus trees, infestation by mealy bugs under care of ants

Climate, relation to cotton boll weeril control__ 15

Climatic conditions, importance in cotton boll weevil control_______ 41

Clinocoris iectularia, destruction by hydrocyanic-acid fumes

Coal oil, use against ant, Iridomyrmex humilis (see also Kerosene) - _._. 82, 84

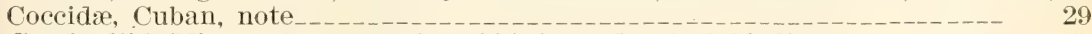

Coccinellid, Minnesota report for 1904 (see also Ladybird)________ 57

Codling moth, Colorado report for $1904 \ldots 58$

fumigation of fruit house for control________ 101-103

Georgia report for $1904 \ldots 70$

Ohio report, $1904 \ldots$

Coffee leaf-miner, remark; discussion (see also Leaf-miner) _____ 28, 97-99

trees, Porto Rico, infestation with leaf-miners

Colaspis favosa, Georgia report for 1904____. 70

Coleoptera, genera subject to legislation

Coleopterous insects, Cuba, note______ 29

College Station, Tex., observations on cotton boll weevil sweet-potato weevil and mosquitoes

Colleges, agricultural, economic entomology, teaching, note

Colorado, insects of the year, 1904, paper by C. P. Gillette________ 58-61

Mormon cricket (Anabrus simplex), distribution and migrations, paper by S. Arthur Johnson

Committees, association, appointment reports _

Connecticut, broods of fall web-worm, discussion

Conotrachelus nenuphar. See Curculio, plum.

Conradi, A. F., paper on "Black-fly studies" _.___ 100-101

"Miscellaneous notes [on insects] from Texas"

C'Ook, MeL 'T., paper on "Notes on Cuban insects"

"The coffee leaf-miner (Leucoptera coffeella)"

Corn, insect injuries in Georgia in 1904

root-worm, Ohio report, $1904 \ldots 51$

Corrosive sublimate, failure as remedy for powder post beetle________ it

Cotton boll weevil. See Boll weevil.
cultuiral methods as remedy for boll weevil

$\begin{array}{lr}\text { cultural methods as remedy for boll weevil } & 39 \\ \text { earliness of maturity as factor against boll weevil }\end{array}$

growing, methods for control of boll weevil

insect injuries in Georgia in 1904__ 70, 71

planting, changes of practices enforcement proposed_._. 20

price, relation of boll weevil, note

squaring, time of boll weevil attack___ 33

stalks, destruction as method of weevil control__________ 31,40 
Cotton-seed meal, insect depredation

Page.

Cottonroods, insect injury in Colorado in 1904

Compeas, relation to injury of cotton by Chalcodermus aneus

70,71

"Crazy ant." See Ant " New Orleans."

Creosote, failure as remedy for powder post beetle

Crepidodera rufipes, injury to peach orchard in Ohio

Cricket, Iormon (Anabrus simplex). distribution and migrations in Colorado, paper by S. Arthur Johnson.

conclusions from study of migrations and distribution or Idaho, Colorado report for 1904

Crop areas, increases as shown by Twelfth Census

growing methods for insect control

losses by insects and savings by economic entomology

Cross-breeding bees, securing of desirable traits.

Croton bug, fumigation with hydrocyanic-acid gas

Cryptorhynchus lapathi. See Curculio and Willow weevil.

Cuban experiment station, coffee leaf-miner

insects, notes, paper by Mel T. Cook

Culicidæ, mosquitoes, publications

Curculio, imported willow, Minnesota report for 1904

plum, injury to peaches in Georgia in 1904

Minnesota report for 1904

Ohio report, 1904

Currants, insect attacks in Colorado in 1904. note.

Cyanide. See Potassium cyanide.

Cylas formicarius. See Weeril, sweet-potato.

Cyprian and other Eastern bees, characteristics

Cyprio-Carniolan bees, desirable traits

\section{Diabrotica 12-punctata, Georgia report for 1904} Tongicornis. Ohio report. 1904 .

Diatraca saccharalis, Georgia report for 1904

Dust spray, experiment in Minnesota against leaf-hoppers

Dynastes tityus. Georgia report for 1904

Eggs, bedbug, destruction by use of hydrocyanic-acid gas

fall webworm (Hyphantria cunea), color, etc., remarks

Mormon cricket (Amabrus simplex), notes.

sweet-potato weeril, notes from Texas for 1904

Elm leaf-beetle, appearance at Dayton, Ohio.

Elms, infestation with leaf-beetle in Ohio in 1904

Emphytus canadensis, New York report, 1904

Empoasca mali. See Leaf hopper.

Entomological erents, most important in recent years, note

investigation, promising field

Nerrs. proposal as semiofticial organ of association, committee

Entomologists. attendance on association meetings. list of names......

increase in number of workers on economic subjects__._._

Entomology, applied, present-day features in America, address of president, A. L. Quaintance

economic, factors in awakening interest

growth and benefit to agriculture

literature, extent, character, and plan for résumé_ problems, conditions, and requirements

sarings on crops, table

Ephestia kuehniella. See Flour moth.

Epicauta pennsylvanica, Texas report for 1904

Epitrix cucumeris, Colorado report for 1904 
Experiment Stations, Office, bibliography of economic entomology, suggestions

Experimental farms for cotton boll weevil control

Page.

Fall web-worm, Ohio report, 1904 (see also Webrorm, fall)

Farm crops, insect enemies, Colorado report for 1904

production. losses by insects and savings by econonic entomology

Farmer, preference for Paris green and other remedies, note

Farming methods for control of cotton boll weevil

Farms, experimental, cotton boll weevil control

Felt, E. P., paper on "Experiments with lime-sulphur washes"

$25-28$

"Notes for the year-New York"

$51-.52$

Fernald, H. T.. opinion as to testing insecticides.

Fidia viticida, Ohio and New York reports, 1904

52,54

Flea-beetle, potato, Colorado report of heavy loss in 1904

red-legged, injury to peach orchard in Ohio

Fleas, fumigation with hydrocranic-acid gas, note

Flood, Brazos, destruction of cotton boll weevil

Flour moth, Mediterranean, Georgia report for 1904

Flowers, destruction by ant, Iridomyrmex humilis

Fly. See Frit and Hessian.

Formule, lime-sulphur wash and method of preparation

Frit-fly, Minnesota report for 1904

Fruit-fly, gooseberry, Colorado report for 1904

Fruit-house fumigation, control of codling moth_________ 101-103

Fruit-moth, grape, Ohio report, 1904_. 54

Fruit-worm, gooseberry, Colorado report for $1904 \ldots$

Fruits, deciduous, increase in plantings, 1889-1899___ 6-7

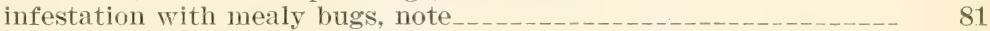

Fumigation, fruit-house. for controlling codling moth. paper by A. F. Bur-

gess _._.

household insects and their eggs with hydrocyanic-acid gas, some notes, paper by J. L. Phillips

Galerucella luteola, appearance at Dayton, Ohio

Gall makers, Minnesota report for 1904

Garden regetables, insect injuries, Colorado rejort for $1904 \ldots 59$

Gas. See Hydrocyanic-acid gas.

Georgia, insects for the year 1904, paper by Wilmon Newell and R. I. Smith

Gillette. C. P. palper on "Insects of the year in Colorado"

Gooseberries, insect attacks in Colorado in 1904

Gooseberry. See Fruit-fly and Fruit worm.

Government. National, relation to cotton boll weevil control

Grape fruit-moth. Ohio report, 1904 injuries in Ohio in 1904

new enemy, member of Cecidomyidie, appearance

Grapevine, protection from leaf-hopper, use of spray

rootworm, Ohio and New York reports for 1904

Grasshoppers, Colorado report for 1904

Heliothis obsoleta, Georgia report for 1904

Hemiptera, genera subject to legislation

Hessian fly, aroidance by delay in wheat planting

Georgia report for 1904

increase in Ohio in 1904

Hibernation, cotton boll weevil, remarks

Hippodamia convergens, Georgia report for 1904 
Honey and bee industry, branches

Page. bees. See Bees.

Hopper, tree, buffalo, New York report, 1904

Household insects. See Insects, household.

Hydrated lime emulsion, insecticide use, note

Hydrocyanic-acid gas, fumigation of household insects and their eggs, some notes, paper by J. L. Phillips

Hymenopterous insects, Cuban, usefulness

Hyperaspis sp., Minnesota report for 1904

Hyphantria cunea. See Web worm, fall.

textor, Georgia report for 1904

Icerya purchasi, destruction by Novius (Vedalia) cardinalis.

Idaho cricket. See Cricket.

Insect control, importance, remarks (see also Insects)

planting and cultivation, relation

Texas proposal

depredation, losses in farm production

relation to increase of crops and orchards

emergence, rainfall as factor

legislation in United States, summary

36

pest, study, suggestions

problems, suggestions of remedies

Insecticide, sweet-potato weevil, use of arsenates (see also Arsenate) _..._.

Insecticides and parasites for insect pests, variableness of results

experiments for cottony maple scale

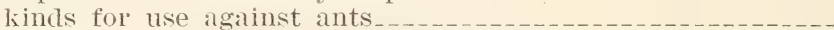

maple scale, preparation and application

more important, note

proprietary, testing, remarkis _._.

testing. committee on cooperation, names

$19-20$

37

24

63

75

$85-88$

84

87

13

74

74

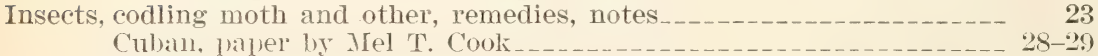

economic; of the year 1904, in Ohio, paper by A. F. Burgess

Georgia, for year 1904, paper by Wilmon Newell and R. I. Smith_- 69-74

hibernating as adults, hypothesis for fixing date of maximum

emergence _........

household, and their eggs, fumigation with hydrocyanic-acid gas, paper by J. L. Phillips _._.

injurious, in Minnesota in 1904, paper by F. L. Washburn

instances of widespread damage

life history, studies, remarks___ 18-19

names recommended for exclusive use, list

notes for the year, New York

of the year [1904] in Colorado, paper by C. P. Gillette______ 58-61

Ohio, brief notes for 1904, paper by Herbert Osborn

(pests), shade tree, Colorado report for 1904_________ 59

predatory,-introduced into New Jersey, present status, paper by

John B. Smith

temperature relation _._._._. 19

Texas, miscellaneous notes, paper by A. F. Conradi____-_66-68

Iridomyrmex humilis. See Ant.

Italian bees, characteristics

JoHnson, JefFerson, statement regarding $\$ 50,000$ prize for boll weevil control ARTHUR, paper on "Distribution and migrations of the MorS. ARTHUR, paper on "Distribution and migrations of the Mor-
mon cricket (Anabrus simplex) in Colorado"

"The cottony maple scale; an unusual outbreak and experiments with insecticides" $85-88$ 
Kerosene. See Coal oil.

Page.

emulsion, insecticide, experiment against maple scale

use against coffee leaf-miner.

$86,87,88$

cottony maple scale

99

use against leaf-hopper in Minnesota

90-91

57

45,46

$\begin{array}{rr}\text { Kero-water, spraying Lecanium species } & 57 \\ \text { use against leaf-hopper in Minnesota_- } & 46,47\end{array}$

Klinophilos lectularia. See Clinocoris lectularia.

Lady beetle. See Ladybird.

Ladybird, Asiatic, use against scale insects

69,79

(Chilocorus similis) introduction into New Jersey-a--

(lady beetle) Chinese, New York report, 1904_________ 51-52

Ohio report for $1904 \ldots$

Ladybug. See Ladybird.

Laurent, Philip, work with Paratenodera sinensis, note

Lead, arsenate. See Arsenate of lead.

Leaf worm, cotton, value in control of cotton boll weevil, note________ 30

Leaf-beetle, elm; appearance at Dayton, Ohio_______ 50

New York report, 1904__ 51

Ohio report for 1904

Leaf-hopper, destructive, work for control, preliminary report, paper by

F. L. Washburu _- $43-47$

Empoasca mati, life history, remarks_____. 44

grapevine protection, use of spray ___________ 47

Mimmesota report for $190 t \ldots 56$

spraying for control

Leaf-miner, beet, Colorado report for 1904

coffee, importance in Cuba______ 28

life history and treatment_______ $98-99$

paper by Mel. T. Cook

picking of coffee leaves in spraying

Lecanium, species, Minnesota report for 1904

Legislation, insect, statement for United States

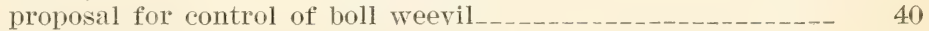

83

28

20

Leucoptera coffeella. See Leaf-miner, coffee.

Lice, plant. See Plant lice.

Lisyrus rusiceps, Georgia report for 1904

Lime and Paris green mixture, use against Alabama argillacea

hydrated, use as insecticide, note

salt, and sulphur wash, usefulness, notes____________ 21, 22

sulphur, and salt wash, usefulness in eastern United States_____._ 13

Lime-sulphur-salt insecticide, experiment on maple scale

wash, new, formula and preparảtion

poor success in New Jersey

use against San Jose scale in Georgia ___ 69

washes, experiments, paper by E. P. Felt

"Lincoln bug." See Cryptocephalus obsoletus.

Live oak, observation of ant nests, note

Locust, black, infestation by flea-beetle___ 53

infestation with gall-makers, note

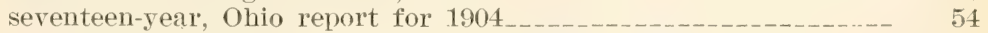

Locusts, black, infestation with cottony maple scale, note_________ 85

Louisiana, distribution of ant Iridomyrmex humilis__________ 82-84

New Orleans, ant pest, report

Loxostege sticticalis. Sce Webworm.

Lyctus striatus, injury to electric cars

Maggot, aple. Ohio report, 1904

radish, (colorado report for $1904 \ldots \ldots$

wheat-stem, Minnesota report for $1904 \ldots 56$ 
Magnolia, insect injuries in Georgia in 1904

Page.

Malacosoma americana, Ohio report for 1904

Malaria, spread by mosquitoes, Texas observation

Mantid, Paratenodera sinensis, introduction into New Jersey.

Mantis, danger to aphid-eating coccinellid, note

Mantis religiosa, introduction into New Jersey

Map, Mormon cricket territory, Colorado

Maple, infestation with cottony maple scale, note

scale, cottony, Colorado report for 1904

food plants, list

life history and sprasing, remarks

Minnesota report for 1904

unusual outbreak and insecticide experiments, paper

by S. Arthur Johnson.

mork for destruction at Chicago

soft, infestation with cottony maple scale

Mayetiola destructor. See Hessian fly.

Mealy bugs, infestation of sugar cane and citrus fruits

Mediterranean flour moth. See Flour moth.

Megapis dorsata and M. zonata. See Bees, giant.

Mlelanoplus spp.. Colorado report for 1904

Melon aphis, Colorado report for 1904

Members. Associatien of Economic Entomologists, list__._._.

Meraporus sp. Cecidomyiid parasite___ 57

Meromyza americana, Minnesota report for $1904 \ldots \ldots$

Migration, sweet-potato weevil, remarks

Migrations. Mormon cricket ( Luabrus simple $x$ ) in Colorado in 1904_____ 62-6ri

Minnesota, injurious insects in 1904, paper by F. L. Washburn_______ 55-57

nurseries, destructive leaf-hopper, note_____._._._._._._. 43

Nite, phytoptus, Colorado report for 1904

Mormon cricket. See Cricket.

Mosquitoes, Texas observations in 1904

transmission of disease, study and publications

Moth. See Codling moth, Flour moth, Gypsy moth, and Webworm.

Myzus cerasi, cherry aphis, Colorado report for $190 t_{\ldots} \ldots$

Naphthalin, effect on eggs of cabinet beetle_____._. 48

Vectarophora pisi, pea aphis, Colorado report for $1904 \ldots 60$

New England, black-fly as pest___ 100

Hampshire, black-fly, annoyance and means of extermination_-_-- 100-101

Jersey, insects injurious and beneficial, discouraging condition _...- 78

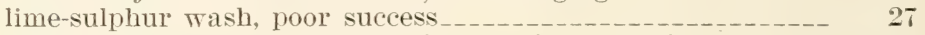

present status of predatory insects introduced, paper by John B. Smith

Orleans, occurrence of pest of ant Iridomyrmex humitis, paper by

E. S. G. Titus

York, insect notes for the year [1904], paper by E. P. Felt_.... 51-52

spraying graperines for control of leaf-hopper

Neweld, Wrimon, aid in introduction of ladybird into New Jersey-...--

and R. I. Smith, paper on "Insects of the year 1904 in

Georgia " -

Nomenclature, committee recommendations

Novius (Tedalia) cardenalis. California work, note

Nurseries, control of San Jose scale, note

injuries by leaf-hopper (Empoasca mali), notes

$69-7 \pm$

Oak, insect injury in Georgia in 1904

Officers. Association of, Economic Entomologists. nomiuation and election_

Ohio, economic insects of 1904 , paper by A. F. Burgess

insects, brief notes for 1904, paper by Herbert Osborn

Oil. See Coal oil.

Omorgus (Campoplex) frumentarius, Georgia report for 1904

Oncideres cingulata, Texas report for 1904 
Orchard enemies, Colorado report for 1904

Orchards, increase in trees in United States, 1890-1900

Orthoptera, grasshoppers subject to legislation

Osborn, Herbert, paper on "Brief notes on Ohio insects for 1904 "

$49-51$

Oscinis soror, Minnesota report for $1904 \ldots$

Oviposition, date, hypothesis for insects hibernating as adults________ 34-37

Mormon cricket (Anabris simplex), notes__________ 62, 62

sweet-potato weevil, remarks _._. 67

Pagoda, Colorado, numbers of Mormon crickets

Paleacrita vernata, Ohio report, 1904__ 53

Palms, infestation with mealy bugs, notes

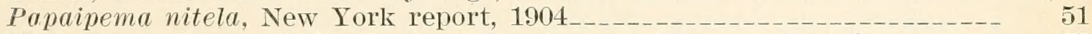

Parasites and insecticides for insect pests, variableness of results_______ 75

Paratenodera sinensis, introduction into New Jersey

Paris green and lime mixture, use against Aletia argillacea

opposing views as to use against boll weevil______________._ 42

use and failure as boll weevil remedy 39

Pea aphis, Colorado report for $1904 \ldots 60$

Peach aphis, black, Colorado report for 1904

borer, numbers in Ohio, 1904_ 50

orchard, injury by red-legged flea-beetle in Ohio__________ 53

orchards, injury by plum curculio

trees and blossoms, injuries by insects in Georgia

Pear blight, insects as means of spread

Psylla, New York report for 1904____ 51

slug, injury to cherry trees in Ohio_________ 49

Pears, destruction by ant, Iridomyrmex humilis

Pecan, injury by insects in Georgia in 1904

Pegomya vicina, Colorado report, 1904__ 61

Pennsylvania, use of lime-sulphur wash______ 28

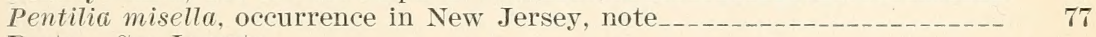

Pests. See Insects.

Phanerotoma tibialis, Georgia report for $1904 \ldots$

Phillips, J. L., paper on "Some notes on the fumigation of household

insects with hydrocyanic-acid gas "

Phinotas oil, use against black-fly 100

Phytoptidæ, genus subject to legislation

Phytoptus mite, Colorado report for 1904

Pines, infestation with Lecanium 57

Plant lice, Colorado report for 1904 (see also Aphis) _____________ 58-59

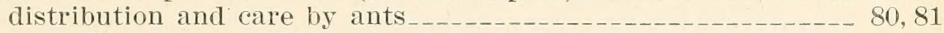

New York report, 1904

Plum aphis, green, Colorado report for 1904

curculio, Georgia report for $1904 \ldots 9$

Minnesota report for 1904

Ohio report for $1904 \ldots 51$

Polychrosis viteana, Ohio report for 1904

Poplar, infestation with oak borer in Colorado, note

Poplars, attack of willow weevil, note

infestation with willow curculio________________ 56

insect injury in Colorado in 1904, note 59

Porto Rico, coffee trees, infestation with leaf miner

Potassium cyanide, use in fumigation against codling moth

insecticide fumigation

Potato flea-beetle, Colorado report for 1904 61

Potatoes, sweet, injury by weevil

Powder post beetle, injury to electric cars ________ $53-54$

President, United States, remarks on protection against insects

Prionoxystus robinice, Colorado report for 1904___ 59

Proprietary insecticides, testing, remarks

Pseudococcus citri, distribution and care by ants 80

Psylla pyri, New York report, 1904___ 51

Publications, economic entomology, character 18

use of trade names, names of persons, etc 73 
Pulvinaria amygdali, destruction by Asiatic ladybird, note

Page.

innumerabilis. See also Maple scale, cottony.

misstatements

some experiences, paper by Howard Evarts

Weed

Quaintance, A. L., address on "Some present-day features of applied entomology in America"

Quarantine, insect, ineffectiveness, note

Radish maggot, Colorado report for 1904

Rainfall, destruction of hibernating brood of boll weevil

relation to insect emergence

variation in weevil-infested region of cotton growing

Red-legged flea-beetle, injury to peach in Ohio

"Remedies," boll weevil, improbability of discovery

Rhagoletis pomonella, Ohio report, 1904

Rhizobius lophante, introduction into New Jersey, result

Root-worm, corn, Ohio report, 1904 (see also Grape)

grapevine, work in New York in $1904 \ldots$

Rotation, cotton with cowpeas; relation to Chalcodermus aneus

Salt, lime, sulphur wash. See Lime.

San Jose scale, coccinellid, introduction, necessity of care

Colorado report for 1904

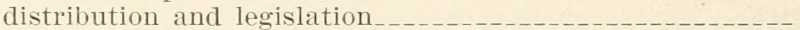

Georgia report for 1904

20,21

New York report, 1904

parasites, failures in introduction into New Jersey

predatory insects for control, problem

$75-77$

Texas report for 1904

$74-75$

Sanderson, E. Dwight, paper on "Some observations on the cotton boll weevil"

Sannindidea exitiosa, numbers in Ohio, 1904

Sawfly, violet, New York report, 1904

$29-41$

Scale insects, kinds subject of legislation (see also Cherry, Maple, San Jose, and Toumeyella turgida)

scurfy, proposed cyanide fumigation

Schizoneura lanigera, Colorado report for 1904

Scientific activity, present era, remarks

Screw worm, occurrence in Ohio in 1904

Scymnus marginicollis, introduction into New Jersey, result.

Shade tree pests, Colorado report for 1904

$5-76$

trees, infestation with cottony maple scale__._.

Silk, production, American, preliminary work

Simulium venustum. See Black fly.

Sinoxylon basilare, Georgia report for 1904

Slug, pear, injury to cherry trees in Ohio

Sмith, John B., paper on "The present status of predatory insects introduced into New Jersey"

R. I. and WILMon Newell, paper on "Insects of the year 1904 in Georgia "

Soap, soft, 50 per cent naphtha, use in kerosene emulsion.

caustic and sal, use in lime-sulphur wash (see also Caustic soda) _-_

Sorghum, shelter for cotton boll weevil

Spray, dust, experiments against leaf-hoppers in Minnesota_._._._._._.

kerosene emulsion and kero-water, use against leaf-hoppers_._-_-

Spraying, codling moth, Colorado report for 1904 cottony maple scale, suggestions machine, for leaf-hopper, details of construction maple scale, use of kerosene emulsion

use of lime-sulphur and other washes

Squash bug, Ohio report, 1904 
Sugar-beet webworm. See Webworm.

Page.

Sulphur, lime, salt wash. See Lime.

Sulphuric acid, use in making hydrocyanic-acid gas for fumigation.

95,102

Summers, heat and dryness, relation to boll weevil increase

Sweet-potato weevil. See Weevil.

Systena blanda, Georgia report for 1904

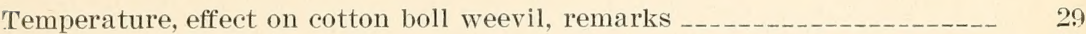

limitation of insect pests

relation to emergence of boll weevil_______________ $33,34-37$

Tent caterpillar, Ohio report, $1904 \ldots$

Tests, proprietary insecticides, remarks, and committee _._________ 74

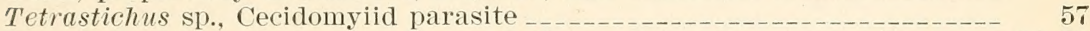

Texas, climatic variation, relation to boll weevil _._._.

cotton boll weevil problem, $\$ 50,000$ reward for control, results of offer.

insect control proposed, remarks___

miscellaneous notes [insects], paper by A. F. Conradi________ 66-68

southern, climatic conditions, as cause of loss of cotton by weevil__ 32,33

Thyridoptery $x$ ephemercformis, Ohio report, $1904 \ldots 50$

Tibicen septendecim, cicada, Ohio report for 1904____________ 54

Titus, E. S. G., paper on "New Orleans ant, Iridomyrmex humilis"

Tobacco stems, insecticide, experiment against cottony maple scale______ 87, 88

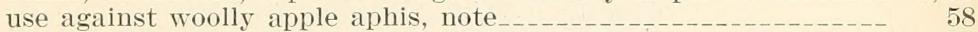

T'oumeyella turgida, Georgia report for $1904 \ldots$

Trade names, use in publications, discussion $\quad 73$

Trap crop, cowpeas, for Chalcodermus aneus__________. 71

lights, use against Oncideres cingulata in Texas

Tree-hoppers, buffalo, New York report, 1904______ 51

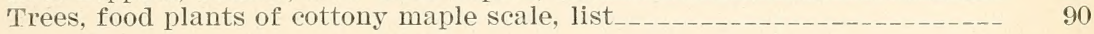

Victoria, Tex, observations on cotton boll weevil____________ 30, 32, 33

VIERECK, Henry L., paper on "Additions to our knowledge of the cabinet

beetle (Anthrenus verbasci)" "-_ 48-49

Violet sawfly, New York report, 1904___ 51

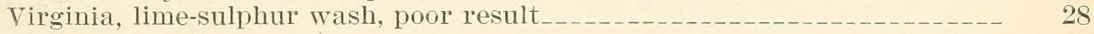

Wash, lime-sulphur-salt. See Lime.

WashburN, F. L., paper on "Injurious insects in Minnesota in 1904",_-_ 55-57

"Preliminary report upon work against a destructive leaf-hopper (Empoasca mali) _... 43-47

Weather, effect on Hessian fly in Georgia_______ 71 fall and winter, effect on cotton boll weevil______ $15,29,30,31,32,33$ relation to boll weevil emergence___ 33 cultural methods for control of boll weevil_______ $39-40$

Webworm, fall, broods in Connecticut, paper by W. E. Britton_______ 42-43

Ohio report, 1904

sugar-beet, Colorado report for 1904_____________ 60-61

Weed, Howard Evarts, paper on "Some experiences with Pulvinaria""- 88-91

Weevil, cotton boll. See Boll weevil, cotton.

sweet-potato, life history, notes _._____ 67

Texas report for 1904

willow, spread in Ohio

Whale-oil soap insecticide, experiment against maple scale_______ $86,87,88$

Wheat, Hessian fly damage in Georgia

Wheat-stem maggot, Minnesota report for $1904 \ldots$

Williams River Mountains, Colorado, breeding ground of Mormon cricket_ 62 ,

$\begin{array}{rr}\text { Willow curculio, imported, Minnesota report for } 1904 \quad 63,64,65 \\ \text { tree, New Orleans, infestation with ant, Iridomyrmex humilis } & 83\end{array}$

$\begin{array}{lr}\text { tree, New Orleans, infestation with ant, Iridomyrmex humilis } & 83 \\ \text { weevil, spread in Ohio_-- } & 49-50\end{array}$

Willows, attack of willow weevil, note

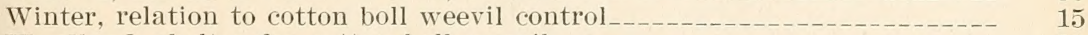

Woodland, shelter for cotton boll weevil_____ 31

Worm, screw, occurrence in Ohio in 1904 50

Zophodia grossularia, Colorado report for 1904__-___-_______ 59 
- 